Aus der Klinik für Gynäkologie und Geburtshilfe

(Prof. Dr. med. J. Gallwas)

der Medizinischen Fakultät der Universität Göttingen

\title{
Einfluss von ARHGAP29 auf die Invasion von aggressiven und mesenchymal transformierten Mammakarzinomzellen
}

\author{
INAUGURAL-DISSERTATION \\ zur Erlangung des Doktorgrades \\ der Medizinischen Fakultät der \\ Georg-August-Universität zu Göttingen
}

vorgelegt von

Katharina Kolb

aus

Nürnberg

Göttingen 2021 
Dekan:

Prof. Dr. med. W. Brück

\section{Betreuungsausschuss}

Betreuer/in:

Prof. Dr. rer. nat. C. Gründker

Ko-Betreuer/in:

Prof. Dr. med. H. Hahn

\section{Prüfungskommission}

Referent/in:

Prof. Dr. rer. nat. C. Gründker

Ko-Referent/in:

Prof. Dr. med. H. Hahn

Drittreferent/in:

Prof. Dr. hum. biol. M. Schön

Datum der mündlichen Prüfung: 15.12.2021 
Hiermit erkläre ich, die Dissertation mit dem Titel "Einfluss von ARHGAP29 auf die Invasion von aggressiven und mesenchymal transformierten Mammakarzinomzellen" eigenständig angefertigt und keine anderen als die von mir angegebenen Quellen und Hilfsmittel verwendet zu haben.

Göttingen, den 
Die Daten, auf denen die vorliegende Arbeit basiert, wurden teilweise publiziert:

Kolb K, Hellinger J, Kansy M, Wegwitz F, Bauernschmitz G, Emons G, Gründker C (2020): Influence of ARHGAP29 on the invasion of mesenchymal-transformed breast cancer cells. Cells $\underline{9}, 2616$ 


\section{Inhaltsverzeichnis}

Abbildungsverzeichnis .............................................................. IV

Tabellenverzeichnis ........................................................................ VI

Abkürzungsverzeichnis ............................................................... VII

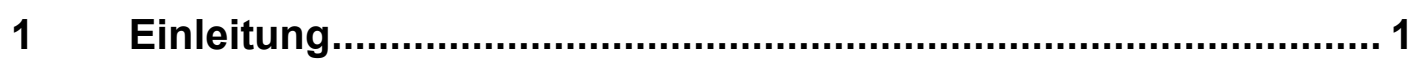

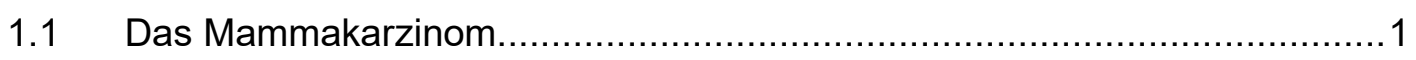

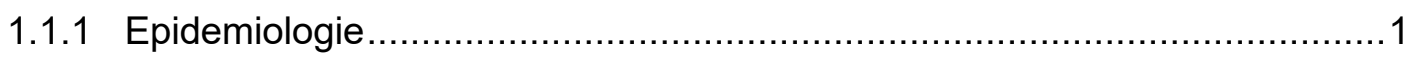

1.1.2 Histopathologische und molekulare Einteilung .....................................

1.1.3 Therapie des Mammakarzinoms ….................................................... 4

1.2 Invasion und Metastasierung ........................................................... 6

1.2 .1 Invasions-Metastasierungskaskade ............................................... 6

1.2.2 Migrations- und Invasionsmechanismen ........................................... 8

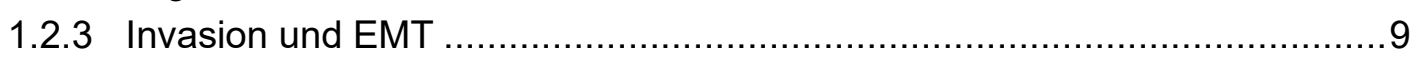

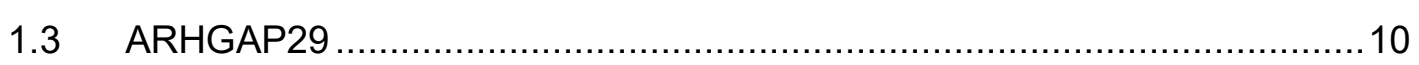

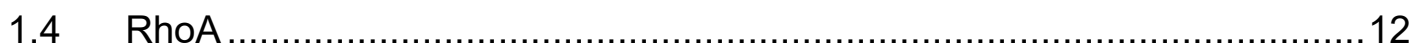

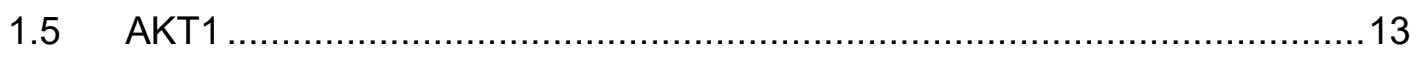

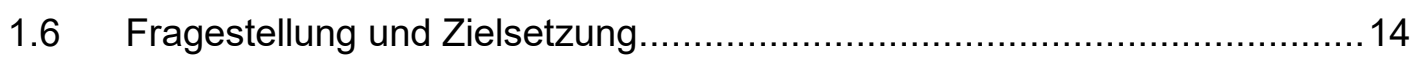

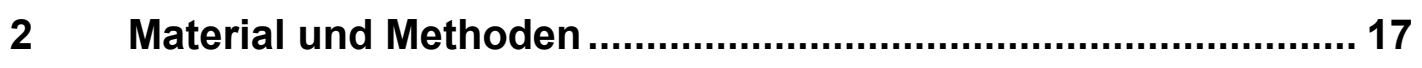

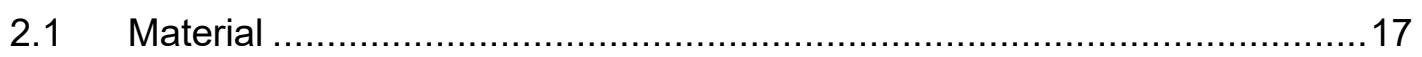

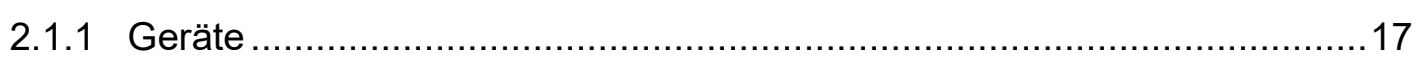

2.1.2 Verbrauchsmaterialien.................................................................. 19

2.1.3 Chemikalien, biologischen Materialien, Lösungen und Puffer .................... 19

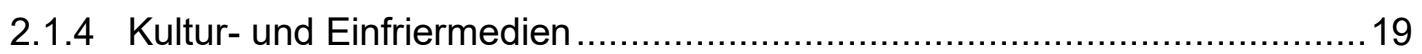

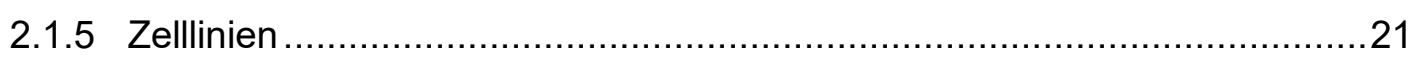

2.1.6 Kommerzielle Kits, Reagenzien und Assays.......................................22

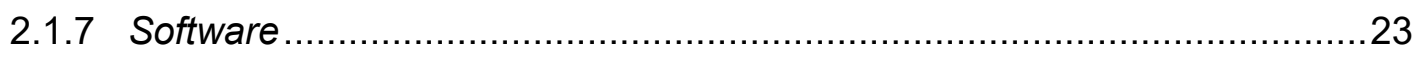

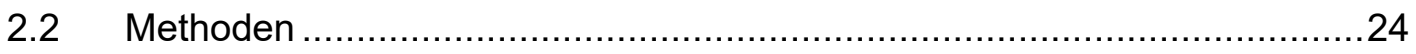

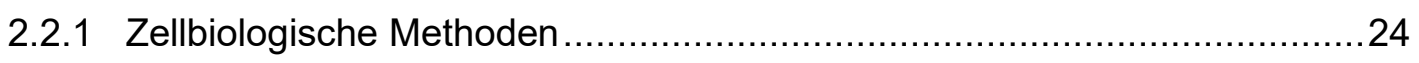

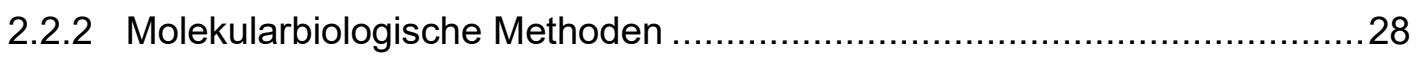

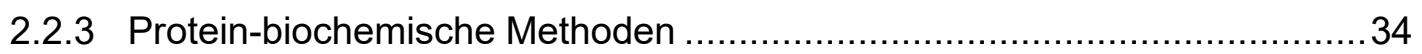

2.2.4 Datenbasierte Analyse von Interaktionspartnern .....................................42

2.2.5 Statistische Analyse und Dokumentation............................................. 42

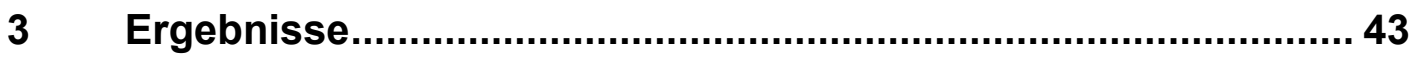

3.1 Genexpression von ARHGAP29 in invasiven Mammakarzinomzellen .......43

3.1.1 Analyse der Genexpression nach epithelialer-mesenchymaler Transition .43

3.1.2 Analyse der ARHGAP29-Expression in diversen invasiven Mammakarzinomzellinien verglichen mit MCF-7-Mammakarzinomzellen und nach dem knockdown von ARHGAP29 
3.2 Untersuchung des Einflusses eines knockdowns von ARHGAP29 auf die Invasivität von Mammakarzinomzellen

3.2.1 Einfluss einer verminderten ARHGAP29-Expression auf die Invasivität der Mammakarzinomzellinie MDA-MB-231

3.2.2 Einfluss einer verminderten ARHGAP29-Expression auf die Invasivität der Mammakarzinomzelllinie HCC1806.

3.2.3 Einfluss einer verminderten ARHGAP29-Expression auf die Invasivität von mesenchymal transformierten MCF-7-EMT-Mammakarzinomzellen..........56

3.2.4 Einfluss einer verminderten ARHGAP29-Expression auf die Invasivität der mesenchymal transformierten T-47D-EMT-Mammakarzinomzellen...........58

3.3 Untersuchung der Auswirkungen des knockdowns von ARHGAP29 auf die Proliferation von Mammakarzinomzellen

3.3.1 Einfluss einer reduzierten ARHGAP29-Expression auf die Proliferation der Mammakarzinomzellinie MDA-MB-231

3.3.2 Einfluss einer reduzierten ARHGAP29-Expression auf die Proliferation der Mammakarzinomzelllinie HCC1806.

3.3.3 Einfluss einer reduzierten ARHGAP29-Expression auf die Proliferation der mesenchymal transformierten MCF-7-EMT-Mammakarzinomzellen.

3.3.4 Einfluss einer reduzierten ARHGAP29-Expression auf die Proliferation der mesenchymal transformierten T-47D-EMT-Mammakarzinomzellen.

3.4 Proteinexpression von ARHGAP29 und AKT1 in Mammakarzinomzelllinien

3.4.1 Analyse möglicher Interaktionspartner von ARHGAP29

3.4.2 Proteinexpression von ARHGAP29 und AKT1 in der Mammakarzinomzelllinie MDA-MB-231 nach dem knockdown von ARHGAP29

3.4.3 Proteinexpression von ARHGAP29 und AKT1 in der Mammakarzinomzelllinie HCC1806 nach dem knockdown von ARHGAP29.

3.4.4 Proteinexpression von ARHGAP29 und AKT1 in der Mammakarzinomzellinie MCF-7-EMT nach dem knockdown von ARHGAP29

3.4.5 Proteinexpression von ARHGAP29 und AKT1 in der Mammakarzinomzellinie T-47D-EMT nach dem knockdown von ARHGAP29

4 Diskussion

4.1 Einfluss des knockdowns auf die ARHGAP29-Expression von Mammakarzinomzellen.

4.2 Einfluss der verminderten ARHGAP29-Expression auf die Invasivität von Mammakarzinomzellen.

4.2.1 Einfluss der verminderten ARHGAP29-Expression auf die Invasivität der Mammakarzinomzelllinien HCC1806, MCF-7-EMT und T-47D-EMT ........77

4.2.2 Einfluss der verminderten ARHGAP29-Expression auf die Invasivität der Mammakarzinomzelllinie MDA-MB-231

4.3 Einfluss von ARHGAP29 auf die Proliferation von Mammakarzinomzellen 82

4.4 Einfluss des ARHGAP29-knockdowns auf die Proteinexpression von AKT1

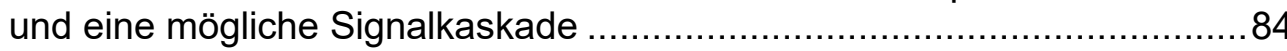

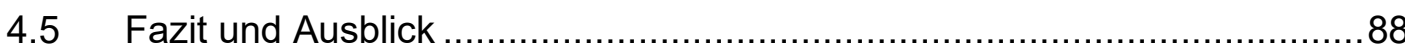




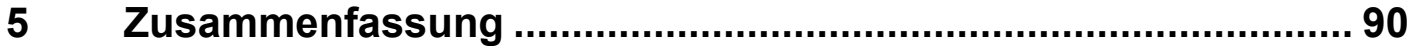

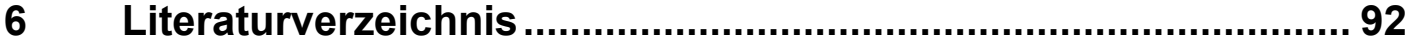




\section{Abbildungsverzeichnis}

Abbildung 1: Schematische Darstellung der modifizierten Boyden-Kammer .27

Abbildung 2: Schematische Darstellung der Schnittmenge von 223 durch induzierte EMT hochregulierten Genen und 32 in Microarrays betrachteten Rho GTPase aktivierenden Proteinen (Kolb et al. 2020).

Abbildung 3: Nachweis der signifikant erhöhten basalen Expression von ARHGAP29 in MCF-7-EMT-Zellen (Kolb et al. 2020).

Abbildung 4: Nachweis der signifikant erhöhten ARHGAP29-Expression in den Zelllinien MCF-7-EMT, T-47D-EMT, HCC1806 und MDA-MB-231, verglichen mit der Zelllinie MCF-7 (Kolb et al. 2020).

Abbildung 5: Nachweis der signifikant verminderten ARHGAP29-Expression nach erfolgter transienter siRNA-Transfektion der Mammakarzinomzellinie MDA-MB-231.

Abbildung 6: Nachweis der signifikant verminderten ARHGAP29-Expression nach erfolgter transienter siRNA-Transfektion der Mammakarzinomzelllinie HCC1806 (Kolb et al. 2020).

Abbildung 7: Nachweis der signifikant verminderten ARHGAP29-Expression nach erfolgter transienter siRNA-Transfektion der Mammakarzinomzelllinie MCF-7-EMT (Kolb et al. 2020).

Abbildung 8: Nachweis der signifikant verminderten ARHGAP29-Expression nach erfolgter transienter siRNA-Transfektion der Mammakarzinomzelllinie T-47D-EMT (Kolb et al. 2020).

Abbildung 9: Nachweis der signifikant erhöhten Invasivität nach erfolgter transienter siRNA-Transfektion der Mammakarzinomzellen MDA-MB-231.

Abbildung 10: Nachweis der signifikant reduzierten Invasivität nach erfolgter transienter siRNA-Transfektion der Mammakarzinomzellen HCC1806 (Kolb et al. 2020).

Abbildung 11: Nachweis der signifikant reduzierten Invasivität nach erfolgter transienter siRNA-Transfektion der Mammakarzinomzellen MCF-7-EMT (Kolb et al. 2020).

Abbildung 12: Nachweis der signifikant reduzierten Invasivität nach erfolgter transienter siRNA-Transfektion der Mammakarzinomzellen T-47D-EMT (Kolb et al. 2020).

Abbildung 13: Nachweis der nicht signifikant veränderten Proliferation der Mammakarzinomzelllinie MDA-MB-231 nach erfolgter siRNATransfektion

Abbildung 14: Nachweis der signifikant gesteigerten Proliferation der Mammakarzinomzellinie HCC1806 nach erfolgter siRNATransfektion (Kolb et al. 2020).

Abbildung 15: Nachweis der signifikant gesteigerten Proliferation der Mammakarzinomzellinie MCF-7-EMT nach erfolgter siRNATransfektion (Kolb et al. 2020).

Abbildung 16: Nachweis der nicht signifikant veränderten Proliferation der Mammakarzinomzelllinie T-47D-EMT nach erfolgter siRNATransfektion (Kolb et al. 2020).

Abbildung 17: Darstellung der Interaktionswahrscheinlichkeit zwischen ARHGAP29 und einer Auswahl von Genen im menschlichen Brustdrüsengewebe (Kolb et al. 2020). 
Abbildung 18: Nachweis der signifikant verminderten Expression von ARHGAP29 und AKT1 nach erfolgter transienter siRNA-Transfektion der Mammakarzinomzelllinie MDA-MD-231.

Abbildung 19: Nachweis der signifikant verminderten Expression von ARHGAP29 und AKT1 nach erfolgter transienter siRNA-Transfektion der Mammakarzinomzelllinie HCC1806 (Kolb et al. 2020). 69

Abbildung 20: Nachweis der verminderten Expression von ARHGAP29 und AKT1 nach erfolgter transienter siRNA-Transfektion der Mammakarzinomzellinie MCF-7-EMT (Kolb et al. 2020). 71

Abbildung 21: Nachweis der signifikant verminderten Expression von ARHGAP29 und AKT1 nach erfolgter transienter siRNA-Transfektion der Mammakarzinomzellinie T-47D-EMT (Kolb et al. 2020). 


\section{Tabellenverzeichnis}

Tabelle 1: Intrinsische molekulare Subtypen des Mammakarzinoms, nach Holliday und Speirs (2011)

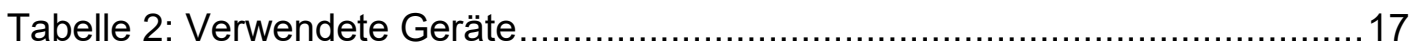

Tabelle 3: Verwendete Nähr- und Einfriermedien ............................................20

Tabelle 4: Verwendete Mammakarzinomzelllinien ..................................................21

Tabelle 5: Andere verwendete Zelllinien..........................................................22

Tabelle 6: Verwendete Kits, Reagenzien und Assays......................................22

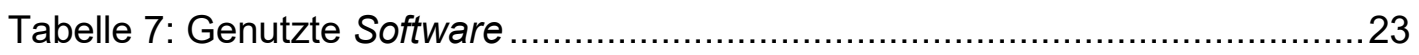

Tabelle 8: Zusammensetzung des Kokulturmediums .....................................27

Tabelle 9: Verwendete Oligonukleotide ............................................................ 33

Tabelle 10: Abfolge der durchgeführten qPCR-Zyklen......................................... 34

Tabelle 11: BSA-Verdünnungsreihe für die lineare Regression ............................36

Tabelle 12: Zusammensetzung der Gele für die SDS-Polyacrylamid-

Gelelektrophorese................................................................ 37

Tabelle 13: Zusammensetzung des Elektrophorese-Puffers..............................38

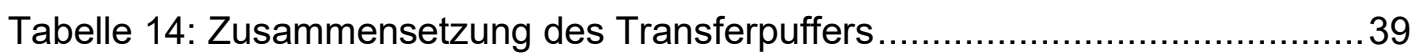

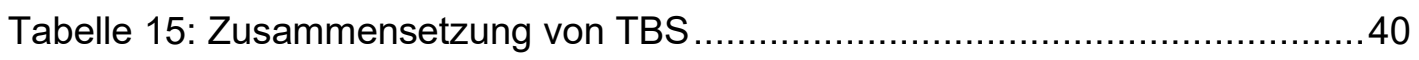

Tabelle 16: Zusammensetzung der Milchpulverlösung ......................................40

Tabelle 17: Verwendete Primär-Antikörper ...................................................41

Tabelle 18: Verwendeter Sekundär-Antikörper .............................................. 41 


\section{Abkürzungsverzeichnis}

ARHGAP29 Rho GTPase activating protein 29

ATCC

American Type Culture Collection

AWMF

Arbeitsgemeinschaft der Wissenschaftlichen Medizinischen

Fachgesellschaften e.V.

BSA Bovines Serumalbumin

cDNA

Complementary desoxyriboclueic acid

CDC42

Cell division cycle 42; cell division control protein 42 homolog

Cis

Carcinoma in situ

$\mathrm{dd}_{2} \mathrm{O}$

Doppelt destilliertes Wasser

DMEM

Dulbecco's Modified Eagle Medium

DMSO

Dimethylsulfoxid

DNA

Deoxyribonucleic acid

DNase

Desoxyribonuklease

DPBS

Dulbecco's phosphate-buffered saline

EDTA

Ethylendiamintetraacetat

EMT

Epithelial-mesenchymale Transition

ESMO

European Society for Medical Oncology

FBS

Fetal bovine serum

FC

Fold change

GAP

GTPase activating protein

GAPDH

Glyceraldehyd-3-Phosphat-Dehydrogenase

GIANT

GDI

Genome-wide Integrated Analysis of gene Networks in Tissues

GDP

Guanine nucleotide dissociation inhibitor

GEF

GTP

Guanindiphosphat

Guanine nucleotide exchange inhibitor

Guanintriphosphat

HER2/neu

Human epidermal growth factor receptor 2

HRP

Horseradish peroxidase

IARC

International Agency for Research on Cancer

Irf-6

$\mathrm{Ki}-67$

Interferon regulatory factor 6

MEM

Kiel-67

miRNA

Minimum essential medium

MMP

Micro ribonucleic acid

mRNA

Matrixmetalloproteinase

ÖR

Messenger ribonucleic acid

PKB

Östrogenrezeptor

PR

Proteinkinase B

$\mathrm{P} / \mathrm{S}$

Progesteronrezeptor

PTEN

Penicillin/Streptomycin

Phosphatase and tensin homolog 
PVDF

QN IC

qPCR

Rac

Rap1

Rap2

Ras

Rcf

Rho

RKI

RNA

RNase

ROCK

SDS

SiRNA

TBS

TBST

TRIS

TSC2

UICC

YAP

WHO
Polyvinylidenfluorid

QuantiNova internal control

Quantitative polymerase chain reaction

Ras-related C3 botulinum toxin substrate

Ras-related protein Rap1

Ras-related protein Rap2

Rat sarcoma

Relative centrifugal force

Ras homolog

Robert Koch-Institut

Ribonucleic acid

Ribonuklease

Rho associated coiled-coil containing protein kinase

Sodiumdodecylsulfat

Short interfering ribonucleic acid

Tris-buffered saline

Tris-buffered saline with Tween20

Trishydroxymethylaminomethan

Tuberous sclerosus complex 2

Union International Contre le Cancer

Yes-assoziiertes Protein

World Health Organization 


\section{Einleitung}

\subsection{Das Mammakarzinom}

\subsubsection{Epidemiologie}

Mit 2088849 Neuerkrankungen im Jahr 2018 stellt das Mammakarzinom weltweit die zweithäufigste Krebserkrankung insgesamt und die häufigste Krebserkrankung der Frau dar (Bray et al. 2018; Ferlay et al. 2019; Ferlay et al. 2020). In Deutschland wurden zuletzt 68950 Fälle für Brustkrebsneuerkrankungen verzeichnet, sodass auch hier die Brustdrüse mit 29,5\% die häufigste weibliche Tumorlokalisation ist (Barnes et al. 2019a, S. 16-17). Trotz intensiver Forschung und der Einführung des Mammographiescreenings ist das Mammakarzinom in Deutschland mit 17,6\% und generell auch weltweit die führende Lokalisation unter den Krebssterbefällen (Barnes et al. 2019a, S. 16-17; Barnes et al. 2019b, S. 78-81; Cardoso et al. 2019). Zwar konnte ein Rückgang der Sterberaten verzeichnet werden, sodass die relative 5Jahres-Überlebensrate einer deutschen an Brustkrebs erkrankten Frau 2016 bei $87 \%$ lag (Barnes et al. 2019b, S. 78-81), jedoch beträgt das relative 5-Jahres-Überleben bei der Diagnose einer Fernmetastasierung (Union Internationale Contre le Cancer (UICC) Stadium IV) nur noch 29\% (Barnes et al. 2019b, S. 78-81). Dies erklärt den großen Stellenwert, den der Prozess der Metastasierung in der Forschung rund um das Mammakarzinom einnimmt und die Dringlichkeit des Fortschritts in diesem Bereich.

Risikofaktoren für die Entwicklung eines Mamakarzinoms bestehen hinsichtlich des Hormonhaushalts bei einer frühen Menarche und einer späten Menopause, Kinderlosigkeit, dem hohen Alter der Erstgebärenden, aber auch bei einer Hormon(ersatz)therapie (Barnes et al. 2019b, S. 78-81). Des Weiteren steigt das Risiko für eine Brustkrebserkrankung bei bestimmten histologischen Gegebenheiten und benignen Veränderungen der Brustdrüse sowie bei einer früheren Brustkrebsdiagnose (Barnes et al. 2019b, S. 78-81). Eine positive Familienanamnese bezüglich des Mamma- und des Ovarialkarzinoms sowie lebensstilbezogene Aspekte, wie Über- 
gewicht und geringe körperliche Aktivität im postmenopausalen Zustand, der Konsum von Alkohol sowie das Rauchen, und eine Strahlentherapie des Thorax im Kindes- und Jugendalter erhöhen das Risiko für ein Mammakarzinom auch (Barnes et al. 2019b, S.78-81).

\subsubsection{Histopathologische und molekulare Einteilung}

Laut der World Health Organization (WHO) lassen sich die Tumoren der Mamma histopathologisch unter anderem in invasive Karzinome und verschiedene Vorläuferläsionen unterteilen (Lakhani et al. 2012 zitiert nach Sinn und Kreipe 2013). Die Vorläuferläsionen beinhalten das duktale Carcinoma in situ (ductal carcinoma in situ) und lobuläre Neoplasien (Iobular neoplasia) - inklusive des lobulären Carcinoma in situ (lobular carcinoma in situ) und atypischer lobulärer Hyperplasien (atypical lobular hyperplasia) (Lakhani et al. 2012 zitiert nach Sinn und Kreipe 2013). Bei einem Carcinoma in situ (Cis) im Allgemeinen handelt es sich per definitionem um einen malignen epithelialen Tumor, der die Basalmembran noch nicht überschritten hat (Broders 1932). Laut dem American Joint Committee on Cancer Eighth Edition Cancer Staging Manual wiederum gilt das lobuläre Cis jedoch nicht mehr als pTis (pathologisch gesicherter Tumor in situ), sondern als benigne Läsion mit dem Risiko zur Entartung (Giuliano et al. 2017). Daneben erfolgt bei invasiven Karzinomen die Differenzierung zwischen diversen speziellen Subtypen, wie unter anderem dem invasiv-lobulärem Karzinom (invasive lobular carcinoma), und den invasiven Karzinomen ohne speziellen Typ (invasive carcinoma of no special type), die zuvor bekannt waren als invasive duktale Karzinome ohne anderweitige Spezifizierung (invasive ductal carcinoma, not otherwise specified) (Lakhani et al. 2012 zitiert nach Sinn und Kreipe 2013). Auf molekularer Ebene können Mammakarzinome, wie in Holliday und Speirs (2011) zusammengefasst, unter anderem nach dem Vorhandensein der Rezeptoren für Östrogen (ÖR), Progesteron (PR) und des humanen epidermalen Wachstumsfaktorrezeptor 2 (HER2/neu, human epidermal growth factor receptor 2) sowie des Proliferationsindexes Kiel-67 (Ki-67) in mindestens fünf verschiedene intrinsische Subtypen und normales Brust-ähnliches Epithel unterteilt werden: Luminal A, Luminal B, HER2/neu, Claudin Low, Basal-like, siehe auch Tabelle 1 (Perou et al. 1999; Perou et al. 2000; Sørlie et al. 2001; Herschkowitz et al. 2007; Prat et al. 2010). Hormon- und Wachstumsrezeptor-negative Subtypen werden üblicherweise auch als dreifach oder tripel-negativer Brustkrebs bezeichnet 
(Prat et al. 2010). Hinsichtlich der Überlebensraten unterscheiden sich die verschiedenen Subtypen insofern, dass beim Luminal-A-Subtyp mit Abstand die beste Prognose verzeichnet ist (Sørlie et al. 2001; Prat et al. 2010; Prat et al. 2015). Unter den kommerziell verfügbaren Zelllinien als In-vitro-Modell des Mammakarzinoms zählen die Zelllinie MDA-MB-231 und HCC1806 zu den dreifach negativen Subtypen, während MCF-7 und T-47D der luminalen Gruppe zugeordnet werden (Gazdar et al. 1998; Neve et al. 2006; Prat et al. 2010; Holliday und Speirs 2011).

Auch wenn biologische Faktoren wie das Grading zur zytologischen Differenzierung nach Bloom und Richardson (1957), modifiziert nach Elston und Ellis (1991), der Hormonrezeptorstatus und die HER2/neu-Überexpression, sowie die damit verbundene Einteilung in verschiedene Subtypen, Multigenanalysen und weitere molekulargenetische Besonderheiten der Tumore einen immer wichtigeren Stellenwert in der Therapie des Mammakarzinoms einnehmen und auch prognostisch von Bedeutung sind, wird auch heute noch die sogenannte TNM-Klassifikation zur klinischen Einteilung von Brustkrebs genutzt (Sørlie et al. 2001; Giuliano et al. 2017). Diese teilt das Mammakarzinom in verschiedene Stadien je nach Größe des Primärtumors $(\mathrm{T})$, Befall von regionalen Lymphknoten $(\mathrm{N})$ und Fernmetastasierung $(\mathrm{M})$ ein und findet sich in der AJCC(American Joint Commission on Cancer)-Klassifikation wieder (Giuliano et al. 2017).

Tabelle 1: Intrinsische molekulare Subtypen des Mammakarzinoms, nach Holliday und Speirs (2011)

\begin{tabular}{|l|l|l|l|l|}
\hline $\begin{array}{l}\text { Intrinsischer } \\
\text { Subtyp }\end{array}$ & ÖR & PR & HER2/neu & Ki-67 \\
\hline Luminal A & + & + - & - & gering \\
\hline Luminal B & + & +- & + & hoch \\
\hline HER2/neu & - & - & + & hoch \\
\hline Claudin-low & - & - & - & niedrig \\
\hline Basal-like & - & - & - & hoch \\
\hline
\end{tabular}

Auf Holliday und Speirs (2011) basierende Darstellung der intrinsischen Subtypen des Mammakarzinoms. „+“: vorhanden; „-“: nicht vorhanden 


\subsubsection{Therapie des Mammakarzinoms}

\subsubsection{Therapie des lokal begrenzten Mammakarzinoms}

Die leitliniengerechte Therapie des invasiven Mammakarzinoms nach der European Society for Medical Oncology (ESMO) (Cardoso et al. 2019) richtet sich nach den folgenden Faktoren: Ausdehnung und Lokalisation des Primärtumors, Lymphknotenbeteiligung, pathobiologische Charakteristika, Alter, hormoneller Status, Allgemeinzustand und persönliche Präferenzen der Patientinnen (Cardoso et al. 2019). Die Therapie der ersten Wahl beim lokoregionär begrenzten Mammakarzinom soll stets, wenn möglich, die brusterhaltende Resektion im Gesunden sein (Cardoso et al. 2019). In bestimmten Fällen - je nach Verhältnis von Tumor- und Brustgröße, bei Tumoren in mehreren verschiedenen Quadranten der Brust, bei fehlender Aussicht auf eine komplette Entfernung des Tumors, bei vorangegangener Thorax-Bestrahlung, wenn es nicht möglich ist, die Brust zu erhalten und auf Patientinnenwunsch hin (Association of Breast Surgery at Baso 2009 zitiert nach Cardoso et al. 2019) - ist auch eine Mastektomie möglich (Cardoso et al. 2019). Hinsichtlich des Lymphknotenstatus ist die Sentinel-Lymphknotenbiopsie beim axillären Staging und einem klinisch nodalnegativen Befund der totalen axillären Lymphknotendissektion vorzuziehen (Cardoso et al. 2019). Die ESMO-Richtlinien (Cardoso et al. 2019) empfehlen stärkstens, nach der brusterhaltenden Tumorresektion eine Radiotherapie der ganzen Mamma durchzuführen. Je nach der Wahrscheinlichkeit eines Rezidivs und des Ansprechens auf die Therapie, aber auch toxischer Nebenwirkungen dieser, dem Alter, der gesundheitlichen Verfassung, Vorerkrankungen und Wünschen der Patientin (Cardoso et al. 2019) soll gemäß dieser Leitlinie eine adjuvante systemische Therapie durchgeführt werden. Hierbei wird - mit Ausnahme des Luminal-A-Subtyps (außer bei hoher Tumorlast) - für die anderen Subtypen in den meisten Fällen eine adjuvante Chemotherapie, mit Anthrazyklinen und Taxanen als Standardregime, stark empfohlen (Cardoso et al. 2019). In HER2/neu-positiven Fällen legt die Leitlinie eine Kombination der Chemotherapie mit einer Anti-HER2/neuTherapie nahe, standardmäßig mit Trastuzumab über ein Jahr (Cardoso et al. 2019). Beim Vorliegen luminaler Subtypen kommt eine endokrine Therapie zum Einsatz, wobei der selektive Östrogenrezeptormodulator Tamoxifen den Standard für prämenopausale Frauen und neben Aromatase-Inhibitoren jenen für post- 
menopausale Frauen darstellt (Cardoso et al. 2019). Des Weiteren stehen die ovarielle Suppressionstherapie und Gondaotropin-releasing-Hormon(GnRH)-Agonisten zur Verfügung (Cardoso et al. 2019; Leitlinienprogramm Onkologie 2020). Die ESMO-Leitlinie (Cardoso et al. 2019) empfiehlt eine neoadjuvante systemische Therapie, wenn sich der vorliegenden Tumorsubtyp als besonders sensibel für eine Chemotherapie erweist, der Tumor größer als $2 \mathrm{~cm}$ ist, wenn die axillären Lymphknoten befallen sind oder bei lokal fortgeschrittenen großen Tumoren, um eine Mastektomie zu verhindern. Diese umfasst ebenfalls die Chemotherapie sowie die endokrine und die gegen HER2/neu-gerichtete Therapie (Cardoso et al. 2019). Darüber hinaus sind die Gabe von Bisphosphonaten prophylaktisch bei Patientinnen unter ovarieller Suppressionstherapie oder in der Postmenopause sowie bei therapiebedingter Osteoporose sinnvoll (Cardoso et al. 2019).

\subsubsection{Therapie des fortgeschrittenen Mammakarzinoms}

Beim metastasierten Brustkrebs in der Erstdiagnose versprach die Resektion des Primärtumors bisher nicht zwingend einen Überlebensvorteil (Cardoso et al. 2018). Daher ist nach den vierten internationalen Konsensrichtlinien zur Therapie des fortgeschrittenen Mammakarzinoms der European School of Oncology(ESO)-ESMO die Entscheidung zur Resektion patientinnenindividuell zu erwägen (Cardoso et al. 2018). Laut Cardoso et al. (2018) soll sich die systemische Therapie beim fortgeschrittenen Mammakarzinom generell auch nach dem Status der Hormonrezeptorund Wachstumsfaktorrezeptorexpression richten, aber auch nach bisher erfolgter Therapie, dem krankheitsfreien Intervall, dem Ausmaß und der Art der Metastasierung, dem biologischem Alter und dem hormonellen und gesundheitlichen Zustand der Patientinnen, der Dringlichkeit einer Intervention, „sozioökonomischen und psychologischen Faktoren“ (Cardoso et al. 2018) und nicht zuletzt auch nach verfügbaren Mitteln und dem Patientinnenwillen. In den Richtlinien werden Anthrazykline oder Taxane auch hier hinsichtlich der Chemotherapie bei HER2/neu-Negativität meistens präferiert (Cardoso et al. 2018). Auch beim fortgeschrittenen Mammakarzinom soll nach Empfehlung der Richtlinien mit wenigen Ausnahmen die endokrine Therapie bei hormonrezeptorpositiven Tumoren mit Aromatase-Inhibitoren, Tamoxifen oder dem Antiöstrogen Fulvestrant erfolgen, inklusive der Suppression oder Ablation der ovariellen Funktion bei prä- und perimenopausalen Frauen und geziel- 
ter Therapie mit CDK(cyclin-dependent kinase, Cyclin-abhängige Kinase)-4/6-Inhibitoren oder dem Mammalian-target-of-rapamycin(mTOR)-Inhibitor Everolismus als mögliche Ergänzung bei Therapie mit Aromatase-Inhibitoren, Tamoxifen oder Fulvestrant (Cardoso et al. 2018). Beim HER2/neu-positiven fortgeschrittenen Mammakarzinom sehen die Leitlinien eine gegen HER2/neu-gerichtete Therapie vor (Cardoso et al. 2018). Hierbei sind Trastuzumab und Pertuzumab in Kombination mit einer Chemotherapie die Standards der Erstlinientherapie bei fehlender vorangegangener Anti-HER2/neu-Therapie (Cardoso et al. 2018). Der derzeitige Standard der evidenzbasierten Therapie des nicht hereditären tripel-negativen Brustkrebs im fortgeschrittenen Stadium basiert auf der Chemotherapie (Cardoso et al. 2018). Beim fortgeschrittenen Brustkrebs kann außerdem die genetische Testung auf BRCA(breast cancer)1/2-Mutationen sinnvoll sein, deren Ergebnisse in die Therapieplanung miteinzubeziehen sind (Cardoso et al. 2018). Des Weiteren können Metastasen lokalisationsspezifisches Eingreifen erfordern (Cardoso et al. 2018). Bei nur lokal fortgeschrittenem, aber inoperablem Brustkrebs besteht die initiale Therapie aus der systemischen Therapie, eventuell gefolgt von chirurgischer Therapie oder Radiotherapie, und erfolgt nach ähnlichen Prinzipien, wie bereits beschrieben (Cardoso et al. 2018). Die supportive und palliative Therapie soll stets und früh bedacht werden und im Therapieschema enthalten sein (Cardoso et al. 2018).

\subsection{Invasion und Metastasierung}

\subsubsection{Invasions-Metastasierungskaskade}

Zu den wesentlichen Kennzeichen in der Entwicklung und Progression von menschlichen Tumoren zählt der Gewinn der Metastasierungsfähigkeit (Hanahan und Weinberg 2011). Metastasierung meint dabei den Prozess, bei dem sich maligne Zellen des Primärtumors von diesem loslösen und sich letztendlich in entfernten Organen sekundär absiedeln (Fidler 2003). Wie in der Publikation von Fidler (2003) als sogenannte "Invasions-Metastasierungskaskade" (Hanahan und Weinberg 2011) zusammengefasst, bestehen die ersten Schritte dieser Kaskade nach der malignen Transformation aus der Proliferation des Primärtumors und Bildung tumoreigener Gefäße (Folkman 1986; Fidler 2003). Im weiteren Verlauf des Prozesses dringen maligne Zellen des Primärtumors in das umliegende Gewebe ein und finden letztendlich mittels Intravasation Anschluss an das Blut- und Lymphgefäßsystem 
des Körpers (Liotta 1986; Fidler 2003; Hanahan und Weinberg 2011). Nach der Passage des Gefäßsystems kommt es im Bereich des Zielorgans zur Extravasation und zur folgenden Absiedelung und Proliferation der Tumorzellen, sodass im Rahmen der Kolonisation erst Mikro-, dann bei ausreichender Blutversorgung Makrometastasen entstehen können (Folkman 1986; Chambers et al. 2002; Fidler 2003; Hanahan und Weinberg 2011). Gupta und Massagué (2006) beschreiben den Prozess der Metastasierung als eine Art Evolution innerhalb des Organismus, die die genetische Heterogenität von Tumorzellen im Selektionsdruck begründet, dem diese in der Progression von der malignen Entartung bis zur Bildung von Metastasen z. B. durch das Immunsystem, metabolische Aspekte oder die Notwendigkeit bestimmter Fähigkeiten ausgesetzt sind. Die einzelnen Zellen innerhalb eines Primärtumors sind daher nicht mit dem gleichen Repertoire an Fähigkeiten und Eigenschaften ausgestattet, das es innen in unterschiedlichem Ausmaß ermöglicht, die verschiedenen Schritte der "Invasions-Metastasierungskaskade“ (Hanahan und Weinberg 2011) zu durchlaufen (Fidler 2003). Daher sind das Invasions- und das Metastasierungspotential von Tumorzellen sowohl begrifflich als auch pathophysiologisch zu differenzieren und erfordern eine gesonderte Betrachtung (Brabletz et al. 2018).

Die Invasion im Speziellen beschreibt einen der initialen Schritte der „InvasionsMetastasierungskaskade" (Hanahan und Weinberg 2011) nach Fidler (2003), den Tumorzellen auf inrem Weg bis zur Kolonisation in entfernten Geweben durchlaufen. Die malignen Zellen überwinden die Basalmembran und dringen in das umliegende Stroma des Organs ein (Vega und Ridley 2008). Generell erfordert der Prozess der Invasion diverse morphologische und molekulare Veränderungen. Wie in zahlreichen Publikationen erläutert, bewirkt zytoskelettale Reorganisation so den Verlust von Zell-Zell- und Zell-Matrix-Verbindungen und damit phänotypische Veränderungen wie auch den Zugewinn von Motilität der Zellen (Sahai und Marshall 2002; Gupta und Massagué 2006; Vega und Ridley 2008; Wheelock et al. 2008; Yilmaz und Christofori 2009; Hanahan und Weinberg 2011). Die Sekretion von Proteasen ermöglicht die Zersetzung der extrazellulären Matrix und der Basalmembran (Gupta und Massagué 2006; Yilmaz und Christofori 2009). Zugrundliegende Mechanismen beinhalten unter anderem den Verlust der E-Cadherin-Expression und Zytoskelettreorganisationen, die durch kleine GTPasen wie Rho (rat sarcoma (Ras) homolog), Rac (Ras-related C3 botulinum toxin substrate) und CDC42 (cell division 
cycle 42; cell division control protein 42 homolog) als Hauptregulatoren des Aktinzytoskeletts (Post et al. 2015) gesteuert werden (Gupta und Massagué 2006).

\subsubsection{Migrations- und Invasionsmechanismen}

Es existieren sowohl Mechanismen der Einzelzellinvasion als auch der Invasion von Zellgruppen (Friedl und Wolf 2003). Zur Einzelzellinvasion zählen die mesenchymale und die amöboide Form der Migration (Friedl und Wolf 2003). Die mesenchymalen Art der Migration läuft nach dem klassischen Migrationsmodell ab, das Parri und Chiarugi (2010) in folgende fünf Schritte zusammenfassen: Bildung von aktinhaltigen Vorstülpungen am vorderen Zellpol, Formierung neuer fokaler Adhäsionskomplexe, lokalisierte Proteolyse, Kontraktion des Zellkörpers und Ablösung des hinteren Zellteils (Lauffenburger und Horwitz 1996; Friedl und Wolf 2003; Parri und Chiarugi 2010). Dabei nehmen die Zellen eine längliche Form an und durch integrinabhängige Adhäsionen kommt es zur Übertragung von Actomyosin-Kontraktionen auf die extrazelluläre Matrix und damit zusammen mit matrixzersetzenden Proteasen, wie Matrixmetalloproteinasen, zur Fortbewegung der Zellen (Leavesley et al. 1992; Rabinovitz und Mercurio 1997; D'Ortho et al. 1998; Friedl et al. 1998; Maaser et al. 1999; Sameni et al. 2000; Nabeshima et al. 2002; Friedl und Wolf 2003; Ridley et al. 2003; Wolf et al. 2003; Vega und Ridley 2008; Parri und Chiarugi 2010). Die amöboide Art der Migration beinhaltet dagegen keinen proteasenabhängigen Matrixabbau, sondern rundliche Zellen, die „als vorantreibende Kraft die Kontraktilität des Aktomyosin-Zytoskeletts“ (Parri und Chiarugi 2010) und Lücken und vorhandene Strukturen der extrazellulären Matrix als Leitstrukturen nutzen (Sahai und Marshall 2003; Wolf et al. 2003; Vega und Ridley 2008). Die Kettenmigration von Zellen wird zum Teil auch als Form der Einzelzellmigration aufgeführt (Friedl und Wolf 2003). Bei der Gruppeninvasion werden mehrere Tumorzellen durch eine vorangehende Zelle geführt und gezogen, sodass hierbei die Zell-ZellAdhäsionen zwischen den Zellen erhalten bleiben und die umgebende Matrix durch Proteasen zersetzt werden muss (Nabeshima et al. 2002; Wolf et al. 2007; Vega und Ridley 2008). Tumorzellen können sich an die jeweiligen Umgebungsbedingungen während der Tumorprogression anpassen und zwischen den verschiedenen Formen der Invasion variieren (Friedl und Wolf 2003). 


\subsubsection{Invasion und EMT}

Neben den beschriebenen Mechanismen, die den invasionsbedingten Veränderungen zugrunde liegen, ist auch die epithelial-mesenchymale Transition (EMT) zu erwähnen. Die EMT ist ein Prozess, der mit eben diesem Wandel von unbeweglichen, polarisierten epithelialen Zellen in bewegliche, invasive mesenchymale Zellen einhergeht (Yilmaz und Christofori 2009). Sie wird von Nieto als „sehr dynamischer, transienter und plastischer Prozess“ beschrieben (Nieto 2017), der zum einen für physiologische Vorgänge im Rahmen der Implantation, Embryonal- und Organentwicklung (Typ 1) sowie der Wundheilung und Gewebsregeneration (Typ 2) von Bedeutung ist, aber zum anderen auch pathophysiologische Relevanz hinsichtlich der Organfibrose (Typ 2) und der Progression maligner Tumore (Typ 3) besitzt (Kalluri und Weinberg 2009; Zeisberg und Neilson 2009). Auch wenn bis dato noch ungeklärt ist, ob maligne, epitheliale Tumorzellen auch komplett ohne das Durchlaufen der EMT zur Invasion und Metastasierung fähig sind (Brabletz et al. 2018), konnte das Gegenteil beim Mammakarzinom bereits gezeigt werden. So zeigen mesenchymal transformierte Mammakarzinomzellen nicht nur eine erhöhte Expression mesenchymaler Proteine wie N-Cadherin, Vimentin und Twist, sondern sind in Monokultur auch signifikant invasiver als ihre untransformierten Gegenstücke (Ziegler et al. 2014). Auch nach Kokultur mit Osteosarkomzellen oder humanen Osteoblasten lassen sich die Invasionsfähigkeiten von zunächst in Monokultur gering invasiven Mammakarzinomzellen genauso steigern wie diese in Monokultur stärker invasiver Zellen weiter steigern (Von Alten et al. 2006; Ziegler et al. 2014). Mit Modellen wie diesen, die nachweislich invasive Zellen hervorbringen, bieten sich so geeignete Möglichkeiten, die Mechanismen, die neben der EMT die Invasivität von Mammakarzinomzellen beeinflussen und bedingen, experimentell zu ergründen (Von Alten et al. 2006; Ziegler et al. 2014). Neue Erkenntnisse im Bereich der Invasion als einem der initialen Schritte der "Invasions-Metastasierungskaskade“ (Hanahan und Weinberg 2011) nach Fidler (2003) sind dringend nötig, da trotz der intensiven onkologischen Forschung nach wie vor 90\% der Krebssterbefälle auf die erfolgte Metastasierung zurückzuführen sind (Gupta und Massagué 2006). Hinsichtlich des Mammakarzinoms bedeutet eine Fernmetastasierung (UICCStadium IV), die meist in die Lunge, die Knochen, die Leber oder das Gehirn erfolgt (Gupta und Massagué 2006), einen drastischen Abfall der 5-Jahres-Überlebensrate 
(Barnes et al. 2019b, S. 78-81), weswegen diesem dringend Einhalt geboten werden muss.

\subsection{ARHGAP29}

ARHGAP29 (Rho GTPase activating protein 29) wurde 1997 als PARG1 (PTPLassociated Rho GTPase activating protein 1) oder auch PTPL1-assoziiertes Rho GTPase aktivierendes Protein mit $142 \mathrm{kDa}$ entdeckt (Saras et al. 1997). Es findet sich in vielen Geweben mittelmäßig bis hoch exprimiert, wie etwa im Skelettmuskel, im Herzen, in der Plazenta, in der Leber, im Pankreas, in der Milz, im Hoden, in Teilen des Gastrointestinaltraktes und zum Teil auch in der Niere, dem Gehirn, der Lunge und der Haut (Saras et al. 1997; Biggs et al. 2014; Miyazaki et al. 2017). Das intrazelluläre Protein besitzt neben der namensgebenden Domäne zur Interaktion mit PTPL, einer Protein-Tyrosin-Phosphatase, im C-terminalen Bereich, eine Zystein-reiche Domäne sowie N-terminal eine ZPH(ZK667.1a-PARG homology)-Region mit Homologie zum entsprechenden Gen in Caenorhabditis elegans (Saras et al. 1997). Des Weiteren verfügt ARHGAP29 über eine GAP(GTPase activating protein, GTPase aktivierendes Protein)-Domäne, welche seine Funktion als GTPase aktivierendes Protein erklärt und durch die ARHGAP29 neben Rac und CDC42 spezifisch Rho(A) aus der Familie der Rho GTPasen in der Aktivität regulieren kann (Saras et al. 1997; Xu et al. 2011).

ARHGAP29 wirkt supprimierend auf Rho(A) und hat auf diesem Wege Einfluss auf verschiedenste Prozesse (Saras et al. 1997; Xu et al. 2011; Post et al. 2013; Qiao et al. 2017; Leinhos et al. 2019; Leinhos 2019). Als Teil des Signalwegs um Rasrelated protein Rap1 und Interaktionspartner von Rasip1 (Ras-interacting protein 1) ist ARHGAP29 relevant hinsichtlich der endothelialen Barrierefunktion und der Verbreiterung von Endothelzellen sowie der Vaskulogenese, aber steht hierbei auch in Interaktion mit Radil (Rap associating with dilute domain; Xu et al. 2011; Ahmed et al. 2012; Post et al. 2013; Post et al. 2015). Mit Wirkung auf die RhoA/ROCK(Rhoassociated coiled-coil containing protein kinase)-Achse findet sich ARHGAP29 auch in Wechselwirkung mit Afadin in der Rap1-vermittelten Angiogenese und der Migration von endothelialen Zellen wieder (Tagashira et al. 2018). ARHGAP29 ist außerdem als Effektor von Rap2 mit Einfluss auf Rho beschrieben (Myagmar et al. 2005). ARHGAP29, als Suppressor der RhoA-Signalkaskade, wird außerdem im Rahmen 
der Irf6(interferon regulatory factor 6)-vermittelten Migration von Keratinozyten und endometrialer Fibrose durch MicroRNA-1291 erwähnt (Biggs et al. 2014; Xu et al. 2017).

Neben Irf6 und MicroRNA-1291 kann YAP (Yes-assoziiertes Protein) die ARHGAP29-Expression regulieren (Leslie et al. 2012; Biggs et al. 2014; Qiao et al. 2017; Xu et al. 2017). Außerdem induzieren hypoxische Bedingungen die Expression von ARHGAP29 über HIF-1a (hypoxia inducable factor 1a, Hypoxie-induzierter Faktor 1a; Leinhos et al. 2019; Leinhos 2019).

Des Weiteren konnte das ARHGAP29-Gen als ätiologischer Locus von Lippenspalten mit und ohne Gaumenspalte identifiziert werden und damit einhergehend diverse nonsense- und misssense-Mutationen von ARHGAP29 (Leslie et al. 2012; Chandrasekharan und Ramanathan 2014; Letra et al. 2014; Liu et al. 2017; Paul et al. 2017). Nicht nur für die kraniofaziale Entwicklung scheint die ARHGAP29-Expression eine Rolle zu spielen, sondern auch für das Überleben von murinen Embryonen (Leslie et al. 2012; Paul et al. 2017). Im Herzen von murinen Embryonen sowie im Gefäßsystem des Zebrafisches ist die Expression von ARHGAP29 ebenfalls nachgewiesen (Miller et al. 2008; Gomez et al. 2009)

Im Bereich der Tumorforschung ist ARHGAP29 sowohl als Tumorsuppressor in Mantelzelllymphomen (Ripperger et al. 2007) als auch als negativer Prognosefaktor beim Nierenzellkarzinom bekannt (Miyazaki et al. 2017). Des Weiteren ist die ARHGAP29-Expression nicht nur in migrierenden Gliomzellen und zirkulierenden Tumorzellen erhöht, sondern ist dabei auch mit erhöhter Metastasierungstendenz assoziiert (Mariani et al. 2001; Qiao et al. 2017). Hinsichtlich eines Einflusses von ARHGAP29 auf die zuvor beschriebene „Invasions-Metastasierungskaskade“ (Hanahan und Weinberg 2011) existieren erste Belege für die Entitäten des Nierenzellund des Magenkarzinoms (Miyazaki et al. 2017; Qiao et al. 2017). Beim Mammakarzinom, dem häufigsten Karzinom der Frau (Barnes et al. 2019a, S. 1617), wurde der Stellenwert von ARHGAP29 bisher jedoch nicht erforscht, doch die Relevanz der bekannten Interaktionspartner in der Tumorprogression ist mehrfach belegt. Daher gilt es diese Forschungs- und Wissenslücke zu füllen, was auch im Rahmen dieser Arbeit zum Einfluss von ARHGAP29 auf die Invasion des Mammakarzinoms erfolgte. 


\subsection{RhoA}

Rho GTPasen gehören wie auch Ras (rat sarcoma), Arf (adenosine diphosphate ribosylation factor), Raf (rapidly accelerated fibrosarcoma, rat fibrosarcoma), Ran (Ras-related nuclear protein) zur Ras-Superfamilie der GTPasen und sind Bestandteile vieler zellulärer Prozesse und Aspekte, wie etwa der Zellform, der Fortbewegung von Zellen, Phagozytose, zellulärer Kontraktion, Proliferation und Sekretion (Etienne-Manneville und Hall 2002). Dabei nehmen sie Einfluss auf etwa das Aktin-Zytoskelett, die Polarität von Zellen, die Gentranskription, den Zellzyklus, mikrotubuliassoziierte und Vesikeltransportvorgänge und Enzymaktivitäten (Etienne-Manneville und Hall 2002). Bei Säugetieren umschließt die Gruppe der Rho GTPasen 20 verschiedene Proteine, darunter auch die Rho-Gruppe mit RhoA, RhoB und RhoC (Vega und Ridley 2008).

Sowohl die Aktivierung als auch die Suppression von Rho-Proteinen ist im Rahmen der Tumorprogression in fast allen Stadien von Bedeutung - für die ungesteuerte Proliferation der Zellen, die Apoptoseresistenz oder den Gewinn an invasiven Eigenschaften bis hin zur Metastasierung (Sahai und Marshall 2002; Vega und Ridley 2008). RhoA im Speziellen ist einerseits im gesunden Gewebe relevant für die Zellpolarität, ist aber andererseits auch am Verlust der gleichen bei benignen Neoplasien beteiligt (Sahai und Marshall 2002). Im Rahmen der Invasion und Metastasierung von Tumorzellen kann RhoA die Beweglichkeit und die Expression von Matrixzersetzenden Proteinen regulieren (Matsumoto et al. 2001; Sahai und Marshall 2002).

Die Aktivität von Rho GTPasen ist abhängig von gebundenem GTP (Guanintriphosphat) und wird durch drei Arten von regulatorischen Proteinen gelenkt (EtienneManneville und Hall 2002). GTPase aktivierende Proteine, zu denen auch ARHGAP29 gehört, fördern die Hydrolyse des gebundenen GTPs zu GDP (Guanindiphosphat) und damit die Inaktivierung der Rho GTPasen (Etienne-Manneville und Hall 2002). Guaninnukleotidaustauschfaktoren (GEF, gunanine nucleotide exchange factor) stimulieren dagegen die Aktivierung, indem sie den Austausch von GDP zu GTP katalysieren (Etienne-Manneville und Hall 2002). Die dritte Gruppe der regulatorischen Proteine besteht aus Gunaninnukleotidissoziationsinhibitoren (GDI, guanine nucelotide dissociation inhibitors) und entfernt die inaktive Form der Rho GTPase von der Membran (Etienne-Manneville und Hall 2002). Die Aktivierung 
wird initiiert durch Rezeptorbindung von Wachstumsfaktoren oder Integrinen, woraufhin die aktive Rho GTPase mit zahlreichen Effektormolekülen interagieren kann. Zu den bekanntesten Effektoren von aktivem RhoA gehören die ROC-Kinasen I und II (Sahai und Marshall 2002).

\section{$1.5 \quad$ AKT1}

Während ARHGAP29 als Objekt in der Mammakarzinomforschung bisher nahezu unbekannt ist, existieren zahlreichen Studien und Publikationen zur Rolle von AKT in der onkologischen Forschung zum Mammakarzinom. AKT wird auch als Proteinkinase $B(P K B)$ bezeichnet und stellt eine Serin-Threonin-Kinase dar, die Anfang der Neunzigerjahre des 20. Jahrhunderts entdeckt wurde (Bellacosa et al. 1991; Coffer und Woodgett 1991; Jones et al. 1991a). Induziert durch diverse Wachstumsfaktoren, Onkogene und Zytokine, erfolgt die Aktivierung von AKT durch die PI3K(Phosphoinositid-3-Kinase)-vermittelte Rekrutierung zur Plasmamembran und die nachfolgende Phosphorylierung an Thr308 und Ser473 (Crowell et al. 2007). Es existieren drei Isoformen von AKT/PKB - AKT1/PKBa (Jones et al. 1991a), AKT2/ PKB $\beta$ (Jones et al. 1991b) und AKT3/PKBᄉ (Konishi et al. 1995). Bezüglich des Mammakarzinoms ist bekannt, dass die Signalkaskade um die AKT-Isoformen Einfluss auf viele Prozesse in der Tumorentstehung und -progression des Mammakarzinoms nimmt, wie auf die Proliferation und die Apoptose, metabolische Abläufe, die Migration sowie auch auf die Invasion und die Metastasierung, wobei es sich zum Teil um konträre isoformspezifische Funktionen handelt (Hinz und Jücker 2019).

Wie bereits erwähnt, ist die Metastasierung der gefürchtete und ein prognosebestimmender Faktor in der Therapie des invasiven Mammakarzinoms. Gerade hinsichtlich der Rolle in der "Invasions-Metastasierungskaskade“ (Hanahan und Weinberg 2011) des Mammakarzinoms scheinen die drei AKT-Isoformen in ihrer Funktion voneinander abzuweichen und müssen daher differenziert betrachtet werden (Hinz und Jücker 2019). Während die Literatur nahezu einstimmig die metastasierungsfördernde Rolle von AKT2 beim Mammakarzinom belegt, wird die Funktion von AKT1 in diesem Bereich stark diskutiert und dessen Beteiligung in den initialen Schritten der Karzinomentstehung inklusive des Wachstums des Primärtumors gesehen (Hinz und Jücker 2019). So ist AKT1 in malignem Mammagewebe signifikant 
geringer exprimiert als in normalem Brustgewebe (Choi et al. 2016). In einer Reihe von Mammakarzinomzelllinien konnte dagegen eine durch die Reihe stabile Expression von AKT1 nachgewiesen werden, wobei luminale Mammakarzinomzellen eine höhere Expression aufwiesen als basale (lacovides et al. 2013). Auch für den Effekt von AKT1 auf die Prognose Betroffener ist die Datenlage nicht eindeutig. Spears et al. (2012) fanden ein signifikant reduziertes Überleben bei hoher Expression von aktiviertem AKT1 im Vergleich zu geringer AKT1- oder AKT2-Expression vor. In einer anderen Studie korreliert eine hohe AKT1-Expression mit einer besseren Überlebensrate (Li et al. 2016).

Darüber hinaus wird im Zusammenhang von AKT1 und dem Überleben beim Mammakarzinom ein weiterer Faktor erwähnt. So ist das metastasenfreie Überleben bei niedriger AKT1-Expression, aber hoher Expression von TSC2 (tuberous sclerosus complex 2) signifikant verkürzt gegenüber Mammakarzinomfällen mit gegenläufiger Konstellation der Expression der beiden Faktoren (Liu et al. 2006). TSC2 reguliert wie auch ARHGAP29 Rho(A) in der Aktivität (Saras et al. 1997; Astrinidis et al. 2002; Goncharova et al. 2004; Liu et al. 2006; Ju et al. 2007). Publikationen zu einer möglichen Konvergenz der Signalwege, in die ARHGAP29 und AKT1 eingebettet sind, und in welchem Kontext die beiden Proteine zueinanderstehen, existieren bisher aber nicht und müssen daher in Experimenten erschlossen werden.

\subsection{Fragestellung und Zielsetzung}

Die Metastasierung des Mammakarzinoms verschlechtert die Prognose der Patientinnen enorm (Barnes et al. 2019b, S. 78-81). Die Invasion stellt als einer der initialen Schritte der "Invasions-Metastasierungskaskade“ (Hanahan und Weinberg 2011) nach Fidler (2003) somit einen wichtigen Wendepunkt in der Tumorprogression dar. ARHGAP29 ist in die Invasion und Metastasierung von Karzinomen involviert (Miyazaki et al. 2017; Qiao et al. 2017). Doch im Kontext der onkologischen Forschung zum Mammakarzinom wurde ARHGAP29 bisher nicht untersucht. Mit der Etablierung von aggressiven, mesenchymal transformierten Mammakarzinomzellen (Guttilla et al. 2012; Ziegler et al. 2014) und einem 2D-Invasionsmodell in Kokultur mit Osteosarkomzellen (Von Alten et al. 2006) bietet sich eine geeignete Methode zur experimentellen Untersuchung des Invasionsprozesses vom 
Mammakarzinom (Ziegler et al. 2014). Daher soll im Rahmen dieser Arbeit die Möglichkeit eines Einflusses von ARHGAP29 auf die Invasion von Mammakarzinomzellen erforscht werden. Um zelllinienspezifische und rezeptorabhängige Effekte auszuschließen beziehungsweise zu berücksichtigen, werden alle Experimente mit vier verschiedenen Mammakarzinomzellen durchgeführt - MDA-MB-231 und HCC1806 als dreifach negative Zelllinien und MCF-7-EMT und T-47D-EMT als mesenchymal transformierten luminale Zelllinien (Gazdar et al. 1998; Neve et al. 2006; Prat et al. 2010; Holliday und Speirs 2011).

Zunächst wird die ARHGAP29-Expression mithilfe transienter siRNA(short interfering ribonucleic acid)-knockdowns reduziert, um so den Vergleich mit einer mit Kontroll-siRNA transfizierten Zellpopulation zu ermöglichen. Die effiziente Verminderung der mRNA(messenger riconucleic acid)- und Proteinexpression von ARHGAP29 gegenüber der Kontrollgruppe soll mithilfe von quantitativer PCR auf mRNAEbene und mittels Western Blots auf Proteinebene nachgewiesen werden. Außerdem soll untersucht werden, ob sich die Expressionsreduktion von ARHGAP29 auf die Invasionsfähigkeit von den vier Mammakarzinomzelllinien auswirkt. Dafür wird das bereits erwähnte etablierte Invasionsmodell der Arbeitsgruppe verwendet (Von Alten et al. 2006). Entweder gelten die verwendeten Zellinien als besonders aggressiv (Neve et al. 2006) oder ihre Invasivität konnte im Kokultursystem oder durch EMT-Induktion gesteigert werden (Von Alten et al. 2006; Ziegler et al. 2014). Darüber hinaus soll betrachtet werden, ob ARHGAP29 die Proliferationsfähigkeit der Mammakarzinomzellen beeinflusst. So soll eine adäquate Interpretation der Ergebnisse der Invasionsanalysen gewährleistet werden.

Die Forschung über die Signalkaskade um ARHGAP29 hat in den letzten Jahren deutlich an Fahrt gewonnen, doch nach wie vor ist diese nicht weit erschlossen. Die Rolle von AKT1 beim Mammakarzinom stellt dagegen ein großes Forschungsfeld dar. Deswegen soll im letzten Schritt eruiert werden, ob ARHGAP29 die Proteinexpression von AKT1 beeinflussen kann.

Zusammengefasst verfolgt diese Arbeit das Ziel, einerseits die Rolle von ARHGAP29 speziell im Mammakarzinom und seinen Einfluss auf die Invasionsfähigkeiten von Mammakarzinomzellen zu ergründen. Andererseits beabsichtigt diese Arbeit, die Signalkaskade um ARHGAP29 weiter zu erschließen. So soll diese Arbeit dazu beitragen, die Kenntnisse tumorentitätenspezifischer 
Prozesse, wie der Invasion, zu erweitern und involvierte Signalwege weiter aufzudecken, um letztendlich eine noch gezieltere Therapie des Mammakarzinoms zu ermöglichen. 


\section{Material und Methoden}

\subsection{Material}

\subsubsection{Geräte}

Tabelle 2: Verwendete Geräte

\begin{tabular}{|c|c|}
\hline Gerät & Hersteller, Firmensitz \\
\hline$-80^{\circ} \mathrm{C}$ Kühlschrank & GFL, Burgwedel, Deutschland (DE) \\
\hline Analysenwaage BP $161 \mathrm{P}$ & Sartorius, Göttingen, DE \\
\hline arium $®$ mini & Sartorius, Göttingen, DE \\
\hline Autoklav KSG 112 & $\begin{array}{l}\text { KSG-Sterilisatoren } \mathrm{GmbH} \text {, Olching, } \\
\mathrm{DE}\end{array}$ \\
\hline $\begin{array}{l}\text { BioPhotometer ( } 8,5 \mathrm{~mm} \text { Lichtstrahl- } \\
\text { höhe) }\end{array}$ & Eppendorf, Hamburg, DE \\
\hline Biofuge pico & Heraeus, Hanau, DE \\
\hline Bunsenbrenner Flammy S & $\begin{array}{l}\text { Schütt Labortechnik GmbH, Göttin- } \\
\text { gen, DE }\end{array}$ \\
\hline C-Digit Western Blot Scanner & Li-Cor, Lincoln, Nebraska, USA \\
\hline Eismaschine (S.No. 083308) & $\begin{array}{l}\text { Ziegra Eismaschinen } \mathrm{GmbH} \text {, Isernha- } \\
\text { gen, DE }\end{array}$ \\
\hline ErgoOne FAST Pipette Controller & STARLAB GmbH, Hamburg, DE \\
\hline $\begin{array}{l}\text { Fluoreszenzmikroskop Olympus IX51 } \\
\text { + Olympus U-RFL-T (Brenner) }\end{array}$ & $\begin{array}{l}\text { Olympus, Shinjuku, Präfektur Tokio, } \\
\text { Japan }\end{array}$ \\
\hline Flüssigstickstoffbehälter Arpege 140 & Air Liquide, Paris, Frankreich \\
\hline Immersionsmikroskop & Zeiss, Oberkochen, DE \\
\hline Labofuge $400 R$ & Heraeus, Hanau, DE \\
\hline
\end{tabular}




\begin{tabular}{|c|c|}
\hline Gerät & Hersteller, Firmensitz \\
\hline Laborschüttler IKA MTS4 & IKA, Staufen, DE \\
\hline Lichtmikroskop & Zeiss, Oberkochen, DE \\
\hline Magnetrührer & IKA, Staufen im Breisgau, DE \\
\hline Megafuge $1.0 \mathrm{R}$ & Heraeus, Hanau, DE \\
\hline $\begin{array}{l}\text { Mini-PROTEAN® Tetra Vertical Elec- } \\
\text { trophoresis Cell }\end{array}$ & Bio-Rad, Hercules, CA, USA \\
\hline Minizentrifuge MCF-2360 & LMS, Hongo, Tokyo, Japan \\
\hline Mr. Frosty Kryo-Einfriergerät & $\begin{array}{l}\text { Nalgene, Thermo Fisher Scientific, } \\
\text { Waltham, Massachusetts, USA }\end{array}$ \\
\hline Neubauer-Zählkammer & Brand, Wertheim, DE \\
\hline $\begin{array}{l}\mathrm{CO}_{2} \text {-Inkubator SANYO (Modell MCO- } \\
18 \mathrm{AC})\end{array}$ & $\begin{array}{l}\text { Sanyo Electric Co., Ltd., Osaka, Ja- } \\
\text { pan }\end{array}$ \\
\hline $\begin{array}{l}\text { Pipetten „Pipetman“ (1000 } \mu \mathrm{l}, 200 \mu \mathrm{l} \text {, } \\
100 \mu \mathrm{l}, 20 \mu \mathrm{l})\end{array}$ & Gilson, Middleton, Wisconsin, USA \\
\hline PowerPac Basic Power Supply & Bio-Rad, Hercules, CA, USA \\
\hline Präzisionswaage AZ1502 & Sartorius, Göttingen, DE \\
\hline qTower 2.2 & Analytikjena, Jena, DE \\
\hline Reax top Schüttel- und Mischgerät & $\begin{array}{l}\text { Heidolph Instruments, Schwabach, } \\
\text { DE }\end{array}$ \\
\hline Rollenmischer & $\begin{array}{l}\text { Glaswarenfabrik Karl Hecht, Sond- } \\
\text { heim v. d. Röhn, DE }\end{array}$ \\
\hline Schüttelplatte GFL 3011 & GFL, Burgwedel, DE \\
\hline Schüttelwasserbad 1083 & GFL, Burgwedel, DE \\
\hline Sterilwerkbank & $\begin{array}{l}\text { Clean Air Techniek B.V., Woerden, } \\
\text { NL }\end{array}$ \\
\hline Synergy HT Microplate Reader & BIO-TEK, Winooski, Vermont, USA \\
\hline
\end{tabular}




\begin{tabular}{|l|l|}
\hline Gerät & Hersteller, Firmensitz \\
\hline Thermocycler T3000 & Biometra, Göttingen, DE \\
\hline Thermomixer compact & Eppendorf, Hamburg, DE \\
\hline Titramax 1000 & $\begin{array}{l}\text { Heidolph Instruments, Schwabach, } \\
\text { DE }\end{array}$ \\
\hline Vakuumpumpe EcoVac & Schuett biotec, Göttingen, DE \\
\hline Vibrax Schüttelplatte & Serono, Genf, Schweiz \\
\hline
\end{tabular}

\subsubsection{Verbrauchsmaterialien}

Die verwendeten Verbrauchsmaterialien (Einmalartikel) wurden von den Firmen Bemis (Neenah, Wisconsin, USA), Brand GmbH + Co. KG (Wertheim, DE), Eppendorf (Hamburg, DE), Greiner Bio-One (Kremsmünster, Österreich), Kimberly-Clark Professional (Roswell, Georgia, USA), Merck KGaA (Darmstadt, DE), Merck Millipore Ltd. (Burlington, Massachusetts, USA), Paul Hartmann AG (Heidenheim an der Brenz, DE) Sarstedt (Nürnbrecht, DE), STARLAB GmbH (Hamburg, DE), Thermo Fisher Scientific (Waltham, Massachusetts, USA) und Th. Geyer GmbH \& Co. KG (Renningen, DE) bezogen.

Alle verwendeten Materialien wurden vor der Benutzung autoklaviert oder gereinigt, sofern es sich nicht um Sterilgut handelte.

\subsubsection{Chemikalien, biologischen Materialien, Lösungen und Puffer}

Die verwendeten Chemikalien, biologische Materialien, Lösungen und Puffer werden jeweils unter 2.2 im Rahmen der Methode, bei der sie zum Einsatz kamen, genannt.

Zweifach destilliertes Wasser wurde mithilfe des Reinstwassersystems arium $®$ mini (Sartorius, Göttingen, DE) hergestellt.

\subsubsection{Kultur- und Einfriermedien}

Für die Kultivierung der Mammakarzinomzellen wurden das MEM (Minimum Essential Medium) mit Earle's Salzen und stabilem Glutamin von Biowest (Nuaillé, Frankreich) verwendet. Die Osteosarkomzellen wurden in Gibco® DMEM (Dulbecco's 
Modified Eagle Medium) mit Phenolrot, L-Glutamin und hoher Glucosekonzentration (Thermo Fisher Scientific, Waltham, Massachusetts, USA) kultiviert. Die Einfriermedien (siehe Tabelle 3) wurden auf Basis dieser Grundmedien für die entsprechenden Zelllinien erstellt. Im Rahmen der transienten siRNA-Transfektion wurde OptiMEM (sc-36868, Thermo Fisher Scientific Waltham, Massachusetts, USA) genutzt. Alle verwendeten Zusätze sind in der folgenden Tabelle 3 aufgeführt.

Tabelle 3: Verwendete Nähr- und Einfriermedien

\begin{tabular}{|c|c|c|c|}
\hline & $\begin{array}{l}\text { MEM mit Phe- } \\
\text { nolrot }\end{array}$ & $\begin{array}{l}\text { DMEM mit Phe- } \\
\text { nolrot }\end{array}$ & Einfriermedium \\
\hline Funktion & Nährmedium & Nährmedium & Einfriermedium \\
\hline Zelllinie & $\begin{array}{l}\text { HCC1806, MCF- } \\
\text { 7-EMT, MDA- } \\
\text { MB-231, T-47D- } \\
\text { EMT }\end{array}$ & MG-63 & $\begin{array}{l}\text { HCC1806, MCF- } \\
\text { 7-EMT, MDA-MB- } \\
\text { 231, MG-63, T- } \\
\text { 47D- EMT }\end{array}$ \\
\hline $\begin{array}{l}\text { Zusätze (*: zu } \\
500 \mathrm{ml} \text { Grundme- } \\
\text { dium) }\end{array}$ & \multicolumn{2}{|c|}{$\begin{array}{l}10 \%{ }^{*} \text { FBS (Fetal bovine serum; FBS } \\
\text { Superior, Sigma-Aldrich, St. Louis, } \\
\text { Missouri, USA) } \\
\text { 1\%* Gibco® P/S (Penicillin/Strepto- } \\
\text { mycin, Thermo Fisher Scientific, } \\
\text { Waltham, Massachusetts, USA) } \\
\text { 0.1\%* Holo-Transferrin (Sigma-Al- } \\
\text { drich, St. Louis, Missouri, USA; } \\
1 \text { mg/mI DPBS (Dulbecco's phos- } \\
\text { phate-buffered saline, Dulbeccos } \\
\text { Phosphatgepufferte Salzlösung, Pan } \\
\text { Biotech GmbH, Aidenbach, DE) } \\
26 \text { IU Insulin (Insuman® Rapid: Insu- } \\
\text { lin human (40 I.E./ml); Sanofi, Paris, } \\
\text { Frankreich) }\end{array}$} & $\begin{array}{l}75 \% \text { Nährmedium } \\
\text { mit Zusätzen } \\
20 \% \text { FBS (FBS } \\
\text { Superior, Sigma- } \\
\text { Aldrich, St. Louis, } \\
\text { Missouri, USA) } \\
\text { 5\% DMSO (Dime- } \\
\text { thylsulfoxid; } \\
\text { Sigma- Aldrich, } \\
\text { St. Louis, Mis- } \\
\text { souri, USA) }\end{array}$ \\
\hline
\end{tabular}




\subsubsection{Zelllinien}

Für die Versuche wurden die in Tabelle 4 und Tabelle 5 aufgeführten Zelllinien von der Firma American Type Culture Collection (ATCC, Manassas, Virginia, USA) bezogen. Außerdem wurden die ebenfalls dort bezogenen Zelllinien MCF-7 und T-47D, wie von Ziegler et al. (2014) und Guttilla et al. (2012) beschrieben, laborintern durch Mammosphärenkultivierung über fünf Passagen mesenchymal transformiert in MCF-7-EMT und T-47D-EMT. Anschließend konnten diese in Zellkultur über weitere fünf Passagen kultiviert werden. Die Zellen wurden in flüssigem Stickstoff bei $-180^{\circ} \mathrm{C}$ aufbewahrt und bei Bedarf aufgetaut.

Tabelle 4: Verwendete Mammakarzinomzelllinien

\begin{tabular}{|l|l|l|l|}
\hline Zelllinie & Herkunft & Histologie & Referenz \\
\hline HCC1806 & Primärtumor & $\begin{array}{l}\text { Akantholytisches Plat- } \\
\text { tenepithelkarzinom, } \\
\text { Mamma }\end{array}$ & $\begin{array}{l}\text { Gazdar et al. 1998; } \\
\text { ATCC 2016a }\end{array}$ \\
\hline MCF-7 & $\begin{array}{l}\text { Pleuraer- } \\
\text { guss }\end{array}$ & $\begin{array}{l}\text { Adenokarzinom, } \\
\text { Mamma }\end{array}$ & $\begin{array}{l}\text { Soule et al. 1973; ATCC } \\
\text { 2016b }\end{array}$ \\
\hline MCF-7-EMT & $\begin{array}{l}\text { Nach Ziegler et al. (2014) und Guttilla et al. (2012) beschrieben } \\
\text { mesenchymal transformierte MCF-7-Zellen }\end{array}$ \\
\hline MDA-MB-231 & $\begin{array}{l}\text { Pleuraer- } \\
\text { guss }\end{array}$ & $\begin{array}{l}\text { Adenokarzinom, } \\
\text { Mamma }\end{array}$ & $\begin{array}{l}\text { Cailleau et al. 1974; } \\
\text { ATCC 2016c }\end{array}$ \\
\hline T-47D & $\begin{array}{l}\text { Pleuraer- } \\
\text { guss }\end{array}$ & $\begin{array}{l}\text { infiltrierendes dukta- } \\
\text { les Karzinom, Mam- } \\
\text { ma }\end{array}$ & $\begin{array}{l}\text { Keydar et al. 1979; } \\
\text { ATCC 2016e }\end{array}$ \\
\hline mesenchymal transformierte T-47D-Zellen \\
\hline
\end{tabular}


Tabelle 5: Andere verwendete Zelllinien

\begin{tabular}{|l|l|l|l|}
\hline Zelllinie & Herkunft & Histologie & Referenz \\
\hline MG-63 & Primärtumor & $\begin{array}{l}\text { Osteosarkom, } \\
\text { Knochen }\end{array}$ & $\begin{array}{l}\text { Billiau et al. 1977; ATCC } \\
2016 \mathrm{~d}\end{array}$ \\
\hline
\end{tabular}

\subsubsection{Kommerzielle Kits, Reagenzien und Assays}

Tabelle 6: Verwendete Kits, Reagenzien und Assays

\begin{tabular}{|c|c|}
\hline Kit, Reagenz oder Assay & Hersteller, Sitz \\
\hline ARHGAP29-siRNA (sc-78491) & $\begin{array}{l}\text { Santa Cruz Biotechnology, Dallas, } \\
\text { Texas, USA }\end{array}$ \\
\hline $\begin{array}{l}\text { BioRad protein assay dye reagent } \\
\text { concentrate }\end{array}$ & $\begin{array}{l}\text { Bio-Rad Laboratories, Hercules, CA, } \\
\text { USA }\end{array}$ \\
\hline $\begin{array}{l}\text { Celllyse M/Cell-lytic cell lysis rea- } \\
\text { gence }\end{array}$ & $\begin{array}{l}\text { Sigma-Aldrich, St. Louis, Missouri, } \\
\text { USA (Merck KGaA, Darmstadt, DE) }\end{array}$ \\
\hline $\begin{array}{l}\text { Chemilumescent Substrate for Wes- } \\
\text { tern Blotting (Westar Supernova) }\end{array}$ & Cyanagen, Bologna, Italien \\
\hline Control-siRNA (sc-37007) & \multirow{2}{*}{$\begin{array}{l}\text { Santa Cruz Biotechnology, Dallas, } \\
\text { Texas, USA }\end{array}$} \\
\hline $\begin{array}{l}\text { Control-siRNA (Fluorescein-markiert; } \\
\text { sc-36869) }\end{array}$ & \\
\hline $\begin{array}{l}\text { Fast Gene RNA Basic Kit (Cat. No. } \\
\text { FG-80250) }\end{array}$ & $\begin{array}{l}\text { Nippon Genetics Europe GmbH, Dü- } \\
\text { ren, DE }\end{array}$ \\
\hline $\begin{array}{l}\text { Immobilon® Western - Chemilumi- } \\
\text { nescent HRP (horseradish peroxi- } \\
\text { dase) Substrate (Cat. No. } \\
\text { WBKLS0100) }\end{array}$ & $\begin{array}{l}\text { Merck Millipore Ltd., Burlington, Mas- } \\
\text { sachusetts, USA (Merck KGaA, } \\
\text { Darmstadt, DE) }\end{array}$ \\
\hline NuPage $®$ LDS Sample Buffer & $\begin{array}{l}\text { Thermo Fisher Scientific, Waltham, } \\
\text { Massachusetts, USA }\end{array}$ \\
\hline
\end{tabular}




\begin{tabular}{|c|c|}
\hline Kit, Reagenz oder Assay & Hersteller, Sitz \\
\hline NuPage $®$ Sample Reducing Agent & $\begin{array}{l}\text { Thermo Fisher Scientific, Waltham, } \\
\text { Massachusetts, USA }\end{array}$ \\
\hline Phosphatase-Inhibitor & $\begin{array}{l}\text { Sigma-Aldrich, St. Louis, Missouri, } \\
\text { USA (Merck KGaA, Darmstadt, DE }\end{array}$ \\
\hline $\begin{array}{l}\text { Protein Marker VI (10-245), pre- } \\
\text { stained }\end{array}$ & $\begin{array}{l}\text { PanReac AppliChem GmbH, Darm- } \\
\text { stadt, DE }\end{array}$ \\
\hline Protease-Inhibitor & $\begin{array}{l}\text { Sigma-Aldrich, St. Louis, Missouri, } \\
\text { USA (Merck KGaA, Darmstadt, DE }\end{array}$ \\
\hline $\begin{array}{l}\text { RNase-Free DNase (Desoxyribonu- } \\
\text { clease) Set (Ref. 79254) }\end{array}$ & Qiagen $\mathrm{GmbH}$, Venlo, NL \\
\hline Transfektionsreagenz (sc-29528) & $\begin{array}{l}\text { Santa Cruz Biotechnology, Dallas, } \\
\text { Texas, USA }\end{array}$ \\
\hline $\begin{array}{l}\text { QuantiNova }{ }^{\mathrm{TM}} \text { Internal Control RNA } \\
\text { and Assay (Mat. No. 1093674) }\end{array}$ & \multirow{3}{*}{ Qiagen $\mathrm{GmbH}$, Venlo, NL } \\
\hline $\begin{array}{l}\text { QuantiNova }{ }^{\mathrm{TM}} \text { Reverse Transcription } \\
\text { Kit (Ref. 205413) }\end{array}$ & \\
\hline $\begin{array}{l}\text { QuantiNova }{ }^{\mathrm{TM}} \text { SYBR® Green PCR } \\
\text { Kit (Cat. No. 208056) }\end{array}$ & \\
\hline
\end{tabular}

\subsubsection{Software}

Tabelle 7: Genutzte Software

\begin{tabular}{|l|l|}
\hline Software & Hersteller, Sitz \\
\hline AxioVision 3.1 & Zeiss, Jena und Oberkochen, DE \\
\hline Gen5 1.08 & BIO-TEK, Winooski, VT, USA \\
\hline $\begin{array}{l}\text { GraphPad Prism® 6.01 (8.4.3 } \\
\text { und 9.1.0 nur zur Bearbeitung } \\
\text { der Graphen) }\end{array}$ & $\begin{array}{l}\text { GraphPad Software, San Diego, Kalifornien, } \\
\text { USA }\end{array}$ \\
\hline
\end{tabular}




\begin{tabular}{|l|l|}
\hline Software & Hersteller, Sitz \\
\hline ImageJ 1.50i und 1.52a & $\begin{array}{l}\text { Wayne Rasband, National Institutes of } \\
\text { Health, Bethesda, Maryland, USA }\end{array}$ \\
\hline Image Studio 4.0 & Li-Cor, Lincoln, NE, USA \\
\hline Microsoft Office Version & $\begin{array}{l}\text { Microsoft Corporation, Redmond, Washing- } \\
\text { ton, USA }\end{array}$ \\
\hline qPCR soft 1.1 $1907,2002,2008,2103$ & AnalytikJena, Jena, DE \\
\hline Zotero 5.0.93 und 5.0.96.2 & $\begin{array}{l}\text { Roy Rosenzweig Center } \\
\text { for History and New Media } \\
\text { der George Mason University, Washington } \\
\text { DC, Virginia, USA }\end{array}$ \\
\hline
\end{tabular}

\subsection{Methoden}

\subsubsection{Zellbiologische Methoden}

\subsubsection{Zellkultur und Passagieren der Zellen}

Alle Maßnahmen im Rahmen der Zellkultivierung wurden unter Nutzung steriler Arbeitsweise durchgeführt. Die Zellen wurden in $75 \mathrm{~cm}^{2}$ großen Zellkulturflaschen von Sarstedt (Nürnbrecht, DE) mit $10 \mathrm{ml}$ Nährmedium (siehe 2.1.4) bei $37^{\circ} \mathrm{C}$ in einer wasserdampfgesättigten Atmosphäre mit 5\% $\mathrm{CO}_{2}$-Anteil kultiviert. Zweimal wöchentlich erfolgte ein Mediumswechsel oder das Passagieren der Zellen bei einer Konfluenz von $70 \%$ bis $90 \%$. Dafür wurden die adhärenten Tumorzellen nach Entfernung des Nährmediums zuerst mit $5 \mathrm{ml}$ DPBS (Dulbecco's phosphate-buffered saline, Dulbeccos phosphatgepufferte Salzlösung, Pan Biotech $\mathrm{GmbH}$, Aidenbach, DE) gewaschen. Anschließend wurden $3 \mathrm{ml}$ der zuvor auf $37^{\circ} \mathrm{C}$ erwärmten Trypsin/Ethylendiamintetraacetat(EDTA)-Lösung (c-c-pro $\mathrm{GmbH}$, Oberdorla, DE) zugegeben und die Zellen bei $37^{\circ} \mathrm{C}$ und $5 \% \mathrm{CO}_{2}$ inkubiert. Die Zellsuspension wurde in $7 \mathrm{ml}$ Nährmedium resuspendiert und in einem passenden Verhältnis verdünnt und die Zellen weiter bei $37^{\circ} \mathrm{C}$ und $5 \% \mathrm{CO}_{2}$ kultiviert. 


\subsubsection{Bestimmung der Zellzahl}

Zur Quantifizierung der Zellen in Zellsuspension wurden diese zuerst, wie unter 2.2.1.1 beschrieben, gewaschen, trypsiniert, resuspendiert. Anschließend wurde die Zellsuspension für fünf Minuten bei 1200 rcf (relative centrifugal force, relative Zentrifugalkraft) pelletiert. Nach dem Absaugen des Überstandes wurde das Zellpellet in einem geeigneten Volumen des entsprechenden Versuchsmediums resuspendiert. Nach Verdünnung von $10 \mu$ Zellsuspension mit $10 \mu \mathrm{l}$ Trypanblau (SigmaAldrich, St. Louis, Missouri, USA) wurden $10 \mu \mathrm{l}$ der Lösung auf eine Neubauer-Zählkammer pipettiert. Diese besteht aus neun Großquadraten mit einer Fläche von jeweils $1 \mathrm{~mm}^{2}$ und einer Kammertiefe von 0,1 mm. Im nächsten Schritt wurden die vier großen Eckquadrate unter dem Lichtmikroskop ausgezählt. Die Berechnung der Zellzahl pro $\mu \mathrm{l} \mathrm{bzw.} \mathrm{pro} \mathrm{ml}$ erfolgte folgendermaßen:

$$
\text { Zellen je } \begin{aligned}
\mu \mathrm{l} & =\frac{\text { gezählte Zellen }}{\text { ausgezählte Fläche }\left[\mathrm{mm}^{2}\right] \times \text { Kammertiefe }[\mathrm{mm}] \times \text { Verdünnung }} \\
& =\frac{\text { gezählte Zellen } \times 2}{4 \mathrm{~mm}^{2} \times 0,1 \mathrm{~mm}}
\end{aligned}
$$

Zellen je $\mathrm{ml}=\frac{\left(\text { gezählte Zellen } \times 2 \times 10^{4}\right)}{4}$

\subsubsection{Kryokonservierung der Zellen}

Für die Kryokonservierung wurden die Zellen zunächst, wie unter 2.2.1.1 und 2.2.1.2 beschrieben, trypsiniert und pelletiert. Die Zellpellets wurden in einem geeigneten Volumen von Einfriermedium (siehe Tabelle 3 unter 2.1.4) resuspendiert und in Kryoröhrchen für mindestens 24 Stunden bei $-80^{\circ} \mathrm{C}$ in Mr. Frosty Kryo-Einfriergerät (Nalgene, Thermo Fisher Scientific, Waltham, Massachusetts, USA), gefüllt mit Isopropanol (Chemsolute ${ }^{\circledR}$, Th. Geyer GmbH \& Co. KG, Renningen, DE) langsam eingefroren und konnten daraufhin für eine langfristige Lagerung in flüssigen Stickstoff überführt werden.

\subsubsection{Revitalisierung kryokonservierter Zellen}

Zur Revitalisierung kryokonservierter Zellen wurden die Zellen in einem Wasserbad von $37^{\circ} \mathrm{C}$ aufgetaut und hierauf in mit $10 \mathrm{ml}$ kaltem Nährmedium versehene Zellkulturflaschen überführt und bei $37^{\circ} \mathrm{C}$ und $5 \% \mathrm{CO}_{2}$ kultiviert. Am nächsten Tag wurde das Medium erneuert, um das restliche Dimethylsulfoxid (DMSO) zu entfernen. 


\subsubsection{Proliferationsanalyse}

Für die Proliferationsanalyse wurden vorerst, wie unter 2.2.2.1 beschrieben, Zellen angesät und transfiziert. 24 Stunden nach erfolgter Transfektion wurden jeweils 50000 Zellen in einer 6-Well-Platte angesät. Nach 120 Stunden erfolgte die Analyse der Proliferation mittels Auszählung der Zellen, wie unter 2.2.1.2 erläutert. Die ermittelte Zellzahl (pro ml) der transient mit ARHGAP29-spezifischer siRNA transfizierten Zellen wurde auf die der Kontrollgruppe bezogen.

\subsubsection{Invasionsanalyse}

Das Invasionsassay wurde mit einigen Modifikationen wie durch von Alten et al. (2006) beschrieben durchgeführt. Der Ursprung der im Folgenden erwähnten Boyden-Kammer geht auf Stephen Boyden zurück (Boyden 1962). Es wurden verschiedene Mammakarzinomzelllinien nach erfolgter transienter siRNA-Transfektion (beschrieben unter 2.2.2.1) mit humanen Osteosarkomzellen (MG-63) in einer modifizierten Boyden-Kammer für 96 Stunden kokultiviert, um in vitro die knochengerichtete Mammakarzinom-Zellinvasion zu imitieren (Von Alten et al. 2006). Die modifizierte Boyden-Kammer bestand dabei aus einem unteren Well, mit angesäten Osteosarkomzellen und einem Zellkultureinsatz aus Polycarbonat (siehe Abbildung 1). Die Zellkultureinsätze mit einer 8- $\mu \mathrm{m}$-porigen Membran wurden mit $30 \mu \mathrm{l}$ einer Matrigel-Lösung (Franklin Lakes, New Jersey, USA; 1:2 in Phenolrot-freiem DMEM, Thermo Fisher Scientific, Waltham, Massachusetts, USA) beschichtet und für eine Stunde bei $37^{\circ} \mathrm{C}$ und $5 \% \mathrm{CO}_{2}$ inkubiert, um die Polymerisation des Gels zu bewirken. In diesen beschichteten Zellkultureinsätzen wurden 10000 transient transfizierten Mammakarzinomzellen in $400 \mu \mathrm{l}$ Kokulturmedium (siehe Tabelle 8) angesät. In das untere Well wurden 20000 Osteosarkomzellen in $600 \mu \mathrm{l}$ Kokulturmedium angesät. Nach einer 24-stündigen Inkubation bei $37^{\circ} \mathrm{C}$ und $5 \% \mathrm{CO}_{2}$ wurden die beschichteten Zellkultureinsätze mit den transient transfizierten Mammakarzinomzelllen in die Wells mit den Osteosarkomzellen umgesetzt und für 96 Stunden kokultiviert. 


\section{Mammakarzinomzellen}

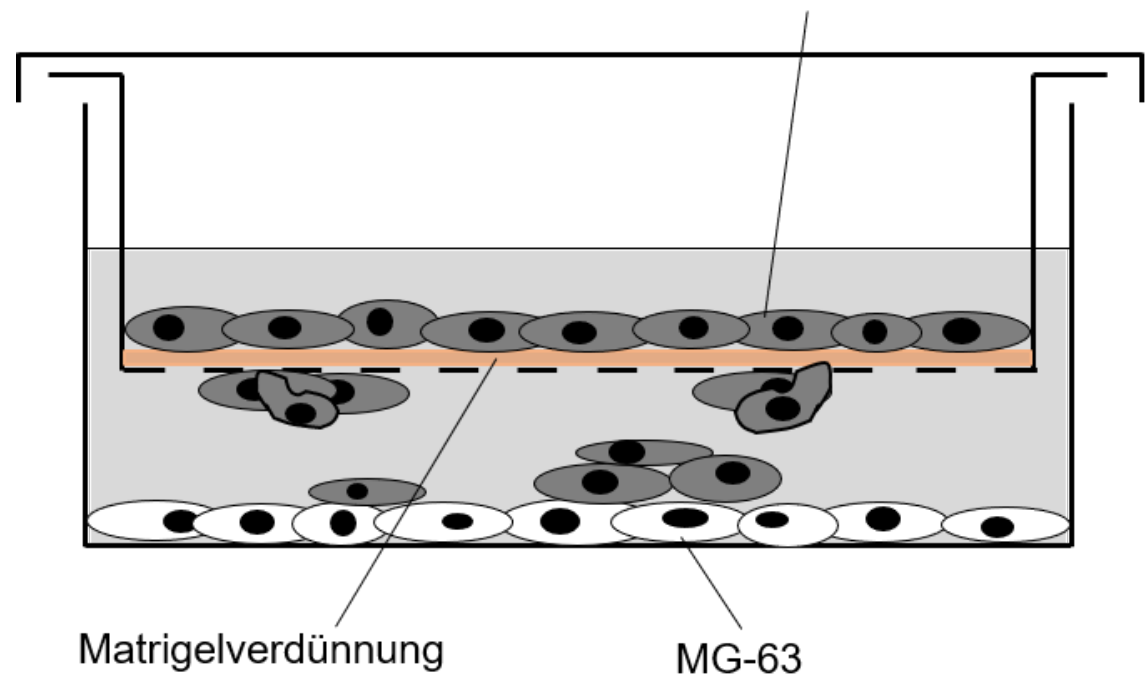

Abbildung 1: Schematische Darstellung der modifizierten Boyden-Kammer. Abbildung basierend auf von Alten et al. (2006). Für die Invasionsanalyse wurde eine nach von Alten et al. (2006) modifizierte Boyden-Kammer entsprechend dieser Abbildung verwendet. Der obere Zellkultureinsatz, bestehend aus Polycarbonat, mit 8- $\mu \mathrm{m}$-Poren wurde mit einer Matrigel@-Verdünnung beschichtet und transient transfizierte Mammakarzinomzellen darin angesät. Osteosarkomzellen der Zelllinie MG-63 wurden im unteren Well angesät. In der Behandlungsgruppe der Mammakarzinomzellen erfolgte die transiente Transfektion mit ARHGAP29-spezifischer siRNA und in der Kontrollgruppe mit unspezifischer siRNA. Nach 96-stündiger Kokultivierung wurde die Anzahl der invadierten Zellen der Behandlungsgruppe auf die Zellzahl der Kontrollgruppe normiert.

Tabelle 8: Zusammensetzung des Kokulturmediums

\begin{tabular}{|l|c|}
\hline Zusatz & Anteil \\
\hline $\begin{array}{l}\text { DMEM (Gibco® Dulbecco's Modified Eagle Medium ohne Phenolrot, } \\
\text { L-Glutamin und HEPES; Thermo Fisher Scientific, Waltham, Massa- } \\
\text { chusetts, USA) }\end{array}$ & $88 \%$ \\
\hline $\begin{array}{l}\text { cs-FCS (Charcoal-stripped fetale calf serum, mit Aktivkohle behan- } \\
\text { deltes fetales Kälberserum; Pan Biotech GmbH, Aidenbach, DE) }\end{array}$ & $10 \%$ \\
\hline $\begin{array}{l}\text { Gibco® Penicillin/Streptomycin (Thermo Fisher Scientific, Wal- } \\
\text { tham, Massachusetts, USA) }\end{array}$ & $1 \%$ \\
\hline L-Alanyl-L-Glutamin (Biochrom GmbH, Berlin, DE) & $1 \%$ \\
\hline
\end{tabular}


Während der 96-stündigen Kokultivierung konnten invasive Mammakarzinomzellen durch die basalmembranartige Matrix die Poren der Zellkultureinsätze passieren und an die Unterseite der Zellkultureinsätze invadieren. Nach 96 Stunden wurden die Zellen in den Zellkultureinsätzen mit Mayers Hämalaunlösung behandelt, welche nukleäre Strukturen nachhaltig blau anfärbt (Kiernan 2018). Dafür wurden die Zellkultureinsätze für fünf Minuten in DPBS (Pan Biotech $\mathrm{GmbH}$, Aidenbach, DE) gewaschen, mit zweifach-destilliertem Wasser $\left(\mathrm{ddH}_{2} \mathrm{O}\right)$ gespült und mit hundertprozentigem Methanol (Th. Geyer GmbH \& Co. KG, Renningen, DE) für zehn Minuten bei Raumtemperatur fixiert. Nach Spülung der Zellkulturinserts mit zweifach-destilliertem Wasser erfolgte die fünfminütige Inkubation in Mayers Hämalaunlösung (Merck KGaA, Darmstadt, DE) bei Raumtemperatur. Anschließend wurden die Zellkulturinserts mit zweifach-destilliertem Wasser gespült und durch Zugabe von Leitungswasser die Mammakarzinomzellen angefärbt. Nicht-invasive Mammakarzinomzellen in den Zellkultureinsätzen wurden mit Watterollen von der Zellkultureinsatzmembran entfernt und letztere folglich auf einem Objektträger ausgestanzt und mit Aquatex (Merck KGaA, Darmstadt, DE) fixiert.

Nach dem Trocknen der Objektträger wurde jede Membran manuell in vier Teile aufgeteilt und pro Teileinheit mikroskopisch mit Hilfe des Programmes AxioVision die am dichtesten besiedelte Stelle abgebildet. Anschließend konnten die Zahl der invadierten Zellen auf jeder Aufnahme mithilfe des Programms ImageJ ermittelt werden. Die Summe der ermittelten Teileinheit- Zellzahlen der transient mit ARHGAP29-spezifischer siRNA transfizierten Mammakarzinomzellen wurde anschließend auf den Mittelwerten der addierten Werte der transient mit einer siRNA-Kontrolle transfizierten Mammakarzinomzellen normiert.

\subsubsection{Molekularbiologische Methoden}

\subsubsection{Transiente siRNA-Transfektion}

Die transiente Verminderung der ARHGAP29-Expression in den verwendeten Mammakarzinomzelllinien wurde mithilfe eines Pools von drei spezifisch ARHGAP29-mRNA-bindenden siRNAs bewerkstelligt. Diese Methode basiert auf der sogenannten RNA-Interferenz, deren Mechanismus 1998 erstmals von Fire et al. (1998) als Verminderung spezifischer Genexpression durch doppelsträngige RNA 
beschrieben wurde. Die erfolgreiche Verwendung von sogenannten siRNAs in Säugetierzellen wiederum wurde durch Elbashir et al. (2001) publik (McManus und Sharp 2002). Die hier verwendete Transfektion der Zelllinien wurde wie bereits von Girgert et al. (2012) modifiziert durchgeführt.

Dafür wurden die ARHGAP29-siRNA (sc-78491; SCBT, Dallas, Texas, USA) und die siRNA-Kontrolle (sc-37007; SCBT, Dallas, Texas, USA) in einer Konzentration von $10 \mu \mathrm{M}$ in RNase-freiem Wasser gelöst. Zudem wurde eine fluoresceinmarkierte siRNA-Kontrolle (sc-36869; SCBT, Dallas, Texas, USA) beim ersten Versuchsdurchgang mit der Zelllinie MDA-MB-231 mitgeführt, um die Transfektionseffizienz beurteilen zu können. Von den Mammakarzinomzellen wurden zunächst, je nach Zelllinie, 500000 Zellen (MDA-MB-231 und HCC1806) oder 1000000 Zellen (MCF-7-EMT und T-47D-EMT) in $2 \mathrm{ml} \mathrm{P/S(Penicillin/Streptomycin)-freiem} \mathrm{Medium}$ (MEM, 10\% FBS (fetal bovine serum, fetales Rinderserum), 0,1\% Transferrin, 2,6 IU Insulin, für Produktinformationen siehe auch 2.1.4) und $25 \mathrm{~cm}^{2}$ Zellkulturflaschen für 24 Stunden angesät. Für alle Zelllinien wurden mindestens zwei Proben angesetzt: jeweils eine Zellpopulation, deren ARHGAP29-Expression vermindert werden sollte („ARHGAP29-“) sowie eine Kontrollpopulation („siRNA-Kontrolle“), die mit einer siRNA-Kontrolle behandelt wurde. Nach 24 Stunden erfolgte die transiente Transfektion durch Lipofektion. Hierbei wurden $4 \mu$ der siRNA in $100 \mu \mathrm{L}$ Opti-MEM (sc-36868, Thermo Fisher Scientific, Waltham, Massachusetts, USA) gelöst. Des Weiteren wurden $4 \mu \mathrm{L}$ Transfektionsreagenz (sc-29528, SCBT, Dallas, Texas, USA) in $100 \mu \mathrm{L}$ Opti-MEM gelöst und zusammen mit der siRNA-Lösung für $45 \mathrm{Mi}$ nuten bei Raumtemperatur im Dunkeln inkubiert. Die Mammakarzinomzellen wurden für zehn Minuten mit Opti-MEM Medium inkubiert. Anschließend wurde dem siRNA-Transfektionsgemisch $800 \mu \mathrm{L}$ Opti-MEM hinzugegeben und die Lösung auf die Mammakarzinomzellen gegeben. Folglich einer sechsstündigen Inkubation bei $37^{\circ} \mathrm{C}$ und $5 \% \mathrm{CO}_{2}$ wurde den Zellen $1 \mathrm{ml}$ MEM-Kulturmedium mit einer zweifachen Konzentration an P/S (2\%) und FBS (20\%) sowie 0,1\% Transferrin und 2,6 IU Insulin (bei $50 \mathrm{ml}$ Medium; für Produktinformationen siehe 2.1.4) hinzugegeben und die Mammakarzinomzellen für weitere 18 Stunden bei $37^{\circ} \mathrm{C}$ und $5 \% \mathrm{CO}_{2}$ inkubiert. Anschließend wurde das Transfektionsgemisch durch MEM-Kulturmedium (siehe 2.1.4) ersetzt und die Zellen bis zu ihrem weiteren Gebrauch kultiviert. 


\subsubsection{Zelllyse, RNA-Isolation und Quantifizierung der Nukleinsäuren}

Nach der wie unter 2.2.2.1 beschriebenen transienten Transfektion der Mammakarzinomzellen wurden diese 120 Stunden ( $\mathrm{t}_{120 h)}$ nach der Transfektion lysiert. Dafür wurde das FastGene ${ }^{\circledR}$ RNA Basic Kit von Nippon Genetics Europe GmbH (Düren, $D E)$ nach Herstellerangaben verwendet. Für die Zelllyse einer Probe wurden jeweils $600 \mu \mathrm{l}$ RL-Puffer aus dem FastGene ${ }^{\circledR}$ RNA Basic Kit von Nippon Genetics Europe GmbH (Düren, DE) mit $6 \mu$ 2-Mercaptoethanol (Sigma-Aldrich, St. Louis, Missouri, USA) versehen. Nach dem Waschen mit DPBS (Pan Biotech GmbH, Aidenbach, $\mathrm{DE})$ wurde jeder Probe $600 \mu \mathrm{l}$ dieses Lysepuffers zugegeben und für mindestens zehn Minuten unter Schütteln inkubiert. Im weiteren Verlauf wurde das Lysat in ein $1,5 \mathrm{ml}$-Reaktionsgefäß überführt und bis zur weiteren Verwendung bei $-20^{\circ} \mathrm{C}$ aufbewahrt.

Im weiteren Verlauf wurden die RNA aus den zuvor lysierten Proben isoliert. Für die RNA-Isolation wurde das FastGene ${ }^{\circledR}$ RNA Basic Kit von Nippon Genetics Europe $\mathrm{GmbH}$ (Düren, DE) und das zugehörige Protokoll, basierend auf einer RNA bindenden Silikagelmembran und nachfolgenden Waschschritten zur Entfernung von Verunreinigungen, unter Verwendung der Herstellerangaben, genutzt.

Die zuvor lysierte Probe wurde 1:2 mit 70\%-Ethanol (hergestellt aus Ethanol (99\%), Th. Geyer Ingredients GmbH \& Co. KG, Höxter, DE) verdünnt. Maximal $700 \mu \mathrm{L}$ der Probe wurden auf eine Säule mit Silikagelmembran gegeben und bei $>8000 \mathrm{rcf}$ für eine Minute zentrifugiert. Dieser Schritt wurde bei einen Probevolumen $>700 \mu \mathrm{L}$ wiederholt. Der Durchfluss wurde verworfen und $350 \mu \mathrm{l}$ RW1 Puffer wurde auf die Säule gegeben und bei $>8000$ rcf für 30 Sekunden zentrifugiert. Anschließend wurden $80 \mu \mathrm{L}$ Dase(Desoxyribonuklease)-Lösung mit dem RNase(ribonuclease)-Free DNase Set (Qiagen GmbH, Venlo, NL) zur Entfernung genomischer DNA (Desoxyribonucleic acid, Desoxyribonukeinsäure) hergestellt, bestehend aus $10 \mu \mathrm{l}$ DNase I und $70 \mu \mathrm{l}$ RDD Puffer, direkt auf die Säule pipettiert und 15 Minuten bei Raumtemperatur inkubiert. Es folgte ein weiterer Waschschritt mit $350 \mu \mathrm{l}$ RW1 Puffer und eine Zentrifugation bei > 8000 rcf für 15 Sekunden, der Durchlauf wurde verworfen. Danach wurde $700 \mu \mathrm{l}$ RW2 Puffer auf die Säule gegeben und diese bei $>8000$ rcf für 30 Sekunden zentrifugiert, der Durchlauf wurde verworfen. Nach der Trockenzentrifugation bei > 8000 rcf für eine Minute wurden $30 \mu \mathrm{l}$ RNase freies Wasser auf die 
Säule gegeben, um die RNA zu eluieren. Nach einer zweiminütigen Inkubation bei Raumtemperatur folgte eine Zentrifugation bei > 8000 rcf für eine Minute.

Für die Konzentrationsbestimmung der isolierten RNA wurden $7 \mu$ l jeder Probe mit $63 \mu$ l RNase-freiem Wasser versetzt (1:10-Verdünnung). Die Quantifizierung der Nukleinsäuren wurde anschließend mithilfe der Photometrie durchgeführt. Die Messung der Absorption erfolgte dabei bei $260 \mathrm{~nm}$, um die Konzentration der RNA in $\mu \mathrm{g} / \mathrm{ml}$ zu ermitteln. Um mögliche Kontaminationen mit organischen Substanzen zu erkennen, wurde die Absorption auch bei $230 \mathrm{~nm}$ sowie für den Fall von Verunreinigungen mit Proteinen und Phenolen auch bei 260 nm gemessen und die Quotienten 260/230 und 260/280 erfasst (Armbrecht und Eppendorf AG 2013; Matlock und Thermo Fisher Scientific Inc. 2015).

\subsubsection{Reverse Transkription}

Um die Genexpressionsanalyse mittels quantitativer Polymerasekettenreaktion (qPCR) durchführen zu können, wurden die wie unter 2.2.2.2 isolierte RNA mit Hilfe des QuantiNova ${ }^{\text {TM }}$ Reverse Transcription Kit (Qiagen $\mathrm{GmbH}$, Venlo, NL) unter Verwendung der Herstellerangaben transkribiert. Die Entdeckung der dem Prozess zugrunde liegenden Reversen Transkriptase als RNA-abhängige DNA-Polymerase geht auf David Baltimore und Howard M. Temin und Satoshi Mizutani zurück (Baltimore 1970; Temin und Mizutani 1970).

Es wurde $2 \mu \mathrm{g}$ RNA ad $13 \mu \mathrm{L}$ in RNase-freiem Wasser verdünnt. Nach Zugabe von $2 \mu \mathrm{l}$ DNA Removal Mix wurden die Proben bei $45^{\circ} \mathrm{C}$ im ThermoCycler für zwei Minuten inkubiert, um genomische DNA-Verunreinigungen zu entfernen. Folglich wurden jeder Probe $5 \mu$ l Mastermix hinzugegeben, bestehend aus $1 \mu$ l Reverse Transkriptase(RT)-Enzym und $4 \mu \mathrm{l}$ RT-Mix. Für die cDNA(complementary deoxyribonucleic acid, komplementäre Desoxyribonukleinsäure)-Synthese erfolgten folgende Inkubationsschritte: $25^{\circ} \mathrm{C}$ für drei Minuten für die Anlagerung der Primer, gefolgt von einer zehnminütigen Inkubation bei $45^{\circ} \mathrm{C}$ zur Reversen Transkription und letztendlich der Inaktivierung der Reversen Transkription bei $85^{\circ} \mathrm{C}$ über einen Zeitraum von fünf Minuten. Es wurde außerdem das QuantiNova ${ }^{\mathrm{TM}}$ Internal Control RNA and Assay (Qiagen $\mathrm{GmbH}$, Venlo, NL) verwendet. Die interne Kontrolle, QuantiNova Internal Control (QNIC), ist eine synthetische RNA, mit der sich eine mögliche Inhibition der reversen Transkription erkennen lässt. Dafür wurde eine Probe, bestehend aus $1 \mu \mathrm{l}$ QN IC RNA und $12 \mu \mathrm{l}$ RNase-freiem Wasser und eine zweite Probe aus $1 \mu \mathrm{l}$ 
QN IC RNA, RNase-freiem Wasser ad $13 \mu$ und $2 \mu \mathrm{g}$ einer hoch konzentrierten RNA-Probe, nach der Entfernung von DNA Verunreinigungen ebenfalls in cDNA transkribiert.

\subsubsection{Real-time-qPCR}

Bei der qPCR handelt es sich um eine Methode zur Vervielfältigung spezifischer cDNA-Abschnitte mit geringer Ausgangsmenge und zur (relativen) Quantifizierung dieser. Sie basiert auf den Grundprinzipien der klassischen Polymerasekettenreaktion, die 1986 von Mullis und Kollegen publiziert wurde (Mullis et al. 1986). Im Rahmen dieser Arbeit wurde die qPCR zur Genexpressionsanalyse von ARHGAP29 nach erfolgter transienter siRNA-Transfektion genutzt. Es wurden das Quantinova ${ }^{\circledR}$ SYBR $®$ Green PCR Kit und das QuantiNova ${ }^{\mathrm{TM}}$ Internal Control RNA and Assay Kit (Qiagen $\mathrm{GmbH}$, Venlo, NL) unter Verwendung der Herstellerangaben genutzt. Die hier durchgeführte quantitative real-time-PCR unterscheidet sich von der klassischen PCR im Wesentlichen darin, dass die Produktmenge in Echtzeit, also nach jedem Zyklus, mithilfe eines zur DNA-Konzentration proportionalen Fluoreszenzsignals erfasst wird (Sigma-Aldrich und Merck KGaA). Der hierbei verwendete Fluoreszenzfarbstoff SYBR® Green wird detektiert und die Intensität quantifiziert. Mithilfe der Korrelation zwischen Fluoreszenzsignal und DNA-Produktmenge und dem sogenannten Ct-Wert kann auf die DNA-Konzentration der Probe rückgeschlossen werden (Sigma-Aldrich und Merck KGaA). Der Ct -Wert stellt hierbei die Anzahl an PCR-Zyklen dar, nach der das Fluoreszenzsignal der Probe erstmalig signifikant über dem Schwellenwert liegt (Sigma-Aldrich und Merck KGaA). Letzterer wurde von der verwendeten Software (qPCR soft 1.1) automatisch ermittelt.

Die, wie unter 2.2.2.3 beschrieben, im Rahmen der Reversen Transkription generierten cDNA-Proben wurden mit jeweils 138,4 $\mu$ l RNase-freiem Wasser und 1,6 $\mu \mathrm{l}$ QuantiNova Yellow Diluting Buffer (Quantinova ${ }^{\circledR}$ SYBR® Green PCR Kit; Qiagen $\mathrm{GmbH}$, Venlo, NL) für die folgende qPCR verdünnt (1:8 Verdünnung). Jeder Probe $(4 \mu \mathrm{l})$ wurden $16 \mu \mathrm{l}$ Mastermix, bestehend aus $10 \mu \mathrm{l}$ QuantiNova ${ }^{\text {TM }}$ SYBR尺 Green PCR Master Mix (Quantinova® SYBR® Green PCR Kit, Qiagen GmbH, Venlo, NL), jeweils 0,7 $\mu \mathrm{l}$ ARHGAP29- und GAPDH(Glyceraldehyd-3-Phosphat-Dehydrogenase)-sequenzspezifischer Forward und Reverse Primer $(20 \mu \mathrm{M}$, siehe Tabelle 9, bezogen von Eurofins Scientific, Luxemburg, Belgien) und 4,6 $\mu$ l Wasser, hinzugegeben. Den beiden Proben zur internen Kontrolle (je $4 \mu \mathrm{l}$; siehe 2.2.2.3) wurde 
ebenfalls $16 \mu \mathrm{l}$ des zugehörigen QN IC Mastermixes aus $10 \mu \mathrm{l}$ QuantiNova ${ }^{\mathrm{TM}}$ SYBR ${ }^{\circledR}$ Green PCR Master Mix, $2 \mu \mathrm{l}$ QN IC Primer (QuantiNova ${ }^{\mathrm{TM}}$ Internal Control RNA and Assay, Qiagen $\mathrm{GmbH}$, Venlo, NL) und $4 \mu \mathrm{l}$ Wasser hinzugefügt. Die 96Well-Platte wurde verschlossen und drei Minuten bei 1500 rcf zentrifugiert. Der Ablauf der qPCR ist in Tabelle 10 dargestellt.

Tabelle 9: Verwendete Oligonukleotide

\begin{tabular}{|l|l|l|}
\hline & ARHGAP29 & GAPDH \\
\hline $\begin{array}{l}\text { Forward } \\
\text { '3‘ }\end{array}$ & TTGCAGCTCTCCAGGCTAAC & GAAGGTCGGAGTCAACGGAT \\
\hline $\begin{array}{l}\text { Reverse } \\
3^{\prime}-5^{‘}\end{array}$ & AGATGCTCCTCTTCTGCACG & TGGAATTTGCCATGGGTGGA \\
\hline $\begin{array}{l}\text { Denaturie- } \\
\text { rung }\end{array}$ & $5 \mathrm{~s}, 95^{\circ} \mathrm{C}$ \\
\hline $\begin{array}{l}\text { Anlage- } \\
\text { rung \& } \\
\text { Verlänge- } \\
\text { rung }\end{array}$ & $15 \mathrm{~s}, 60^{\circ} \mathrm{C}$ \\
\hline Tm & \multicolumn{2}{|c|}{} \\
\hline $\begin{array}{l}\text { Exon- } \\
\text { spannend }\end{array}$ & \multicolumn{2}{|c|}{60} \\
\hline $\begin{array}{l}\text { Amplifikat- } \\
\text { länge }\end{array}$ & Ja Basenpaare \\
\hline
\end{tabular}

Die in der Tabelle dargestellten, verwendeten Oligonukleotide wurden bezogen von Eurofins Scientific, Luxemburg, Belgien. 
Tabelle 10: Abfolge der durchgeführten qPCR-Zyklen

\begin{tabular}{|l|l|l|l|}
\hline Zyklen & Temperatur $\left[^{\circ} \mathbf{C}\right]$ & Zeit $[\mathbf{s}]$ & Bemerkung \\
\hline $\mathbf{1}$ & 95 & 120 & $\begin{array}{l}\text { Polymerase-Ak- } \\
\text { tivierung }\end{array}$ \\
\hline $\mathbf{3 5 - 4 0}$ & 95 & 5 & Denaturierung \\
\cline { 2 - 4 } & 60 & 10 & $\begin{array}{l}\text { Anlagerung \& } \\
\text { Verlängerung }\end{array}$ \\
\hline Schmelzkurve & $60-95$ & 6 & \\
\hline
\end{tabular}

Neben der Expression von ARHGAP29 wurde außerdem die Expression eines Referenzgens (GAPDH), QN IC-Proben als interne Kontrolle zur Erkennung einer möglichen inhibierten reversen Transkriptase (siehe 2.2.2.3) sowie Negativkontrollen ohne DNA analysiert. Es erfolgte für jede Probe eine Dreifachbestimmung. Zur Untersuchung der Spezifität der PCR-Amplifikate wurde darüber hinaus eine Schmelzkurve angefangen bei $60-95^{\circ} \mathrm{C}$ erstellt.

Die abschließende Auswertung erfolgte nach der $\Delta \Delta$ Ct-Methode:

1) Mittelwertbestimmung der Ct-Werte jeder Dreifachbestimmung

2) Für jeden Mittelwert gilt: $\Delta \mathrm{Ct}=\mathrm{Ctzielgen}-\mathrm{Ct}_{\text {Referenzgen }}=\mathrm{Ct}_{\text {ARHGAP29 }}-\mathrm{Ct}_{\text {GAPDH }}$

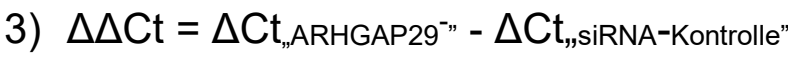

4) Ermittlung des relativen Expressionsunterschieds zwischen „ARHGAP29-“ und „siRNA-Kontrolle“: Ratio $=2^{-\Delta \Delta C t}$

\subsubsection{Protein-biochemische Methoden}

\subsubsection{Proteinisolation}

Zur Proteinanalyse nach Bradford wurden zunächst Mammakarzinomzellen, wie unter 2.2.2.1 beschrieben, transient mit siRNA transfiziert. Nach 120 Stunden erfolgte die Proteinisolierung. Dafür wurden die adhärenten transient transfizierten Mammakarzinomzellen zunächst in $2 \mathrm{ml}$ DPBS-EDTA- Lösung (2\% EDTA (Affymetrix, Santa Clara, Kalifornien, USA) in DPBS (Pan Biotech GmbH, Aidenbach, 
DE) für fünf Minuten bei Raumtemperatur inkubiert. Nach der Ablösung der Zellen mithilfe eines Zellschabers wurde die Zellsuspension abgenommen und die Zellkulturflasche mit $3 \mathrm{ml}$ DPBS gespült. Es folgte die Zentrifugation der Zellsuspension über fünf Minuten bei 1300 rcf. Im Anschluss daran wurde das Zellpellet in $30 \mu \mathrm{l}$ Lysepuffer, bestehend aus Celllyse M, 0,01\% Protease-Inhibitor und 0,01\% Phosphatase-Inhibitor (jeweils Sigma-Aldrich, St. Louis, Missouri, USA), resuspendiert und lysiert. Die Lagerung der Proteinproben erfolgte bei $-20^{\circ} \mathrm{C}$.

\subsubsection{Bestimmung der Proteinkonzentration nach Bradford}

Die Bestimmung der Proteinkonzentration der Proben wurde nach der BradfordMethode (Bradford 1976) durchgeführt, die auf der Bindung des Farbstoffs Coomassie Brilliant Blue G-250 an Proteine und der damit einhergehenden Änderung seiner Farbe und seines Absorptionsmaximum von $470 \mathrm{~nm}$ auf $595 \mathrm{~nm}$ beruht (Reisner et al. 1975; Compton und Jones 1985). Über die zur Proteinkonzentration proportionale Zunahme der Absorption bei $595 \mathrm{~nm}$ und die Eichung mithilfe einer Proteinstandardreihe lässt sich die absolute Konzentration der Proteinproben photometrisch bestimmen. Als Proteinstandards wurden Verdünnungen mit bekannten Konzentrationen von BSA (Bovines Serumalbumin/Albumin Fraktion V, Carl Roth $\mathrm{GmbH}$, Karlsruhe, DE; siehe Tabelle 11) und eine Kontrolle aus zweifach destilliertem Wasser verwendet. Nach dem Auftauen der Proteinproben auf Eis wurden diese bei 13000 rpm über fünf Minuten zentrifugiert und $5 \mu$ les entstandenen Überstands in $45 \mu \mathrm{l}$ zweifach destilliertem Wasser gelöst (1:10- Verdünnung). Jeweils $10 \mu \mathrm{l}$ der entstandenen verdünnten Proteinproben sowie der Kontrolle $\left(\mathrm{ddH}_{2} \mathrm{O}\right)$ und der Proteinstandards wurden einer Doppelbestimmung entsprechend in einer 96-Well-Platte aufgetragen. Im Anschluss wurden den Proben jeweils $200 \mu \mathrm{l}$ BioRad-Lösung, einer 1:5-Verdünnung von BioRad protein assay dye reagent concentrate (Bio-Rad Laboratories, Hercules, CA, USA) in Ampuwa (Fresenius Kabi AG, Bad Homburg, DE), zugegeben. Nach fünfminütiger Inkubation bei Raumtemperatur erfolgte die photometrische Messung der Absorption bei $595 \mathrm{~nm}$ mithilfe des Multi-Detektions-Readers BioTek Synergy HT und dem Programm Gen 5.1. Zur Ermittlung der Proteinkonzentration wurde die Differenz des Messwertes der jeweiligen Proteinprobe vom Messwert der Kontrolle $\left(\mathrm{ddH}_{2} \mathrm{O}\right)$ mit der linearen Regression der Messwerte der Proteinstandards verglichen. 
Tabelle 11: BSA-Verdünnungsreihe für die lineare Regression

\begin{tabular}{|l|l|l|}
\hline $\begin{array}{l}\text { Konzentration }[\mathrm{mg} / \mathrm{ml}] \\
\text { (Verdünnung) }\end{array}$ & $\begin{array}{l}\text { BSA-Stammlösung }[\mu \mathrm{l}] \\
\text { (Carl Roth } \mathrm{GmbH,} \\
\text { Karlsruhe, DE) }\end{array}$ & $\begin{array}{l}\text { DPBS }[\mu \mathrm{l}] \text { (Biotech } \\
\text { GmbH, Aidenbach, } \\
\text { DE) }\end{array}$ \\
\hline $1(1: 10)$ & 100 & 900 \\
\hline $0,75(1: 13,33)$ & 75 & 925 \\
\hline $0,5(1: 20)$ & 50 & 950 \\
\hline $0,25(1: 40)$ & 25 & 975 \\
\hline $0,1(1: 100)$ & 10 & 990 \\
\hline
\end{tabular}

\subsubsection{SDS-Polyacrylamid-Gelelektrophorese}

Die Sodiumdodecylsulfat(SDS)-Polyacrylamid-Gelelektrophorese ist ein Verfahren nach U. Laemmli, mit dem Proteine in einem elektrischen Feld nach ihrer Molekülmasse aufgetrennt werden können (Laemmli 1970). Die durch die Bindung an SDS negativ geladenen Proteine wandern hierbei je nach Molekülmasse unterschiedlich schnell durch Polyacrylamidgele zur Anode des elektrischen Feldes.

Dafür wurden die wie in 2.2.3.1 generierten Proteinproben nach der in 2.2.3.2 erwähnten Konzentrationsbestimmung 1:2 mit Laemmli-Puffer (45,45\% Ampuwa (Fresenius Kabi AG, Bad Homburg, DE), 45,45\% NuPage ${ }^{\circledR}$ LDS Sample Buffer, 9,09\% NuPage $®$ Sample Reducing Agent; jeweils Thermo Fisher Scientific, Waltham, Massachusetts, USA) verdünnt. Bis zur weiteren Verwendung wurden die Proben bei $-20^{\circ} \mathrm{C}$ gelagert.

Die BioRad-Aparatur wurde nach den Herstellerangaben zusammengebaut. Das Trenngel (für die Zusammensetzung siehe Tabelle 12) wurde in die Apparatur gegossen, mit 2-Isopranol (Chemsolute®, Th. Geyer GmbH \& Co. KG, Renningen, $\mathrm{DE})$ beschichtet, um einen geraden, glatten Meniskus zu erzeugen, und für $30 \mathrm{Mi}-$ nuten bei Raumtemperatur polymerisiert. Nach der Polymerisation des Gels und Entfernung des Isopropanols wurde auch das Sammelgel (siehe Tabelle 12) gegossen. Die Proteinproben wurden über fünf Minuten bei $95^{\circ} \mathrm{C}$ denaturiert. Nach der Polymerisation des Sammelgels wurden sowohl einmalig $5 \mu$ l eines Größenmarkers (Protein Marker VI (10-245), prestained, PanReac AppliChem GmbH, Darmstadt, 
DE) als auch jeweils $40 \mu \mathrm{g}$ jeder denaturierten Proben in die Geltaschen aufgetragen und die Apparatur mit Laufpuffer (100 ml Elektrophorese-Puffer (5x, siehe Tabelle 13), $5 \mathrm{ml}$ Lösung C (10\% SDS, Sigma-Aldrich, St. Louis, Missouri, USA) ad $500 \mathrm{ml}$ zweifach-destilliertes Wasser) vollständig aufgefüllt. Anschließend erfolgten Elektrophoresen bei $80 \mathrm{~V}$ über 30 Minuten sowie bei $100 \mathrm{~V}$ über 60 Minuten.

Tabelle 12: Zusammensetzung der Gele für die SDS-Polyacrylamid-Gelelektrophorese

\begin{tabular}{|c|c|c|}
\hline & $\begin{array}{l}\text { Trenngel } \\
10,5 \% \text { (Menge } \\
\text { für } 2 \text { Gele) }\end{array}$ & $\begin{array}{l}\text { Sammelgel } \\
4,8 \% \text { (Menge } \\
\text { für } 2 \text { Gele) }\end{array}$ \\
\hline $\begin{array}{l}\text { Lösung A: Prosieve } 50 \text { Gel Solution } \\
\text { Acrylamid ( } 50 \% \text {; Lonza, Basel, Schweiz) }\end{array}$ & $2,3 \mathrm{ml}$ & $0,75 \mathrm{ml}$ \\
\hline $\begin{array}{l}\text { Lösung B: TRIS (Trishydroxymethyla- } \\
\text { minomethan; pH 8,8; Sigma-Aldrich, St. } \\
\text { Louis, Missouri, USA) }\end{array}$ & $2,8 \mathrm{ml}$ & - \\
\hline $\begin{array}{l}\text { Lösung C: SDS (SDS 10\%; Sigma-Ald- } \\
\text { rich, St. Louis, Missouri, USA) }\end{array}$ & $110 \mu \mathrm{l}$ & $75 \mu l$ \\
\hline $\begin{array}{l}\text { Lösung D: TRIS (Trishydroxymethyla- } \\
\text { minomethan; pH 6,8; Sigma-Aldrich, St. } \\
\text { Louis, Missouri, USA) }\end{array}$ & - & $1,9 \mathrm{ml}$ \\
\hline $\mathrm{ddH}_{2} \mathrm{O}$ & $5,7 \mathrm{ml}$ & $5 \mathrm{ml}$ \\
\hline $\begin{array}{l}\text { TEMED (Tetramethylethylenediamine; } \\
\text { Carl Roth GmbH, Karlsruhe, DE) }\end{array}$ & $22 \mu \mathrm{l}$ & $22 \mu \mathrm{l}$ \\
\hline $\begin{array}{l}\text { APS (Ammoniumpersulfat; 10\%; Merck } \\
\text { KGaA, Darmstadt, DE) }\end{array}$ & $37 \mu \mathrm{l}$ & $37 \mu \mathrm{l}$ \\
\hline
\end{tabular}


Tabelle 13: Zusammensetzung des Elektrophorese-Puffers

\begin{tabular}{|l|l|l|l|}
\hline & $\begin{array}{l}\text { TRIS-Base (Sigma-Al- } \\
\text { drich, St. Louis, Mis- } \\
\text { souri, USA) }\end{array}$ & $\begin{array}{l}\text { Glycin (Alfa Aesar, } \\
\text { Haysham, UK) }\end{array}$ & $\mathbf{d d H}_{2} \mathbf{O}$ \\
\hline $\begin{array}{l}\text { Masse [g] } \\
\text { bzw. Volu- } \\
\text { men [ml] }\end{array}$ & $15,1 \mathrm{~g}$ & $72 \mathrm{~g}$ & Ad $1000 \mathrm{ml}$ \\
\hline
\end{tabular}

\subsubsection{Western Blot}

Der Western Blot, eine von George R. Stark und W. Neal Burnette etablierte und von Twobin et al. modifizierte Methode (Renart et al. 1979; Towbin et al. 1979; Burnette 1981), stellt ein Verfahren zum Nachweis und zur Analyse von Proteinen in Proteingemischen dar. Die mittels SDS-Polyacrylamid-Gelelektrophorese aufgetrennten Proteinproben (siehe 2.2.3.3) werden hierbei durch ein senkrecht zum Polyacrylamidgel angelegtes elektrisches Feld auf eine Polyvinylidenfluorid(PVDF)Membran (Immobilon Pore, 0,43 $\mu \mathrm{m}$, Millipore, USA) transferiert. In der vorliegenden Arbeit wurde mit der beschriebenen Methode sowohl die Expression von ARHGAP29 als auch die Expression von AKT1 und des Referenzgens GAPDH untersucht.

Zunächst wurde die PVDF-Membran zur Aktivierung über mindestens 30 Sekunden in hundertprozentigem Methanol (Th. Geyer GmbH \& Co. KG, Renningen, DE) geschwenkt und dann in Transferpuffer (pH 8,3; siehe Tabelle 14) überführt. Die BioRad-Apparatur wurde den Herstellerangaben entsprechend aufgebaut und das Trenn-Gel und die aktivierte Membran nach dem folgenden Schema mit zuvor in Transferpuffer getränkten Filterpapieren und Schaumstoffschwämmen angeordnet und in die Apparatur eingesetzt: Schwamm - drei Lagen Filterpapier - PVDFMembran - Gel - drei lagen Filterpapier - Schwamm. Es folgte eine Elektrophorese über 60 Minuten bei $100 \mathrm{~V}$, in der die Proteinproben von dem der Kathode zugewandtem Gel auf die der Anode zugewandten Membran übertragen wurden. 
Tabelle 14: Zusammensetzung des Transferpuffers $(\mathrm{pH} 8,3)$

\begin{tabular}{|l|l|l|l|l|}
\hline & $\begin{array}{l}\text { TRIS-Base } \\
\text { (Sigma-Al- } \\
\text { drich, St. } \\
\text { Louis, Mis- } \\
\text { souri, USA) }\end{array}$ & $\begin{array}{l}\text { Glycin (Alfa } \\
\text { Aesar, Hay- } \\
\text { sham, UK) }\end{array}$ & $\begin{array}{l}\text { Methanol }(20 \% ; \\
\text { Th. Geyer GmbH } \\
\text { \& Co. KG, Ren- } \\
\text { ningen, DE) }\end{array}$ & $\mathbf{d d H}_{2} \mathbf{O}$ \\
\hline $\begin{array}{l}\text { Masse [g] } \\
\text { bzw. Volu- } \\
\text { men [ml] }\end{array}$ & $3,03 \mathrm{~g}$ & $14,41 \mathrm{~g}$ & $100 \mathrm{ml}$ & $\begin{array}{l}\text { Ad } \\
1000 \mathrm{ml}\end{array}$ \\
\hline
\end{tabular}

\subsubsection{Detektion und Auswertung}

Nach dem Transfer wurde die Membran zunächst über fünf Minuten in TRIS-buffered saline with Tween20/Trishydroxymethylaminomethan-gepufferter Salzlösung mit Tween-20 (TBST) gewaschen, bestehend aus TRIS-buffered saline/TRIS-gepufferter Salzlösung (TBS, siehe Tabelle 15) und 0,1\% Tween-20 (PanReac AppliChem $\mathrm{GmbH}$, Darmstadt, DE), und in Folge für 60 Minuten in Milchpulverlösung (siehe Tabelle 16) inkubiert, um unspezifische Bindungen zu blockieren. Es wurden drei Waschvorgänge in TBST über jeweils fünf Minuten durchgeführt, anschließend wurde die Membran mit der Primär-Antikörper-Lösung, spezifisch für das zu detektierende Protein (siehe Tabelle 17), bei $4^{\circ} \mathrm{C}$ über Nacht inkubiert. Am nächsten Tag wurden unspezifisch gebundene oder nicht gebundene Antikörper durch dreimaliges Waschen über zehn Minuten in TBST entfernt. Es folgte die Inkubation mit der Zweitantikörper-Lösung (siehe Tabelle 18) für eine Stunde und zwei weitere Waschvorgänge mit TBST sowie einmal in TBS. Für die Detektion der gebundenen Antikörper wurde die Chemilumineszenz-Lösung (Westar Supernova, Cyanagen, Bologna, Italien bzw. Immobilon Western von Merck Millipore Ltd., Burlington, Massachusetts, USA, für den GAPDH-Primärantikörper) und der C-Digit $\circledast$ Blot-Scanner (Li-Cor, Lincoln, USA) genutzt. Hierbei wurde die Luminesenz des an den Sekundärantikörper konjugierten Enzyms HRP (horseradish peroxidase, Meerrettichperoxidase) nach 2,5-minütiger Inkubation erfasst. Die Signalintensität wurde mit dem Programm Image Studio 4.0 quantifiziert und auf der GAPDH-Signalintensität normiert. Zur Expressionsanalyse weiterer Proteine, wie AKT1 oder GAPDH als Referenzgen, wurde im Rahmen des sogenannten Strippings die Membran mehrfach 
gewaschen, zuerst über zwei Minuten in TBST, nachfolgend für 15 Sekunden in 25 ml Stripping-Puffer (Interchim, Montluçon, Frankreich), einmal mit zweifach destilliertem Wasser und dreimalig über jeweils fünf Minuten in TBST. Nach der Blockierung unspezifischer Bindungen durch 60-minütige Inkubation in Milchpulverlösung konnte die Inkubation mit weiteren Antikörpern nach dem oben beschriebenen Vorgehen erfolgen.

Tabelle 15: Zusammensetzung von TBS

\begin{tabular}{|c|c|c|c|c|c|}
\hline & $\begin{array}{l}\text { TRIS- } \\
\text { Base } \\
\text { (Sigma-Al- } \\
\text { drich, St. } \\
\text { Louis, } \\
\text { Missouri, } \\
\text { USA) }\end{array}$ & $\begin{array}{l}\text { NaCl } \\
\text { (Merck } \\
\text { KGaA, } \\
\text { Darmstadt, } \\
\text { DE) }\end{array}$ & $\begin{array}{l}\text { KCl (Merck } \\
\text { KGaA, } \\
\text { Darmstadt, } \\
\text { DE) }\end{array}$ & $\mathrm{ddH}_{2} \mathrm{O}$ & $\begin{array}{l}\mathrm{HCl} \\
\text { (Merck } \\
\text { KGaA, } \\
\text { Darmstadt, } \\
\text { DE) }\end{array}$ \\
\hline $\begin{array}{l}\text { Masse } \\
\text { [g] bzw. } \\
\text { Volumen } \\
{[\mathrm{ml}]}\end{array}$ & $30 \mathrm{~g}$ & $80 \mathrm{~g}$ & $2 \mathrm{~g}$ & $\begin{array}{l}\text { Ad } \\
1000 \mathrm{ml}\end{array}$ & $A d \mathrm{pH} 7,4$ \\
\hline
\end{tabular}

Tabelle 16: Zusammensetzung der Milchpulverlösung

\begin{tabular}{|l|l|l|}
\hline TBS & $\begin{array}{l}\text { Tween-20 (PanReac Appli- } \\
\text { Chem GmbH, Darmstadt, DE) }\end{array}$ & $\begin{array}{l}\text { Milchpulver (Nonfat dried milk } \\
\text { powder, PanReac AppliChem } \\
\text { GmbH, Darmstadt, DE) }\end{array}$ \\
\hline $94,9 \%$ & $0,1 \%$ & $5 \%$ \\
\hline
\end{tabular}


Tabelle 17: Verwendete Primär-Antikörper

\begin{tabular}{|l|l|l|l|l|}
\hline $\begin{array}{l}\text { Primär-Antikör- } \\
\text { per }\end{array}$ & Herkunft & $\begin{array}{l}\text { Verdün- } \\
\text { nungsfaktor } \\
\text { (in TBST) }\end{array}$ & $\begin{array}{l}\text { Moleku- } \\
\text { lare Mas- } \\
\text { se [kDa] }\end{array}$ & Hersteller \\
\hline $\begin{array}{l}\text { AKT1 (\#9272) } \\
\text { (Kanin- } \\
\text { chen) }\end{array}$ & $1: 1000$ & 60 & $\begin{array}{l}\text { Cell Signalling } \\
\text { Technology, } \\
\text { Danvers, Mas- } \\
\text { sachusetts, } \\
\text { USA }\end{array}$ \\
\hline $\begin{array}{l}\text { ARHGAP29 } \\
\text { (NBP1-05989) }\end{array}$ & Rabbit & $1: 2000$ & 171 & $\begin{array}{l}\text { Novus Biologi- } \\
\text { cals, Centen- } \\
\text { nial, Colorado, } \\
\text { USA }\end{array}$ \\
\hline $\begin{array}{l}\text { GAPDH } \\
\left(\begin{array}{l}\text { D16H11) XP® } \\
\text { Rabbit mAB } \\
(\# 5174)\end{array}\right.\end{array}$ & Rabbit & $1: 2000$ & 38 & $\begin{array}{l}\text { Cell Signalling } \\
\text { Technology, } \\
\text { Danvers, Mas- } \\
\text { sachusetts, } \\
\text { USA }\end{array}$ \\
\hline
\end{tabular}

Tabelle 18: Verwendeter Sekundär-Antikörper

\begin{tabular}{|c|c|c|c|}
\hline $\begin{array}{l}\text { Sekundär-Anti- } \\
\text { körper }\end{array}$ & Herkunft & $\begin{array}{l}\text { Verdünnungsfak- } \\
\text { tor (in TBST) }\end{array}$ & Hersteller \\
\hline $\begin{array}{l}\text { Amersham }{ }^{\mathrm{TM}} \\
\text { ECL }{ }^{\mathrm{TM}} \text { Rabbit } \\
\text { IgG, HRP-linked } \\
\text { F(ab') }{ }_{2} \text { Fragment } \\
\text { (from donkey; } \\
\text { NA9340) }\end{array}$ & Rabbit & $1: 20000$ & $\begin{array}{l}\text { GE Healthcare, } \\
\text { Chalfont St. } \\
\text { Giles, GB }\end{array}$ \\
\hline
\end{tabular}




\subsubsection{Datenbasierte Analyse von Interaktionspartnern}

Die Analyse der Wahrscheinlichkeit von gewebe- und prozessspezifischen Interaktionen bezüglich ARHGAP29 und möglichen Interaktionspartnern erfolgte mithilfe des GIANT(Genome-wide Integrated Analysis of gene Networks in Tissues)-Webservers, bereitgestellt von HumanBase (https://hb.flatironinstitute.org/, zuletzt abgerufen am 26.07.2019), und war wie bereits von Greene et al. (2015) beschrieben durchgeführt worden. Dafür waren ursprünglich 987 genomweite Datensätze „probabilistisch gewichtet" (Huttenhower et al. 2009) und einer funktionalen Integration nach Bayes'scher Methode unterzogen worden (Greene et al. 2015; Wong et al. 2018). Die Datensätze für die Proteininteraktion waren laut Greene et al. (2015) bezogen worden von Bio GRID (Biological General Repository for Interaction Datasets: https://thebiogrid.org/; Chatr-aryamontri et al. 2013), IntAct Molecular Interaction Database (https://www.ebi.ac.uk/intact/; Kerrien et al. 2012), MINT (Molecular INTeraction Database: https://mint.bio.uniroma2.it/; Licata et al. 2012) und MIPS (http://www.mips.biochem.mpg.de/; Mewes et al. 1999) und die Daten die miRNA(micro-RNA)-Zielstrukturen betreffend von MSigDB (Molecular Signatures Database: http://broadinstitute.org/msigdb; Subramanian et al. 2005). Es wurde nach möglichen Interaktionspartnern für das Protein ARHGAP29 gesucht. Als minimales Konfidenzintervall wurde 0,1 gewählt und die maximale Anzahl von betrachteten Genen betrug sieben. Die Analyse lieferte den Vergleich von Interaktionswahrscheinlichkeiten zwischen ARHGAP29 und sechs verschiedenen Interaktionspartnern.

\subsubsection{Statistische Analyse und Dokumentation}

Alle Ergebnisse wurden im Rahmen von mindestens biologischen und technischen Triplikaten gewonnen. Die statistischen Analysen wurden mithilfe von Excel-Berechnungen und des Programms GraphPad Prism® (Version 6.01) durchgeführt. Verwendete Statistikanalyse war hierfür ein ungepaarter t-Test zwischen der jeweiligen Kontroll-siRNA-Gruppe und der ARHGAP29-siRNA-Gruppe, wobei ein p-Wert unter 0,05 als statistisch signifikant gewertet wurde. 


\section{Ergebnisse}

\subsection{Genexpression von ARHGAP29 in invasiven Mammakarzinomzellen}

\subsubsection{Analyse der Genexpression nach epithelialer-mesenchymaler Transition}

Die epitheliale-mesenchymale Transition ist ein Prozess, der die Umwandlung von einem epithelialen Zellphänotyp in einen mesenchymalen Phänotyp beschreibt und mit vielfältigen Veränderungen, wie unter anderem dem Verlust von Zellpolarität und epithelialen Zell-Zell-Kontakten sowie einem Zugewinn an Motilität, einhergeht (Yilmaz und Christofori 2009). Es konnte bereits gezeigt werden, dass mesenchymal transformierte Tumorzellen außerdem eine erhöhte Invasivität aufweisen (Ziegler et al. 2014). Der dahinter liegende Mechanismus, durch den die Induktion einer EMT eine gesteigerte Invasivität hervorbringt, ist jedoch noch nicht vollständig geklärt. Eine Microarray-Analyse von durch wiederholte Kokultur mit Osteosarkomzellen mesenchymal transformierten Mammakarzinomzellen - MCF-7-EMT - (Ziegler et al. 2014) zeigte, dass 325 Gene in mesenchymal transformierten Mammakarzinomzellen durch die induzierte EMT von einer veränderten Regulation und davon wiederum 223 Gene von einer Hochregulation betroffen waren (Ziegler 2013; Ziegler et al. 2014). Nach erneuter Analyse der 223 durch die induzierte EMT hochregulierten Genen (Ziegler 2013) durch Frau Dr. rer. nat. Johanna W. Hellinger fand sich nur ein sogenanntes Rho GTPase aktivierendes Protein - ARHGAP29 (siehe Abbildung 2; Kolb et al. 20201). GAPs stellen neben GEFs und GDIs Regulatoren der Aktivität von Rho GTPasen dar (Etienne-Manneville und Hall 2002). Die Frage stellt sich, ob ARHGAP29 Einfluss auf die Invasions- und Proliferationsfähigkeit von Mammakarzinomzellen nimmt und in welche Signalkaskade ARHGAP29 eingebunden ist. Nach dem Vergleich der ARHGAP29-Expression in verschiedenen Mammakarzinomzelllinien durch Frau Dr. rer. nat. Johanna W. Hellinger (siehe

\footnotetext{
${ }^{1}$ Hier (3.1.1) genannte sowie unter 3.1.2.1, 3.1.2.3, 3.1.2.4, 3.1.2.5, 3.2.2, 3.2.3, 3.2.4, 3.3.2, 3.3.3, 3.3.4, 3.4.1, 3.4.3, 3.4.4 und 3.4.5 aufgeführte mit Kolb et al. (2020) versehene, von Frau Dr. rer. nat. Johanna W. Hellinger (3.1.1 und 3.1.2.1) und mir erhobene Daten wurden publiziert in Kolb et al. (2020) mit dem Titel „Influence of ARHGAP29 on the invasion of mesenchymal-transformed breast cancer cells" (https://www.mdpi.com/2073-4409/9/12/2616) und werden mit der Lizenz CC BY 4.0 (https://creativecommons.org/licenses/by/4.0/) hier aufgeführt.
} 
3.1.2.1, Kolb et al. 2020) wurde die ARHGAP29-Expression in diesen mithilfe der Methode des transienten knockdowns mit ARHGAP29-spezifischer siRNA (siehe 2.2.2.1) vermindert, um die Auswirkungen einer verringerten Expression auf die Invasivität und Proliferation von invasiven Mammakarzinomzellen zu untersuchen. Die Effizienz des transienten knockdowns wurde mithilfe der qPCR (siehe 2.2.2.4) 120 Stunden nach erfolgter transienter Transfektion analysiert. In den folgenden Abschnitten sollen die Ergebnisse diesbezüglich dargelegt werden.

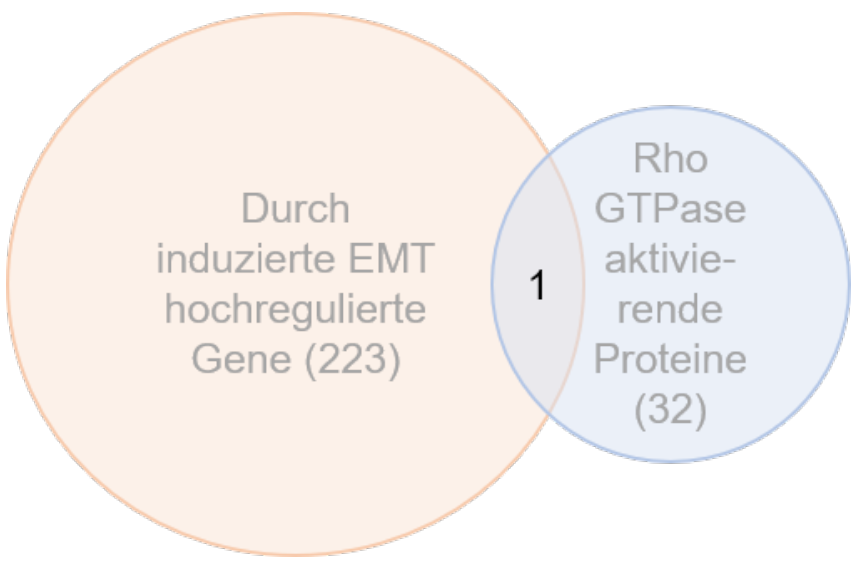

Abbildung 2: Schematische Darstellung der Schnittmenge von 223 durch induzierte EMT hochregulierten Genen und 32 in Microarrays betrachteten Rho GTPase aktivierenden Proteinen (Kolb et al. 2020). Bestehende Microarray-Daten (Ziegler 2013; Ziegler et al. 2014) zum Vergleich der Genexpression von MCF-7-Wildtyp-Zellen und generierten mesenchymal transformierten MCF-7-EMT-Zellen wurden hinsichtlich der Hochregulierung der Expression ausgewählter Gene erneut analysiert (Kolb et al. 2020). Unter den betrachteten Genen befanden sich 32 bis dato als Rho GTPase aktivierende Proteine anerkannte Gene (Kolb et al. 2020). Es zeigte sich bei 223 Genen eine Hochregulation durch die induzierte EMT in den MCF-7-EMT-Zellen im Vergleich zu den MCF-7-WildtypZellen (Ziegler 2013). Als Schnittmenge fand sich das Rho GTPase aktivierende Protein ARHGAP29 (Kolb et al. 2020). Die relative Expressionsänderung (FC, Fold change) der betrachteten Gene betrug 1,0 - 4,53 (Ziegler 2013). Im Rahmen der Microarrays verwendete MCF-7-EMT-Zellen wurden durch mehrfache Kokultivierung von MCF-7-Zellen mit Osteosarkomzellen der Linie MG-63 generiert, wie von Ziegler et al. (2014) beschrieben. Die Abbildung basiert auf Microarray-Daten aus Ziegler (2013) und Ziegler et al. (2014) und einer ursprünglich von Frau Dr. rer. nat. Johanna W. Hellinger erstellten und zur Verwendung und Darstellung bereitgestellten Abbildung. Die hier dargestellte Abbildung entspricht einer übersetzten Version der in Kolb et al. (2020) enthaltenen Abbildung $1 \mathrm{~A}$ "Schematic representation of the overlap of microarray data of 223 genes upregulated by induced epithelial-mesenchymal transition (EMT) and 32 considered Rho GTPase-activating proteins" (https://www.mdpi.com/2073-4409/9/12/2616/htm), Lizenz CC BY 4.0 (https://creativecommons.org/licenses/by/4.0/). Legende abschnittsweise übereinstimmend mit einer Übersetzung der 
zugehörigen Legende aus Kolb et al. (2020), (https://www.mdpi.com/2073-4409/9/12/2616/htm), unter der Lizenz CC BY 4.0 (https://creativecommons.org/licenses/by/4.0/).

\subsubsection{Analyse der ARHGAP29-Expression in diversen invasiven Mammakarzinomzellinien verglichen mit MCF-7- Mammakarzinomzellen und nach dem knockdown von ARHGAP29}

\subsubsection{Analyse der ARHGAP29-Expression in invasiven Mammkarzinomzellen}

Wie bereits mithilfe erneuter Analyse von Microarray-Daten (Ziegler 2013; Ziegler et al. 2014) durch Frau Dr. rer. nat. Johanna W. Hellinger untersucht wurde, exprimieren mesenchymal transformierte MCF-7-EMT-Zellen ARHGAP29 in erhöhtem Maße (MCF-7-EMT: 8,114 \pm 0,1053 SEM Average Expression vs. (versus) „Kontrolle": MCF-7: 6,728 \pm 0,3298 SEM Average Expression; $p=0,0161 ; n=3$; siehe Abbildung 3; Kolb et al. 2020). Weitere Genexpressionsanalysen durch Frau Dr. rer. nat. Johanna W. Hellinger bestätigten, dass ARHGAP29 nicht nur in diesen MCF-7-EMT-Zellen, die durch wiederholte Kokultivierung generiert wurden (Ziegler et al. 2014), signifikant erhöht exprimiert wird, verglichen mit MCF-7, sondern auch in solchen durch Mammosphärenkultivierung nach Guttilla et al. (2012) erzeugten MCF-7-EMT-Zellen und in einer zweiten nach Guttilla et al. (2012) und Ziegler et al. (2014) mesenchymal transformierten Zelllinie, genannt T-47D-EMT, sowie in den dreifach-negativen, aggressiven Mammakarzinomzellinien (Gazdar et al. 1998; Neve et al. 2006; Prat et al. 2010; Holliday und Speirs 2011) HCC1806 und MDA-MB-231 (MCF-7-EMT: 2,35 \pm 0,5765 SEM relative Genexpression (FC, Fold change) vs. "Kontrolle“; $p=0,0473 ; n=5$; T-47D-EMT: 2,235 $\pm 0,4687$ SEM relative Genexpression (FC) vs. „Kontrolle“; $p=0,025 ; n=6$; HCC1806: 1,658 $\pm 0,2178$ SEM relative Genexpression (FC) vs. „Kontrolle“; $p=0,0165 ; n=5$; MDA-MB-231: 7,533 \pm 1,145 SEM relative Genexpression ( $F C$ ) vs. „Kontrolle“; $p=0,0099 ; n=3$; siehe Abbildung 4; Kolb et al. 2020). Daher wurde die ARHGAP29-Expression in diesen vier Zelllinien mithilfe von ARHGAP29-spezifischen siRNA-knockdowns transient vermindert, um nachfolgend den Einfluss von ARHGAP29 auf Prozesse wie Invasion, Proliferation und Proteinexpression zu untersuchen. 


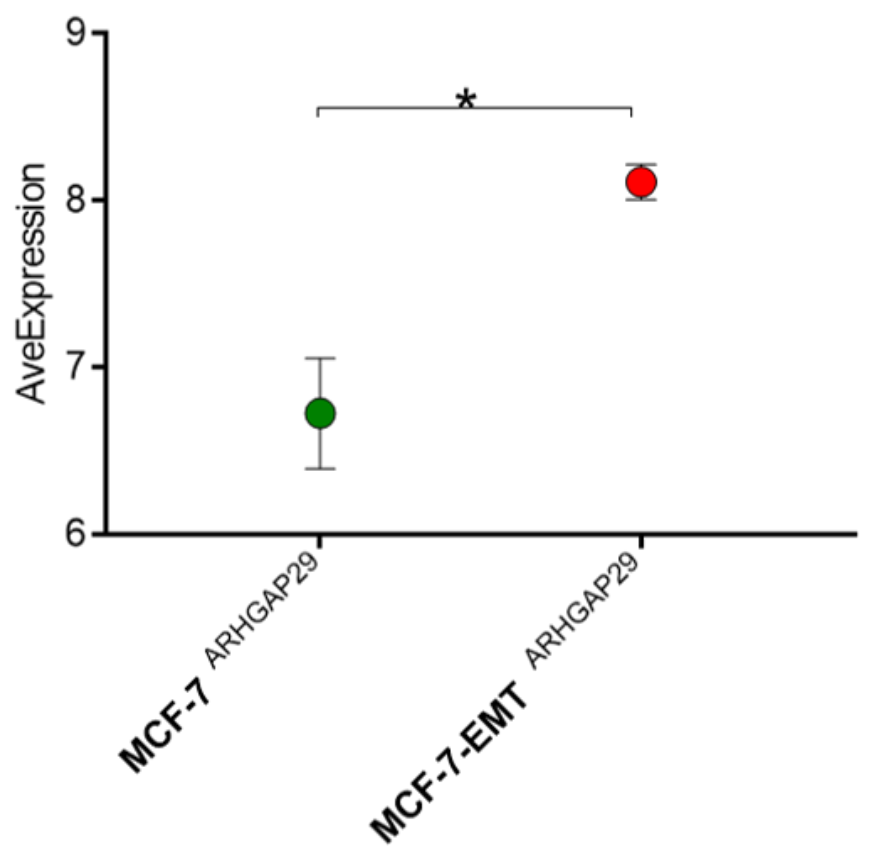

Abbildung 3: Nachweis der signifikant erhöhten basalen Expression von ARHGAP29 in MCF-7-EMTZellen (Kolb et al. 2020). Basale Expression (Average Expression) von ARHGAP29 in den Zelllinien MCF-7 und MCF-7-EMT (Kolb et al. 2020), basierend auf Microarray-Daten von Ziegler (2013) und Ziegler et al. (2014). Bestehende Microarray-Daten (Ziegler 2013; Ziegler et al. 2014) zum Vergleich der Genexpression von MCF-7-Wildtyp-Zellen und mesenchymal transformierten MCF-7-EMT-Zellen wurden hinsichtlich der ARHGAP29-Genexpression untersucht (Kolb et al. 2020). Es wurden mindestens biologische und technische Triplikate verwendet. Angegeben sind MW \pm SEM, Signifikanzen wurden mithilfe ungepaarter t-Tests ermittelt; $\quad\left(^{*}\right) p<0,05$. Originalabbildung von Frau Dr. rer. nat. Johanna W. Hellinger nach freundlicher Genehmigung übernommen, modifizierte Version (veränderte Skalierung der Ordinatenachse) der publizierten Abbildung 1C „Evidence of the significantly increased basal expression of ARHGAP29 in MCF-7-EMT cells was found." von Kolb et al. (2020); Legende abschnittsweise übereinstimmend mit einer Übersetzung der zugehörigen Legende aus Kolb et al. (2020), https://www.mdpi.com/20734409/9/12/2616/htm; in beiden Fällen Lizenz CC BY 4.0 (https://creativecommons.org/licenses/by/4.0/). 


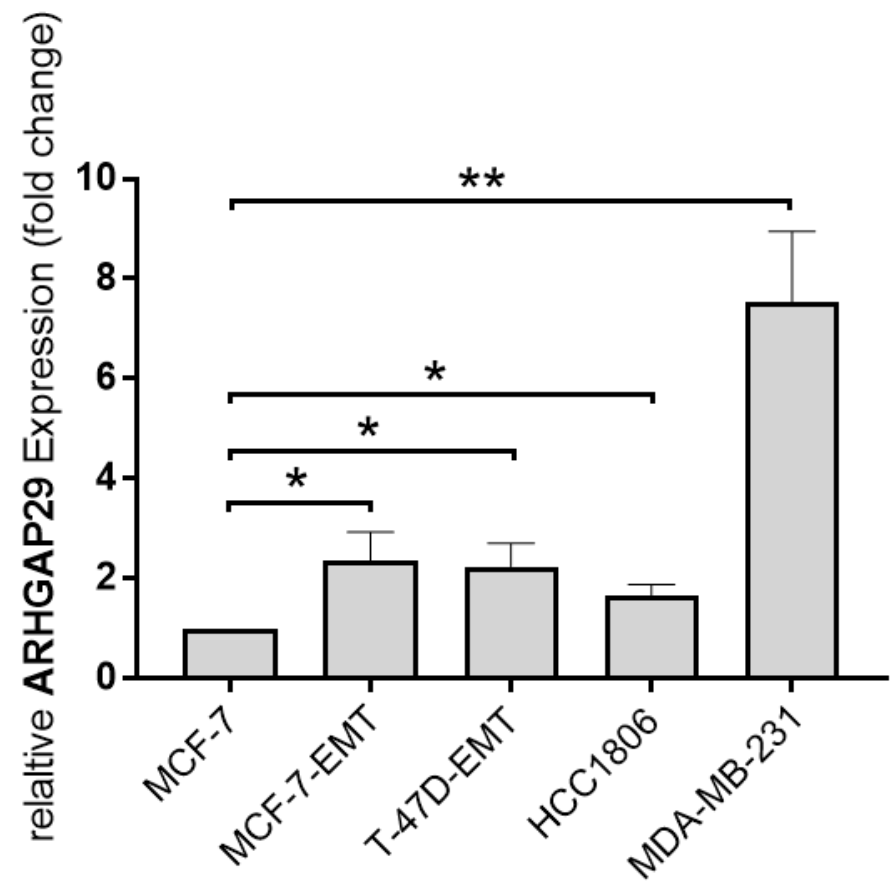

Abbildung 4: Nachweis der signifikant erhöhten ARHGAP29-Expression in den Zelllinien MCF-7-EMT, T-47D-EMT, HCC1806 und MDA-MB-231, verglichen mit der Zelllinie MCF-7 (Kolb et al. 2020). Relative Genexpression von ARHGAP29 in den Zelllinien MCF-7, MCF-7-EMT, T-47D-EMT, HCC1806 und MDA-MB-231 (Kolb et al. 2020). Durch quantitative real-time-PCR wurde die Expression von ARHGAP29 auf RNA-Ebene analysiert und auf die GAPDH-Expression normiert (Kolb et al. 2020). Es wurden mindestens biologische und technische Triplikate verwendet. Angegeben sind MW \pm SEM, Signifikanzen wurden mithilfe ungepaarter t-Tests ermittelt; $\left(^{*}\right) p<0,05,\left({ }^{* *}\right) p$ $<0,01$. Ein Teil der Daten ist außerdem in abgewandelter Form in der Abbildung 1D „Expression of ARHGAP29 in MCF-7, MCF-7-EMT, T-47D, T-47D-EMT, and HCC1806 breast cancer cells." von Kolb et al. (2020), (https://www.mdpi.com/2073-4409/9/12/2616/htm), publiziert (Lizenz CC BY 4.0; https://creativecommons.org/licenses/by/4.0/). Die hier dargestellte Abbildung wurde jedoch im Voraus von Frau Dr. rer. nat. Johanna W. Hellinger erstellt und in dieser ursprünglichen Form nach der freundlichen Bereitstellung und Genehmigung durch sie übernommen. Legende entsprechend der Übersetzung von jener zur Abbildung 1D „Expression of ARHGAP29 in MCF-7, MCF-7-EMT, T-47D, T-47D-EMT, and HCC1806 breast cancer cells." von Kolb et al. (2020), https://www.mdpi.com/20734409/9/12/2616/htm; Lizenz CC BY 4.0 (https://creativecommons.org/licenses/by/4.0/).

\subsubsection{Analyse der ARHGAP29-Genexpression nach transienter siRNA- Transfektion in MDA-MB-231-Mammakarzinomzellen}

Die Zelllinie MDA-MB-231 gilt als dreifach negativ, d.h. die Zellen weisen keine Expression der Hormonrezeptoren für Östrogen und Progesteron sowie keine Überexpression von HER2/neu auf (Neve et al. 2006; Prat et al. 2010). Zudem wurde bereits aufgezeigt, dass diese Zelllinie in vitro hoch-invasive Eigenschaften aufweist 
(Neve et al. 2006). Es bleibt unklar, welche Rolle ARHGAP29 in Bezug auf die EMT und Invasivität dieser Zelllinie einnimmt. Folglich sollte in invasiven MDA-MB-231Mammakarzinomzellen die ARHGAP29-Expression transient vermindert werden und der Einfluss auf die Invasivität und Proliferation analysiert werden. Genexpressionsanalysen 120 Stunden nach erfolgter transienter Transfektion zeigten eine signifikant verminderte ARHGAP29-mRNA-Expression $(0,87 \pm 0,04916$ SEM relative Genexpression (FC) vs. „Kontrolle“; $p=0,0383 ; n=4$; siehe Abbildung 5).

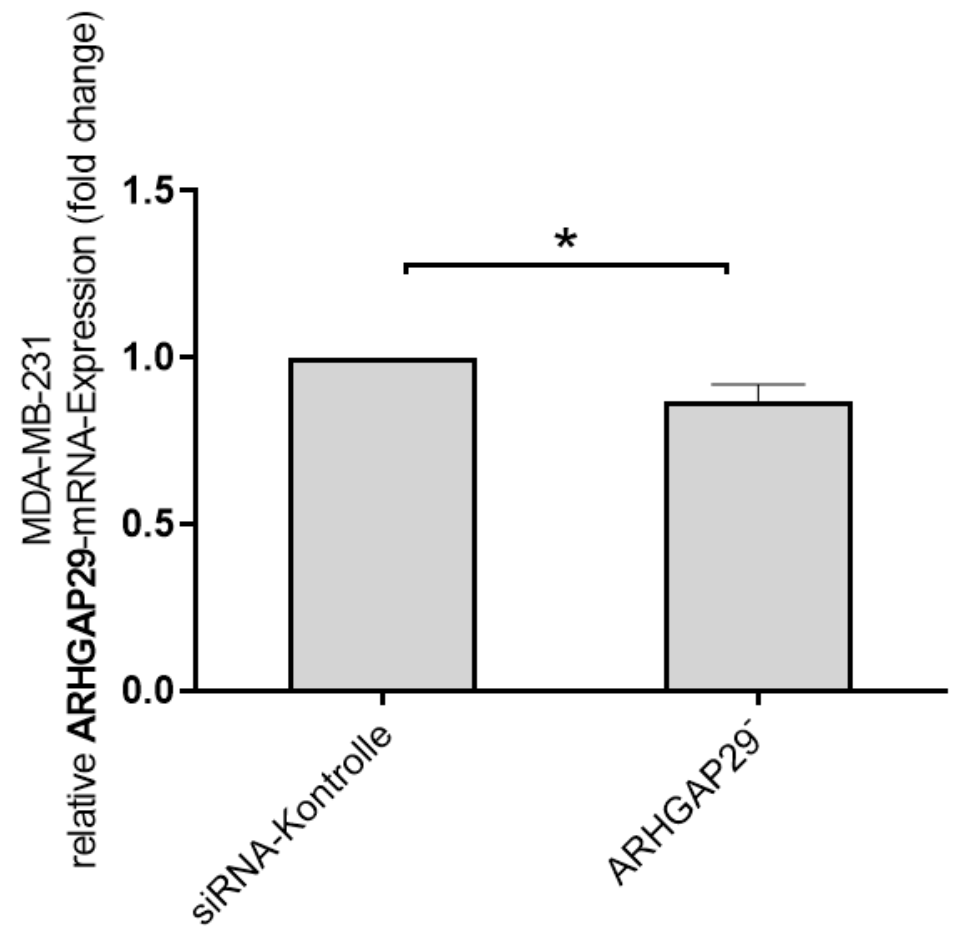

Abbildung 5: Nachweis der signifikant verminderten ARHGAP29-Expression nach erfolgter transienter siRNA-Transfektion der Mammakarzinomzelllinie MDA-MB-231. Genexpression von ARHGAP29 in der Mammakarzinomzelllinie MDA-MD-231 zum Zeitpunkt $t_{120 h}$. Durch quantitative realtime-PCR wurde die Expression von ARHGAP29 auf RNA-Ebene analysiert und auf die GAPDHExpression normiert. In der Behandlungsgruppe („ARHGAP29-“) erfolgte die transiente Transfektion der Mammakarzinomzellinie MDA-MB-231 mit ARHGAP29-spezifischer siRNA und in der Kontrollgruppe („siRNA-Kontrolle“) mit unspezifischer siRNA. Es wurden mindestens biologische und technische Triplikate verwendet. Angegeben sind MW \pm SEM, Signifikanzen wurden mithilfe ungepaarter t-Tests ermittelt; $\left({ }^{*}\right) p<0,05$. 


\subsubsection{Analyse der ARHGAP29-Genexpression nach transienter siRNA-}

Transfektion in HCC1806-Mammakarzinomzellen

HCC1806 stellen ebenfalls eine dreifach-negative Mammakarzinomzelllinie dar (Gazdar et al. 1998). Im Vergleich mit anderen Mammakarzinomzellinien erweisen sich diese als eine Zelllinie mit stärkerem invasiven Potenzial, das durch Kokultur mit Osteosarkomzellen noch gesteigert werden kann (Ziegler et al. 2014). Welchen Einfluss ARHGAP29 auf die Invasivität und Proliferation dieser aggressiven Mammakarzinomzellen nimmt, ist noch ungeklärt. Daher wurde die ARHGAP29Expression in HCC1806 transient vermindert und der Einfluss auf die Invasions- und Proliferationsfähigkeit analysiert. Eine signifikante Verminderung der ARHGAP29Genexpression konnte 120 Stunden nach der transienten Expressionsverminderung gegenüber der Kontrollpopulation festgestellt werden $(0,73 \pm 0,01155$ SEM relative Genexpression (FC) vs. „Kontrolle“; $p<0,0001 ; n=3$; siehe Abbildung 6; (Kolb et al. 2020).

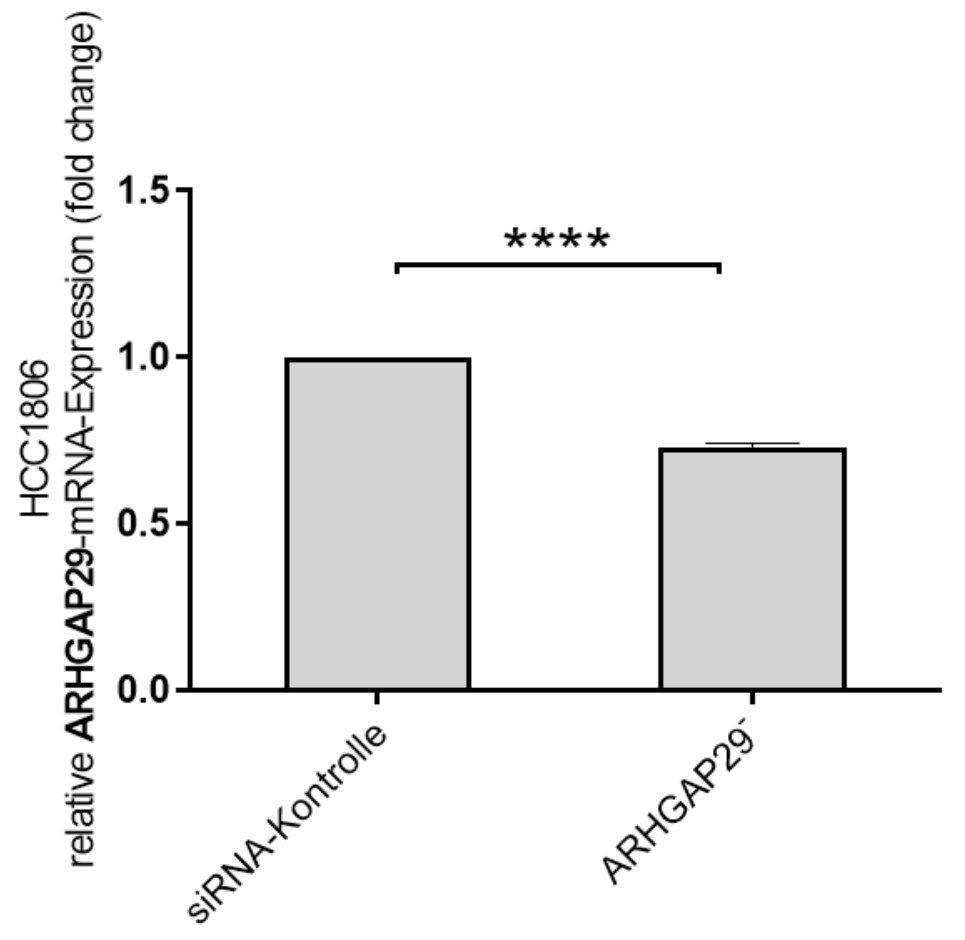

Abbildung 6: Nachweis der signifikant verminderten ARHGAP29-Expression nach erfolgter transienter siRNA-Transfektion der Mammakarzinomzelllinie HCC1806 (Kolb et al. 2020). Genexpression von ARHGAP29 in der Mammakarzinomzelllinie HCC1806 zum Zeitpunkt $\mathrm{t}_{120 h}$ (Kolb et al. 2020). Durch quantitative real-time-PCR wurde die Expression von ARHGAP29 auf RNA-Ebene 
analysiert und auf die GAPDH-Expression normiert. In der Behandlungsgruppe („ARHGAP29““) erfolgte die transiente Transfektion der Mammakarzinomzellinie HCC1806 mit ARHGAP29-spezifischer siRNA und in der Kontrollgruppe („siRNA-Kontrolle“) mit unspezifischer siRNA. Es wurden mindestens biologische und technische Triplikate verwendet. Angegeben sind MW \pm SEM, Signifikanzen wurden mithilfe ungepaarter t-Tests ermittelt; $\left.{ }^{* * * *}\right) p<0,0001$. Diese Abbildung wurde selbstständig erstellt, aber repräsentiert einen in Farbe, Format und Skalierung modifizierten Ausschnitt der Abbildung 2A „Detection of reduced Rho GTPase activating protein 29 (ARHGAP29) expression after transient siRNA transfection of MCF-7-EMT, T-47D-EMT, and HCC1806 breast cancer cells." von Kolb et al. (2020); Legende teilweise übereinstimmend mit einer Übersetzung der Legende zur entsprechenden Abbildung in Kolb et al. (2020), https://www.mdpi.com/20734409/9/12/2616/htm; Lizenz CC BY 4.0 (https://creativecommons.org/licenses/by/4.0/).

\subsubsection{Analyse der ARHGAP29-Genexpression nach transienter siRNA- Transfektion in MCF-7-EMT-Mammakarzinomzellen}

Mit der Etablierung der Zelllinie MCF-7-EMT nach Ziegler et al. (2014) und Guttila et al. (2012) und deren invasiven und EMT-assoziierten Eigenschaften bietet sich die Möglichkeit, damit die Invasion von Tumorzellen in vitro weiter zu untersuchen (Ziegler et al. 2014). Außerdem zeigte sich, dass ARHGAP29 eines von 223 durch induzierte EMT hochregulierten Genen in diesen Zellen war (siehe auch 3.1.1 und Abbildung 2; Ziegler 2013; Ziegler et al. 2014; Kolb et al. 2020). Auch in Bezug auf diese invasive Zelllinie und ihre Invasionsfähigkeit fand ARHGAP29 jedoch noch keine weitere Erwähnung. In der Genexpressionsanalyse erwies sich die mRNAExpression von ARHGAP29 für den Zeitpunkt $t_{120 h}$ in den mit ARHGAP29-siRNA transient transfizierten MCF-7-EMT-Zellen als signifikant reduziert gegenüber der Kontrolle (0,5133 \pm 0,1198 SEM relative Genexpression (FC) vs. „Kontrolle“; $p=0,0153 ; n=3$; siehe Abbildung 7; Kolb et al. 2020). 


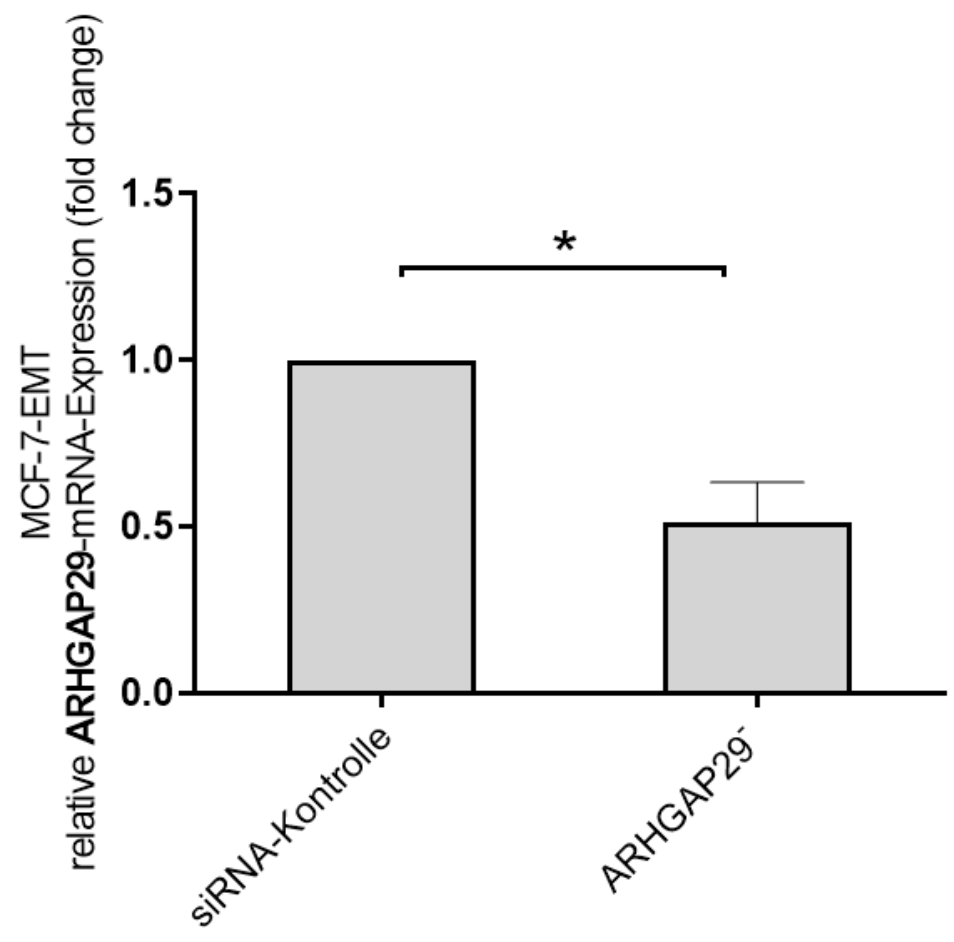

Abbildung 7: Nachweis der signifikant verminderten ARHGAP29-Expression nach erfolgter transienter siRNA-Transfektion der Mammakarzinomzelllinie MCF-7-EMT (Kolb et al. 2020). Genexpression von ARHGAP29 in der Mammakarzinomzelllinie MCF-7-EMT zum Zeitpunkt $t_{120 h}$ (Kolb et al. 2020). Durch quantitative real-time-PCR wurde die Expression von ARHGAP29 auf RNA-Ebene analysiert und auf die GAPDH-Expression normiert. In der Behandlungsgruppe („ARHGAP29““) erfolgte die transiente Transfektion der Mammakarzinomzellinie MCF-7-EMT mit ARHGAP29-spezifischer siRNA und in der Kontrollgruppe („,iRNA-Kontrolle“) mit unspezifischer siRNA. Es wurden mindestens biologische und technische Triplikate verwendet. Angegeben sind MW \pm SEM, Signifikanzen wurden mithilfe ungepaarter t-Tests ermittelt; $\left({ }^{*}\right) p<0,05$. Diese Abbildung wurde selbstständig erstellt, aber repräsentiert einen in Farbe, Format und Skalierung modifizierten Ausschnitt der Abbildung 2A "Detection of reduced Rho GTPase activating protein 29 (ARHGAP29) expression after transient siRNA transfection of MCF-7-EMT, T-47D-EMT, and HCC1806 breast cancer cells." von Kolb et al. (2020); Legende teilweise übereinstimmend mit einer Übersetzung der Legende zur entsprechenden Abbildung in Kolb et al. (2020), https://www.mdpi.com/20734409/9/12/2616/htm; Lizenz CC BY 4.0 (https://creativecommons.org/licenses/by/4.0/).

3.1.2.5 Analyse der ARHGAP29-Genexpression nach transienter siRNATransfektion in T-47D-EMT-Mammakarzinomzellen

T-47D-Mammakarzinomzellen erscheinen gering invasiv (Neve et al. 2006; Ziegler et al. 2014). In Kokultur mit Osteosarkomzellen entwickeln T-47D jedoch gesteigerte Invasionsraten (Von Alten et al. 2006; Ziegler et al. 2014). Um zellinienspezifische Effekte ausschließen zu können, wurde mit T-47D eine weitere nicht-invasive 
Mammakarzinomzellinie nach Guttilla et al. (2012) und Ziegler et al. (2014) mesenchymal transformiert und der Einfluss von ARHGAP29 auf die Invasivität und Proliferation analysiert. Transient mit ARHGAP29-siRNA transfizierte Zellen der Linie T-47D-EMT zeigten 120 Stunden nach transienter Transfektion eine signifikant reduzierte ARHGAP29-mRNA-Expression gegenüber der Kontrolle $(0,7933 \pm$ 0,05840 SEM relative Genexpression ( $F C$ ) vs. „Kontrolle“; $p=0,0240 ; n=3$; siehe Abbildung 8; Kolb et al. 2020).

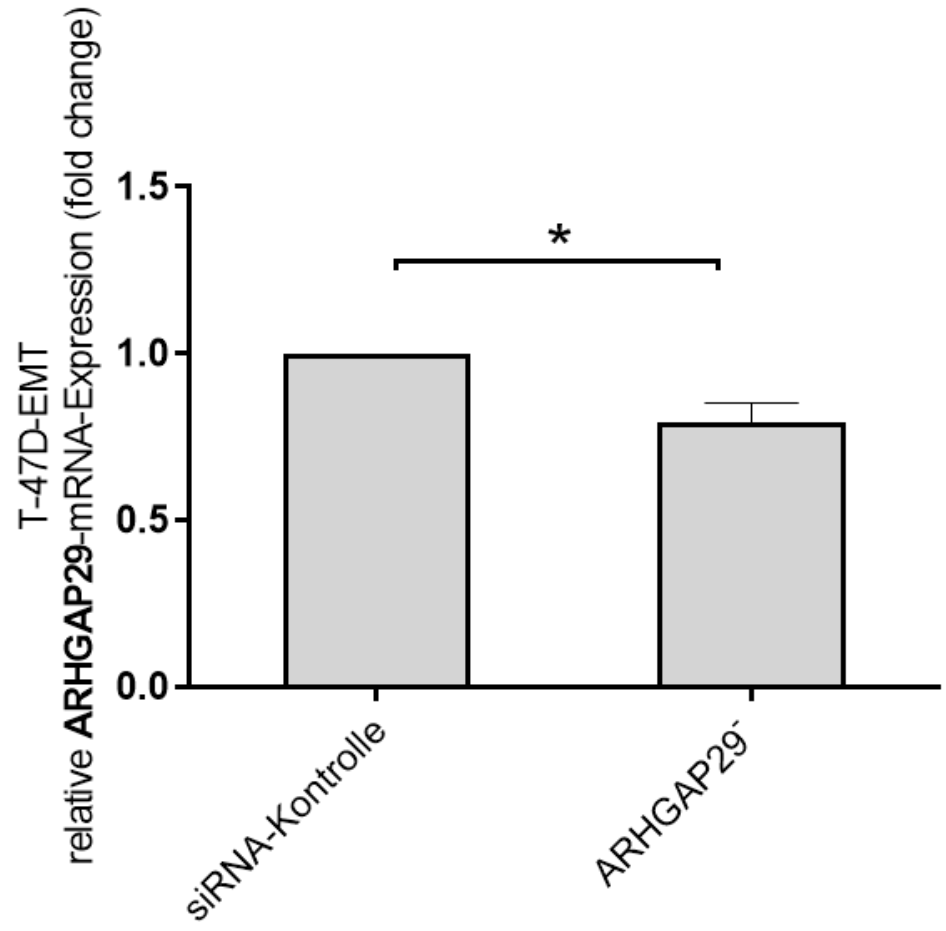

Abbildung 8: Nachweis der signifikant verminderten ARHGAP29-Expression nach erfolgter transienter siRNA-Transfektion der Mammakarzinomzellinie T-47D-EMT (Kolb et al. 2020). Genexpression von ARHGAP29 in der Mammakarzinomzelllinie T-47D-EMT zum Zeitpunkt $\mathrm{t}_{120 \mathrm{~h}}$ (Kolb et al. 2020). Durch quantitative real-time-PCR wurde die Expression von ARHGAP29 auf RNA-Ebene analysiert und auf die GAPDH-Expression normiert. In der Behandlungsgruppe („ARHGAP29-“) erfolgte die transiente Transfektion der Mammakarzinomzellinie T-47D-EMT mit ARHGAP29-spezifischer siRNA und in der Kontrollgruppe („siRNA-Kontrolle“) mit unspezifischer siRNA. Es wurden mindestens biologische und technische Triplikate verwendet. Angegeben sind MW \pm SEM, Signifikanzen wurden mithilfe ungepaarter t-Tests ermittelt; $\left({ }^{*}\right) p<0,05$. Diese Abbildung wurde selbstständig erstellt, aber repräsentiert einen in Farbe, Format und Skalierung modifizierten Ausschnitt der Abbildung 2A „Detection of reduced Rho GTPase activating protein 29 (ARHGAP29) expression after transient siRNA transfection of MCF-7-EMT, T-47D-EMT, and HCC1806 breast cancer 
cells." von Kolb et al. (2020); Legende teilweise übereinstimmend mit einer Übersetzung der Legende zur entsprechenden Abbildung in Kolb et al. (2020), https://www.mdpi.com/20734409/9/12/2616/htm; Lizenz CC BY 4.0 (https://creativecommons.org/licenses/by/4.0/).

\subsection{Untersuchung des Einflusses eines knockdowns von ARHGAP29 auf die Invasivität von Mammakarzinomzellen}

Wie bereits beschrieben, wird ARHGAP29 erhöht exprimiert in invasiven und mesenchymal transformierten Mammakarzinomzellen (siehe 3.1.2.1; Kolb et al. 2020). Nach induzierter EMT ist ARHGAP29 das einzige der betrachteten Rho GAPs, das in mesenchymal transformierten Mammakarzinomzellen hochreguliert wurde (siehe 3.1.1; Ziegler 2013; Kolb et al. 2020). Trotz dessen bleibt es ungeklärt, ob ARHGAP29 an der lokalen Invasion von Tumorzellen beteiligt ist. Daher wurde untersucht, ob eine verminderte ARHGAP29-Expression Einfluss auf die knochengerichtete Invasion von invasiven Mammakarzinomzellen nimmt. Es wurden Invasionsassays mit transient mit ARHGAP29-siRNA transfizierten Mammakarzinomzellen und mit Kontroll-siRNA behandelten Zellen durchgeführt. Dafür wurden die transient transfizierten Zellen für 96 Stunden in einer modifizierten Boyden-Kammer mit der Osteosarkomzelllinie MG-63 kokultiviert (siehe 2.2.1.6).

\subsubsection{Einfluss einer verminderten ARHGAP29-Expression auf die Invasivität der Mammakarzinomzelllinie MDA-MB-231}

Im Rahmen der Invasionsassays mit der invasiven Mammakarzinomzelllinie MDA-MB-231 fiel eine signifikant gegenüber der Kontrolle gesteigerte Invasivität in der Gruppe der Zellen mit verringerter ARHGAP29-Expression auf. So fand sich in dieser annähernd die zweifache Anzahl an invadierten Zellen, verglichen mit der Kontrolle (175,5 Zellen $\pm 22,65$ SEM in \% vs. „Kontrolle“ $100 \pm 12,30$ SEM in \%; $p=0,006 ; n=18 ;$ siehe Abbildung 9). 
A

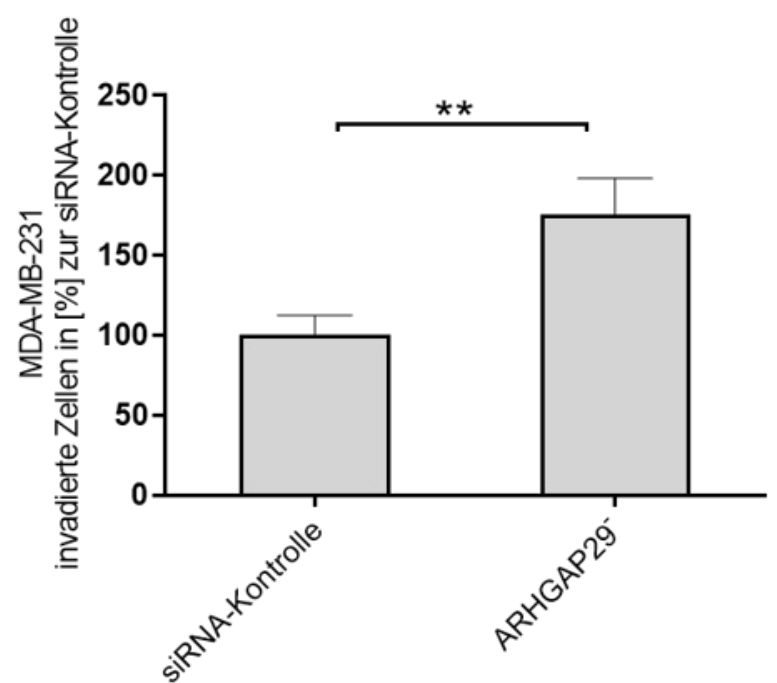

B

MDA-MB-231

siRNA-Kontrolle

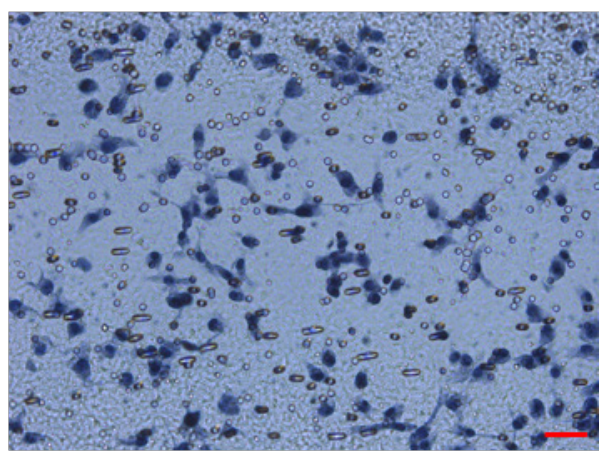

MDA-MB-231

ARHGAP29-

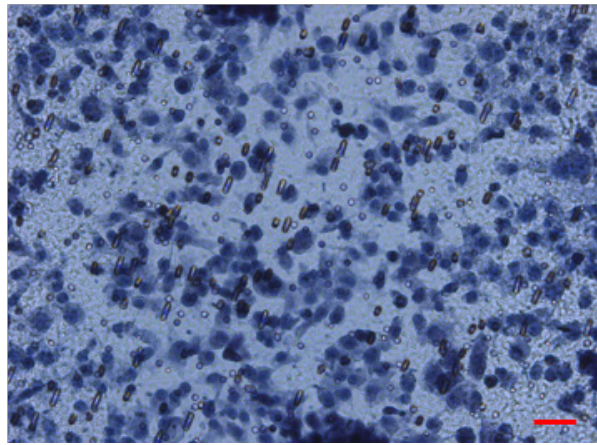

Abbildung 9: Nachweis der signifikant erhöhten Invasivität nach erfolgter transienter siRNA-Transfektion der Mammakarzinomzellen MDA-MB-231.

A: Invasionsanalyse von transient transfizierten Mammakarzinomzellen MDA-MB-231 nach erfolgter 96h-Kokultivierung mit Osteosarkomzellen der Linie MG-63. In der Behandlungsgruppe („ARHGAP29-“) erfolgte die transiente Transfektion der Mammakarzinomzellinie MDA-MB-231 mit ARHGAP29-spezifischer siRNA und in der Kontrollgruppe („siRNA-Kontrolle“) mit unspezifischer siRNA. Die Anzahl der invadierten Zellen der Behandlungsgruppe wurde auf die Zellzahl der Kontrollgruppe normiert.

B: Repräsentative Filterausschnitte nach einer Hämatoxylin-Färbung der invadierten MDA-MB-231Mammakarzinomzellen. Die Behandlungsgruppe ist als „ARHGAP29-“ beschriftet und die Kontrollgruppe als „siRNA-Kontrolle“. Der Maßstabbalken entspricht $100 \mu \mathrm{m}$.

Es wurden mindestens biologische und technische Triplikate verwendet. Angegeben sind MW \pm SEM, Signifikanzen wurden mithilfe ungepaarter t-Tests ermittelt; $\left.{ }^{* *}\right) p<0,01$. 


\subsubsection{Einfluss einer verminderten ARHGAP29-Expression auf die Invasivität der Mammakarzinomzelllinie HCC1806}

Um den unter 3.2.1 beschriebenen Effekt der signifikant gesteigerten Invasivität der MDA-MB-231 mit reduzierter ARHGAP29-Expression besser beurteilen zu können und mögliche zellinienspezifische Effekte zu erfassen, wurden Invasionsassays mit einer weiteren dreifach negativen Zelllinie - HCC1806 - durchgeführt. Die Invasionsfähigkeit der Mammakarzinomzellen mit reduzierter ARHGAP29Expression war signifikant vermindert im Vergleich zur Kontrollgruppe (74,09 Zellen $\pm 6,54$ SEM in \% vs. „Kontrolle“ $100 \pm 6,83$ SEM in \%; $p=0,0082 ; n=30$; siehe Abbildung 10; Kolb et al. 2020).

A

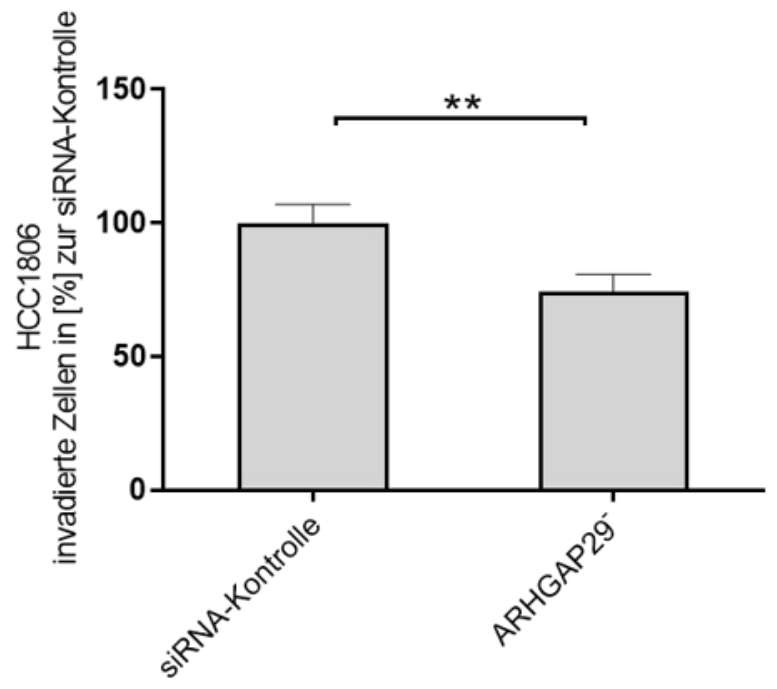

B

HCC1806

siRNA-Kontrolle

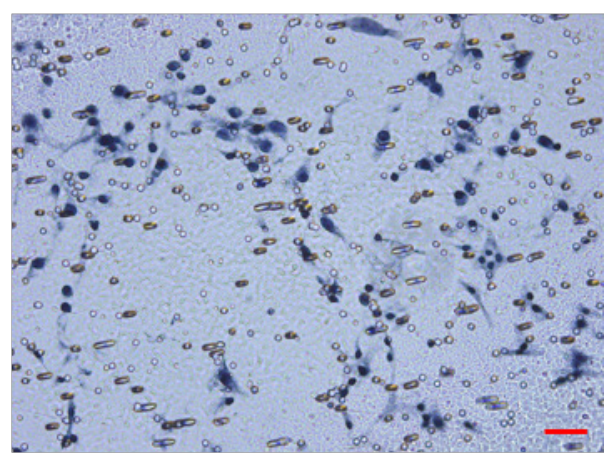

HCC1806 ARHGAP29-

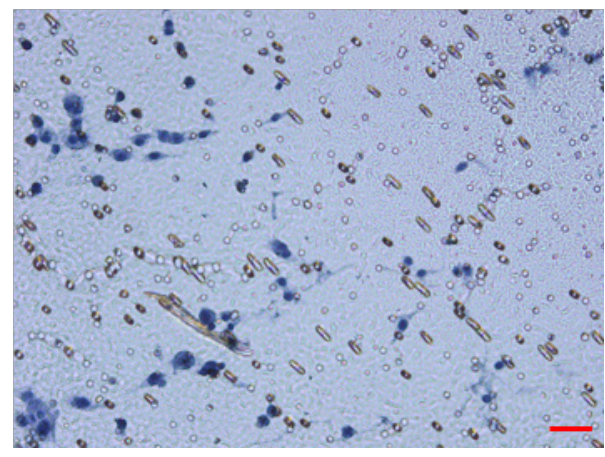

Abbildung 10: Nachweis der signifikant reduzierten Invasivität nach erfolgter transienter siRNATransfektion der Mammakarzinomzellen HCC1806 (Kolb et al. 2020).

A: Invasionsanalyse von transient transfizierten Mammakarzinomzellen HCC1806 nach erfolgter 
96h-Kokultivierung mit Osteosarkomzellen der Linie MG-63, wie in Kolb et al. (2020). In der Behandlungsgruppe („ARHGAP29-“) erfolgte die transiente Transfektion der Mammakarzinomzellinie HCC1806 mit ARHGAP29-spezifischer siRNA und in der Kontrollgruppe („siRNA-Kontrolle“) mit unspezifischer siRNA. Die Anzahl der invadierten Zellen der Behandlungsgruppe wurde auf die Zellzahl der Kontrollgruppe normiert.

B: Repräsentative Filterausschnitte nach einer Hämatoxylin-Färbung der invadierten HCC1806Mammakarzinomzellen (Kolb et al. 2020). Die Behandlungsgruppe ist als „ARHGAP29““ beschriftet und die Kontrollgruppe als „siRNA-Kontrolle“. Der Maßstabbalken entspricht $100 \mu \mathrm{m}$.

Es wurden mindestens biologische und technische Triplikate verwendet. Angegeben sind MW \pm SEM, Signifikanzen wurden mithilfe ungepaarter t-Tests ermittelt; $\left.{ }^{* *}\right) p<0,01$. Diese Abbildung wurde selbstständig erstellt, aber repräsentiert eine in der Formatierung und Beschriftung modifizierte Version der Abbildung 2D von Kolb et al. (2020); Legende teilweise einer Übersetzung jener der zugehörigen Abbildung entsprechend (https://www.mdpi.com/2073-4409/9/12/2616/htm); Lizenz CC BY 4.0 (https://creativecommons.org/licenses/by/4.0/).

\subsubsection{Einfluss einer verminderten ARHGAP29-Expression auf die Invasivität von mesenchymal transformierten MCF-7-EMT-Mammakarzinomzellen}

Der Einfluss von ARHGAP29 auf die Invasionsfähigkeit sollte bei nach Guttilla et al. (2012) und Ziegler et al. (2014) mesenchymal transformierten Mammakarzinomzellen untersucht werden. Dafür wurde die Invasivität von transient transfizierten MCF-7-EMT-Mammakarzinomzellen mittels Invasionsassays nach beschriebenem Verfahren (siehe 2.2.1.6) betrachtet. Bezogen auf die mit unspezifischer siRNA behandelten Zellen, waren die MCF-7-EMT-Zellen mit verringerter ARHGAP29-Expression signifikant schwächer invasiv (Kolb et al. 2020). So fanden sich nur halb so viele invadierte Zelle in der ARHGAP29-knockdown-Gruppe, verglichen mit der Kontrollgruppe (49,51 Zellen \pm 9,911 Zellen SEM in \% vs. „Kontrolle“ 99,99 Zellen $\pm 12,08$ Zellen SEM in \%; $p=0,0027 ; n=18$; siehe Abbildung 11; Kolb et al. 2020). 
A

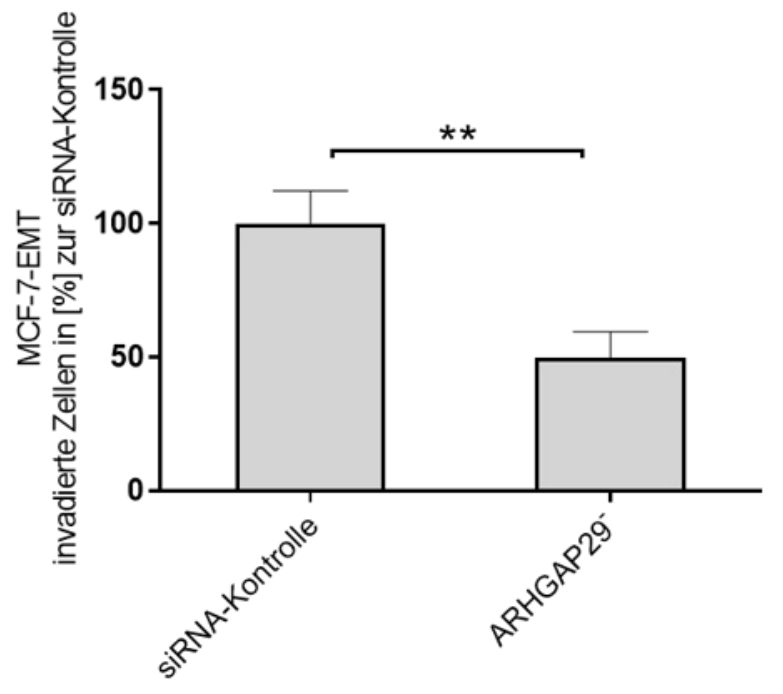

B

MCF-7-EMT

siRNA-Kontrolle

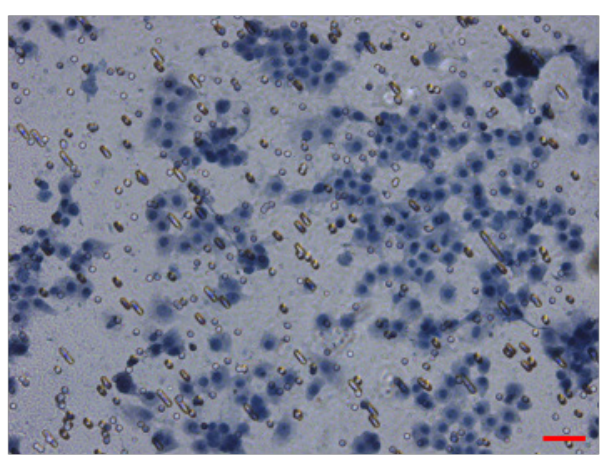

MCF-7-EMT ARHGAP29-

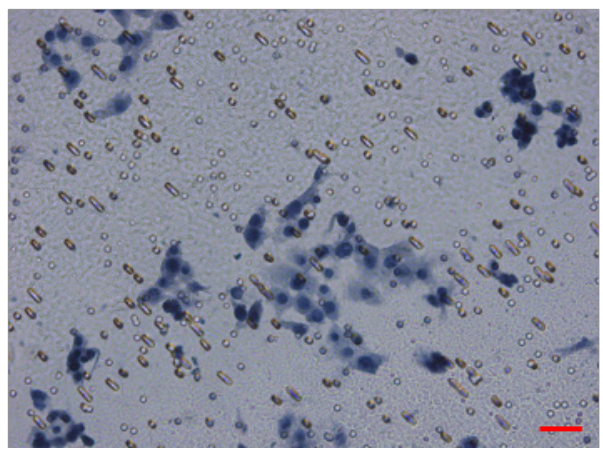

Abbildung 11: Nachweis der signifikant reduzierten Invasivität nach erfolgter transienter siRNATransfektion der Mammakarzinomzellen MCF-7-EMT (Kolb et al. 2020).

A: Invasionsanalyse von transient transfizierten Mammakarzinomzellen MCF-7-EMT nach erfolgter 96h-Kokultivierung mit Osteosarkomzellen der Linie MG-63, wie in Kolb et al. (2020). In der Behandlungsgruppe („ARHGAP29-“) erfolgte die transiente Transfektion der Mammakarzinomzellinie MCF-7-EMT mit ARHGAP29-spezifischer siRNA und in der Kontrollgruppe („siRNA-Kontrolle“) mit unspezifischer siRNA. Die Anzahl der invadierten Zellen der Behandlungsgruppe wurde auf die Zellzahl der Kontrollgruppe normiert.

B: Repräsentative Filterausschnitte nach einer Hämatoxylin-Färbung der invadierten MCF-7-EMTMammakarzinomzellen (Kolb et al. 2020). Die Behandlungsgruppe ist als „ARHGAP29-“ beschriftet und die Kontrollgruppe als „siRNA-Kontrolle“. Der Maßstabbalken entspricht $100 \mu \mathrm{m}$.

Es wurden mindestens biologische und technische Triplikate verwendet. Angegeben sind $M W \pm S E M$, Signifikanzen wurden mithilfe ungepaarter t-Tests ermittelt; $\left({ }^{* *}\right) p<0,01$. Diese Abbildung wurde selbstständig erstellt, aber repräsentiert eine in der Formatierung und Beschriftung modifizierte Version der Abbildung 2B von Kolb et al. (2020); Legende teilweise einer Übersetzung jener der zugehörigen Abbildung entsprechend (https://www.mdpi.com/2073-4409/9/12/2616/htm); Lizenz CC BY 4.0 (https://creativecommons.org/licenses/by/4.0/). 


\subsubsection{Einfluss einer verminderten ARHGAP29-Expression auf die Invasivität der mesenchymal transformierten T-47D-EMT-Mammakarzinomzellen}

Wie auch zwei verschiedene dreifach-negative Mammakarzinomzelllinien hinsichtlich ihrer Invasionsfähigkeit bei reduzierter ARHGAP29-Expression analysiert wurden, sollte neben der Linie MCF-7-EMT eine zweite nach Guttilla et al. (2012) und Ziegler et al. (2014) mesenchymal transformierte Mammakarzinomzellinie dahingehend untersucht werden. Dafür wurden Invasionsassays mit T-47D-EMT-Zellen nach einem transienten knockdown von ARHGAP29 durchgeführt. Mammakarzinomzellen mit verminderter ARHGAP29-Expression zeigten eine signifikante, annähernd um die Hälfte reduzierte Invasivität, verglichen mit der Kontrollgruppe $(58,37$ Zellen \pm 9,317 Zellen SEM in \% vs. „Kontrolle“ 100 Zellen $\pm 13,82$ Zellen SEM in \%; $p=0,0175 ; n=18$; siehe Abbildung 12; Kolb et al. 2020).

A

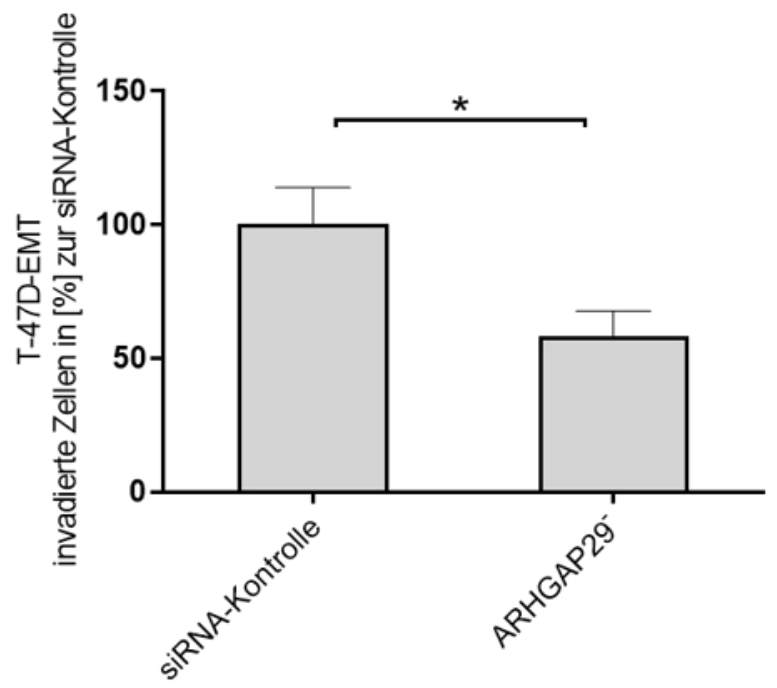

B

T-47D-EMT siRNA-Kontrolle

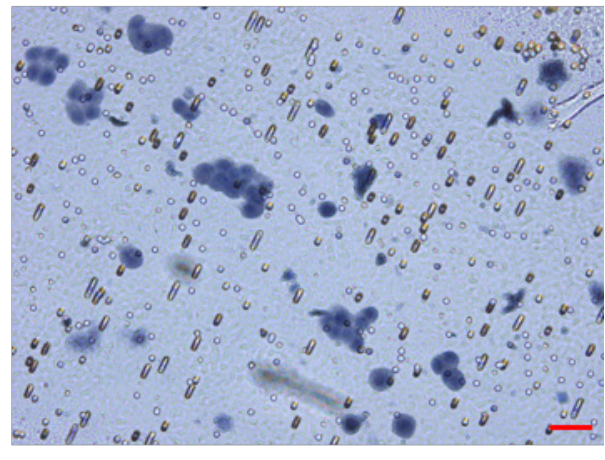

T-47D-EMT ARHGAP29-

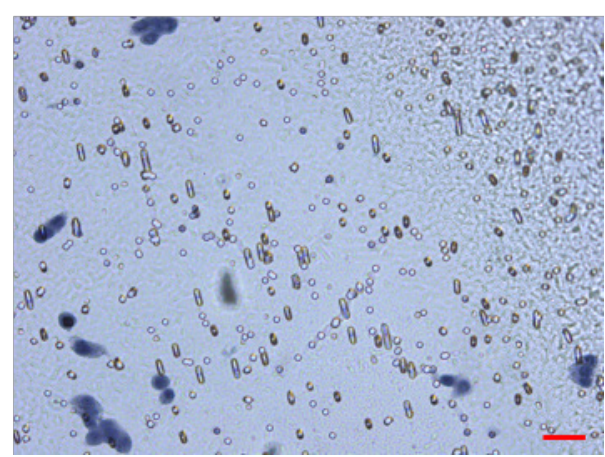

Abbildung 12: Nachweis der signifikant reduzierten Invasivität nach erfolgter transienter siRNATransfektion der Mammakarzinomzellen T-47D-EMT (Kolb et al. 2020). 
A: Invasionsanalyse von transient transfizierten Mammakarzinomzellen T-47D-EMT nach erfolgter 96h-Kokultivierung mit Osteosarkomzellen der Linie MG-63, wie in Kolb et al. (2020). In der Behandlungsgruppe („ARHGAP29-“) erfolgte die transiente Transfektion der Mammakarzinomzelllinie T-47D-EMT mit ARHGAP29-spezifischer siRNA und in der Kontrollgruppe („siRNA-Kontrolle“) mit unspezifischer siRNA. Die Anzahl der invadierten Zellen der Behandlungsgruppe wurde auf die Zellzahl der Kontrollgruppe normiert.

B: Repräsentative Filterausschnitte nach einer Hämatoxylin-Färbung der invadierten T-47D-EMTMammakarzinomzellen (Kolb et al. 2020). Die Behandlungsgruppe ist als „ARHGAP29““ beschriftet und die Kontrollgruppe als „siRNA-Kontrolle“. Der Maßstabbalken entspricht $100 \mu \mathrm{m}$.

Es wurden mindestens biologische und technische Triplikate verwendet. Angegeben sind MW \pm SEM, Signifikanzen wurden mithilfe ungepaarter t-Tests ermittelt; $\left({ }^{*}\right) p<0,05$. Diese Abbildung wurde selbstständig erstellt, aber repräsentiert eine in der Formatierung und Beschriftung modifizierte Version der Abbildung 2C von Kolb et al. (2020); Legende teilweise einer Übersetzung jener der zugehörigen Abbildung entsprechend (https://www.mdpi.com/2073-4409/9/12/2616/htm); Lizenz CC BY 4.0 (https://creativecommons.org/licenses/by/4.0/).

\subsection{Untersuchung der Auswirkungen des knockdowns von} ARHGAP29 auf die Proliferation von Mammakarzinomzellen

Veränderungen in der Proliferationsfähigkeit von Zellen können Einfluss auf die Ergebnisse von Invasionsanalysen nehmen - aus diesem Grund wurden Mammakarzinomzellen der vier Zelllinien hinsichtlich eines möglichen Einflusses von ARHGAP29 auf ihre Proliferation analysiert. Dafür wurden Mammakarzinomzellen nach transienter Transfektion mit gegen ARHGAP29 gerichteter siRNA oder mit KontrollsiRNA bis zum Zeitpunkt $\mathrm{t}_{120 \mathrm{~h}}$ kultiviert und anschließend die ermittelten Zellzahlen der beiden Gruppen miteinander verglichen (siehe 2.2.1.5). Im Weiteren werden diesbezügliche Ergebnisse erläutert.

\subsubsection{Einfluss einer reduzierten ARHGAP29-Expression auf die Proliferation der Mammakarzinomzelllinie MDA-MB-231}

Bei beschriebenem Einfluss von ARHGAP29 auf die Invasivität der MDA-MB-231 (siehe 3.2.1) zeigten Proliferationsanalysen der dreifach-negativen Zelllinie (Neve et al. 2006; Prat et al. 2010) keinen signifikanten Unterschied zum Zeitpunkt $\mathrm{t}_{120 \mathrm{~h}}$ zwischen der Population mit regelrechter und der Population mit herunterregulierter ARHGAP29-Expression (102,3 Zellen \pm 10,6 SEM in \% vs. „Kontrolle“; $p=0,8374$; $\mathrm{n}=3$; siehe Abbildung 13). 


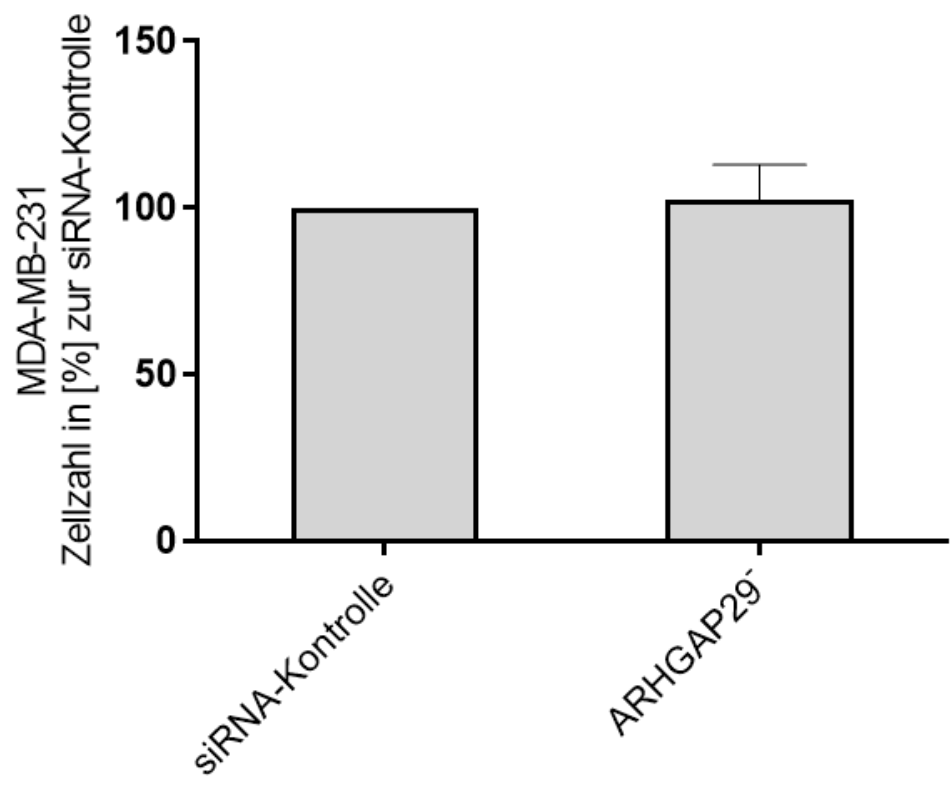

Abbildung 13: Nachweis der nicht signifikant veränderten Proliferation der Mammakarzinomzellinie MDA-MB-231 nach erfolgter siRNA-Transfektion. Proliferationsanalyse von transient transfizierten Mammakarzinomzellen der Linie MDA-MB-231 nach 120 Stunden. In der Behandlungsgruppe („ARHGAP29““) erfolgte die transiente Transfektion der Mammakarzinomzellinie mit ARHGAP29spezifischer siRNA und in der Kontrollgruppe („siRNA-Kontrolle“) mit unspezifischer siRNA. Nach der Kultivierung für 120 Stunden wurden die adhärenten transient transfizierten Mammakarzinomzellen gelöst und mithilfe der Neubauer-Zählkammer ausgezählt. Es konnte kein signifikanter Unterschied bezüglich der Proliferation zwischen der Kontroll- und der Behandlungsgruppe gezeigt werden. Es wurden mindestens biologische und technische Triplikate verwendet. Angegeben sind $M W \pm S E M$, Signifikanzen wurden mithilfe ungepaarter t-Tests ermittelt.

\subsubsection{Einfluss einer reduzierten ARHGAP29-Expression auf die Proliferation der Mammakarzinomzelllinie HCC1806}

Neben dem Einfluss von ARHGAP29 auf deren Invasivität (siehe 3.2.2; Kolb et al. 2020) wurde bei einer zweiten dreifach-negativen Zelllinie - HCC1806 - (Gazdar et al. 1998) ebenfalls die Rolle von ARHGAP29 bei der Proliferationsfähigkeit untersucht. Hier zeigte sich eine signifikant erhöhte Zellzahl auf Seiten der Zellen mit verringerter ARHGAP29-Expression zum Zeitpunkt t120h (Kolb et al. 2020). Diese wiesen eine um mehr als das Zweifache gesteigerte Proliferationsfähigkeit im Vergleich zur Kontrolle auf (225,3 Zellen $\pm 44,46$ SEM in \% vs. „Kontrolle“; $p=0,0479$; $\mathrm{n}=3$; siehe Abbildung 14; Kolb et al. 2020). 


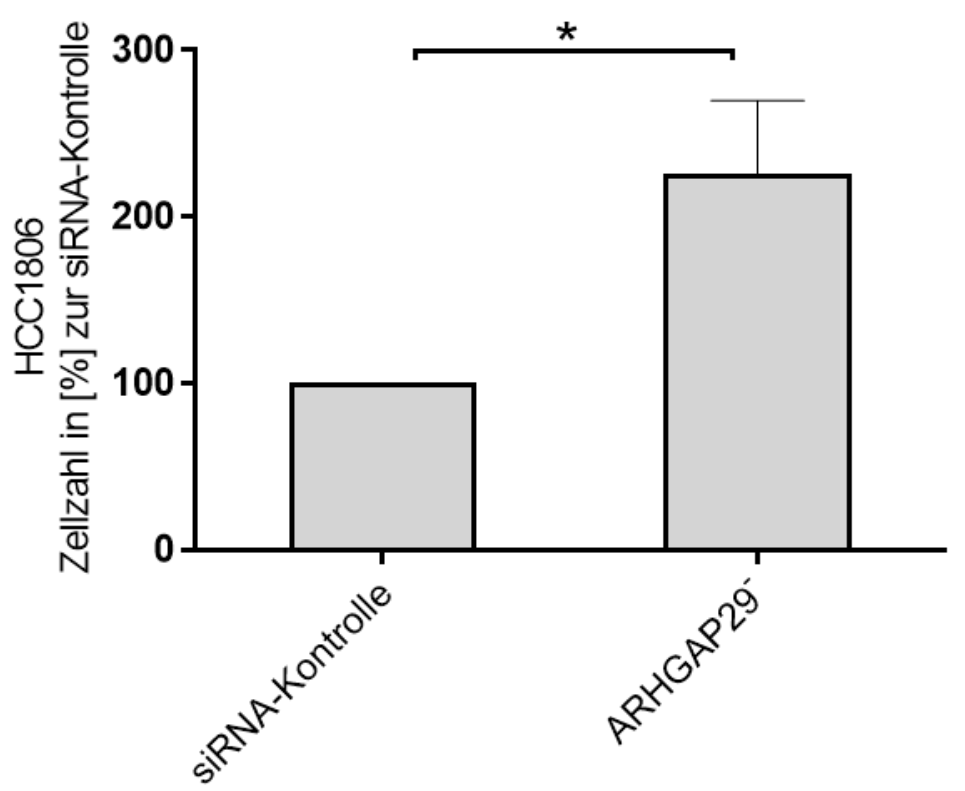

Abbildung 14: Nachweis der signifikant gesteigerten Proliferation der Mammakarzinomzelllinie HCC1806 nach erfolgter siRNA-Transfektion (Kolb et al. 2020). Proliferationsanalyse von transient transfizierten Mammakarzinomzellen der Linie HCC1806 nach 120 Stunden, wie in Kolb et al. (2020). In der Behandlungsgruppe („ARHGAP29-“) erfolgte die transiente Transfektion der Mammakarzinomzelllinie mit ARHGAP29-spezifischer siRNA und in der Kontrollgruppe („siRNAKontrolle") mit unspezifischer siRNA. Nach der Kultivierung für 120 Stunden wurden die adhärenten transient transfizierten Mammakarzinomzellen gelöst und mithilfe der Neubauer-Zählkammer ausgezählt. Es wurden mindestens biologische und technische Triplikate verwendet. Angegeben sind MW \pm SEM, Signifikanzen wurden mithilfe ungepaarter t-Tests ermittelt, $\left({ }^{*}\right) p<0,05$. Diese Abbildung wurde selbstständig erstellt, aber repräsentiert eine in der Formatierung modifizierte und übersetzte Version des Teils C der Abbildung 3 von Kolb et al. (2020) mit dem Titel „Effect of the downregulation of Rho GTPase activating protein 29 (ARHGAP29) on the proliferation of MCF-7EMT (A), T-47D-EMT (B), and HCC1806 (C) breast cancer cells."; Legende teilweise übereinstimmend mit einer Übersetzung der Legende zur entsprechenden Abbildung in Kolb et al. (2020), https://www.mdpi.com/2073-4409/9/12/2616/htm; Lizenz CC BY 4.0 (https://creativecommons.org/licenses/by/4.0/).

\subsubsection{Einfluss einer reduzierten ARHGAP29-Expression auf die Proliferation der mesenchymal transformierten MCF-7-EMT-Mammakarzinomzellen}

Inwiefern die Proliferation durch die Herunterregulierung von ARHGAP29 beeinflusst werden könnte, sollte ebenfalls bei den nach Guttilla et al. (2012) und Ziegler et al. (2014) mesenchymal transformierten Mammakarzinomzellen MCF-7-EMT näher betrachtet werden, da auch bei diesen Zellen Invasionsanalysen vorgenommen wurden (siehe 3.2.3). Die ermittelte Zellzahl für den Zeitpunkt $t_{120 h}$ zeigte sich hierbei 
in der Gruppe der Zellen mit reduzierter ARHGAP29-Genexpression signifikant erhöht, verglichen mit der unspezifisch transfizierten Kontrollgruppe (159,5 Zellen \pm 15,78 SEM in \% vs. „Kontrolle“; $p=0,0054 ; n=5$; siehe Abbildung 15; Kolb et al. 2020).

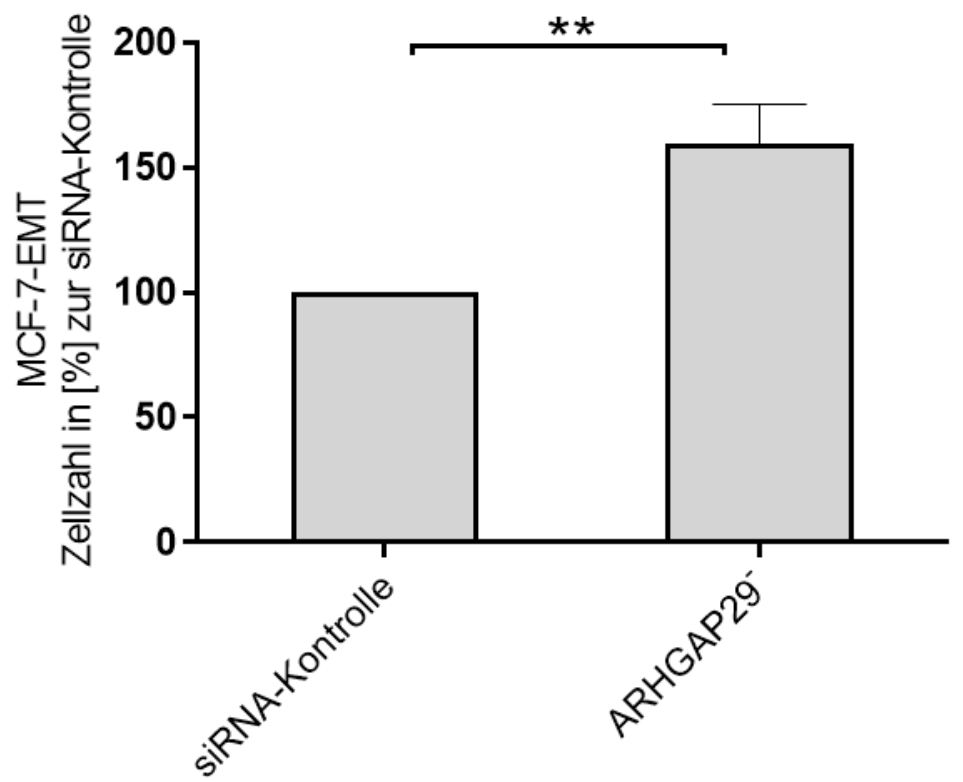

Abbildung 15: Nachweis der signifikant gesteigerten Proliferation der Mammakarzinomzelllinie MCF-7-EMT nach erfolgter siRNA-Transfektion (Kolb et al. 2020). Proliferationsanalyse von transient transfizierten Mammakarzinomzellen der Linie MCF-7-EMT nach 120 Stunden, wie in Kolb et al. (2020). In der Behandlungsgruppe (,ARHGAP29-““) erfolgte die transiente Transfektion der Mammakarzinomzellinie mit ARHGAP29-spezifischer siRNA und in der Kontrollgruppe (,siRNAKontrolle") mit unspezifischer siRNA. Nach der Kultivierung für 120 Stunden wurden die adhärenten transient transfizierten Mammakarzinomzellen gelöst und mithilfe der Neubauer-Zählkammer ausgezählt. Es wurden mindestens biologische und technische Triplikate verwendet. Angegeben sind MW \pm SEM, Signifikanzen wurden mithilfe ungepaarter t-Tests ermittelt; $\left({ }^{* *}\right) p<0,01$. Diese Abbildung wurde selbstständig erstellt, aber repräsentiert eine in der Formatierung modifizierte und übersetzte Version des Teils A der Abbildung 3 von Kolb et al. (2020) mit dem Titel „Effect of the downregulation of Rho GTPase activating protein 29 (ARHGAP29) on the proliferation of MCF-7EMT (A), T-47D-EMT (B), and HCC1806 (C) breast cancer cells."; Legende teilweise übereinstimmend mit einer Übersetzung der Legende zur entsprechenden Abbildung in Kolb et al. (2020), https://www.mdpi.com/2073-4409/9/12/2616/htm; Lizenz CC BY 4.0 (https://creativecommons.org/licenses/by/4.0/). 


\subsubsection{Einfluss einer reduzierten ARHGAP29-Expression auf die Proliferation der mesenchymal transformierten T-47D-EMT-Mammakarzinomzellen}

Wie unter 3.2.4 und in Kolb et al. (2020) beschrieben, wurden T-47D-EMTMammakarzinomzellen in ihrer Invasionsfähigkeit durch die verringerte ARHGAP29-Expression signifikant beeinflusst. Zusätzlich wurden diese ebenfalls einer Proliferationsanalyse unterzogen. Für 120 Stunden nach erfolgte Transfektion wurde ein Trend zur erhöhten Proliferation bei reduzierter ARHGAP29-mRNA-Expression verglichen mit der Kontrolle gefunden, jedoch war dieser Unterschied nicht signifikant (126,3 Zellen $\pm 20,35$ SEM in \% vs. „Kontrolle“; $p=0,2315 ; n=5$; siehe Abbildung 16; Kolb et al. 2020).

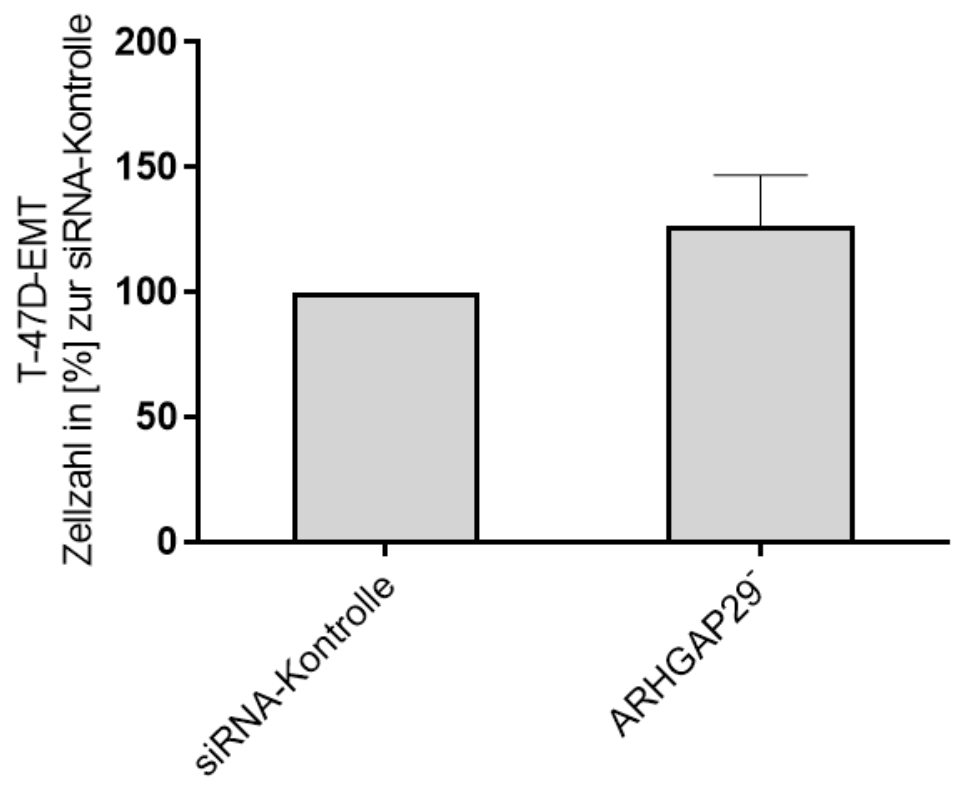

Abbildung 16: Nachweis der nicht signifikant veränderten Proliferation der Mammakarzinomzelllinie T-47D-EMT nach erfolgter siRNA-Transfektion (Kolb et al. 2020). Proliferationsanalyse von transient transfizierten Mammakarzinomzellen der Linie T-47D-EMT nach 120 Stunden, wie in Kolb et al. (2020). In der Behandlungsgruppe („ARHGAP29-“) erfolgte die transiente Transfektion der Mammakarzinomzelllinie mit ARHGAP29-spezifischer siRNA und in der Kontrollgruppe (,siRNAKontrolle“) mit unspezifischer siRNA. Nach der Kultivierung für 120 Stunden wurden die adhärenten transient transfizierten Mammakarzinomzellen gelöst und mithilfe der Neubauer-Zählkammer ausgezählt. Es konnte kein signifikanter Unterschied bezüglich der Proliferation zwischen der Kontroll- und der Behandlungsgruppe gezeigt werden. Es wurden mindestens biologische und technische Triplikate verwendet. Angegeben sind MW \pm SEM, Signifikanzen wurden mithilfe ungepaarter t-Tests ermittelt. Diese Abbildung wurde selbstständig erstellt, aber repräsentiert eine in der Formatierung modifizierte und übersetzte Version des Teils B der Abbildung 3 von Kolb et al. (2020) 
mit dem Titel "Effect of the downregulation of Rho GTPase activating protein 29 (ARHGAP29) on the proliferation of MCF-7-EMT (A), T-47D-EMT (B), and HCC1806 (C) breast cancer cells."; Legende teilweise übereinstimmend mit einer Übersetzung der Legende zur entsprechenden Abbildung in Kolb et al. (2020), https://www.mdpi.com/2073-4409/9/12/2616/htm; Lizenz CC BY 4.0 (https://creativecommons.org/licenses/by/4.0/).

\subsection{Proteinexpression von ARHGAP29 und AKT1 in Mammakarzinomzelllinien}

\subsubsection{Analyse möglicher Interaktionspartner von ARHGAP29}

Es ist bekannt, dass ARHGAP29 eine Spezifität für Rho der Familie der Rho GTPasen (Saras et al. 1997) und damit für einen der „Hauptregulatoren des Aktinzytoskeletts“ (Post et al. 2015) besitzt und die Rho(A)-Signalkaskade hemmt (Xu et al. 2011; Post et al. 2013). Gleichzeitig wird eine aktivitätsverringernde Wirkung auf Rho von einem anderen Protein, genannt AKT1, über einen Zwischenschritt vermutet (Liu et al. 2006). Inwiefern sich ARHGAP29 und AKT1 in ihrer Wirkung auf die Rho-Signalkaskade überschneiden oder welchen Einfluss sie aufeinander besitzen, bleibt jedoch ungeklärt. Inspiriert durch diese Überlegungen wurde AKT1 als weiteres Zielprotein neben ARHGAP29 für Proteinexpressionsanalysen zum Vergleich von Mammakarzinomzellen mit verminderter und regelrechter ARHGAP29-Expression und zur Untersuchung einer möglichen Signalkaskade um ARHGAP29 ausgewählt. Die Auswahl wurde dabei aus einer Reihe von möglichen Interaktionspartnern getroffen, die mithilfe von In-silico-Analysen auf dem GIANT-Webserver (https://hb.flatironinstitute.org/) durchgeführt wurden (siehe 2.2.4; Kolb et al. 2020). Diese zeigte neben MAGEA11 (Interaktionswahrscheinlichkeit 0,4974), RHOD (Interaktionswahrscheinlichkeit 0,2368), CDC42 und PTPN13 (für beide Interaktionswahrscheinlichkeit 0,2358) und SIRT1 (Interaktionswahrscheinlichkeit 0,1336) die Serin-/Threoninkinase AKT1 als möglichen Interaktionspartner mit ARHGAP29 (Wahrscheinlichkeit der Interaktion 0,2358)2, siehe Abbildung 17, (Kolb et al. 2020). Es wurde die ARHGAP29- und AKT1-Proteinexpression in einer Kontrollgruppe so-

\footnotetext{
2 Verwendung der hier aufgeführten Daten des Flatiron Institutes zur Analyse „Tissue-specific interactions" von ARHGAP29 im Brustdrüsengeweben (https://hb.flatironinstitute.org/gene/9411) mit dem minimalen Konfidenzintervall 0,1 und sieben betrachteten Genen mit der Lizenz CC BY 4.0 (https://creativecommons.org/licenses/by/4.0/).
} 
wie in transient mit ARHGAP29-spezifischer siRNA transfizierten Mammakarzinomzellen zum Zeitpunkt t120h untersucht. Die zugehörigen Ergebnisse sind im Folgenden beschrieben.

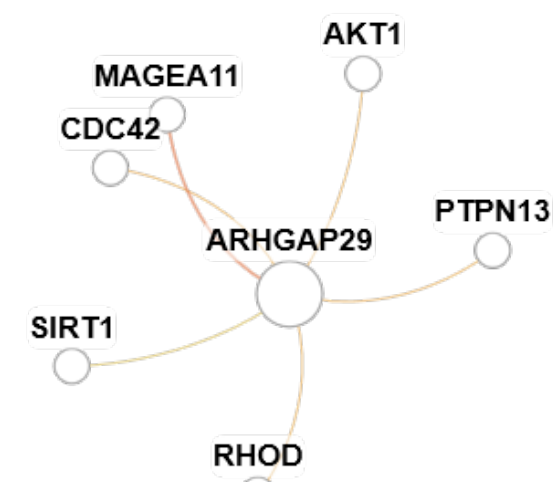

0.0

0.5 1.0

Abbildung 17: Darstellung der Interaktionswahrscheinlichkeit zwischen ARHGAP29 und einer Auswahl von Genen im menschlichen Brustdrüsengewebe (Kolb et al. 2020). Graphik als Ergebnis der Analyse unter https://hb.flatironinstitute.org/gene/9411. Interaktionswahrscheinlichkeit von ARHGAP29 mit AKT1, SIRT1, PTPN13, CDC42, MAGEA11 und RHOD im Brustdrüsengewebe. In-silico-Analysen wurden mithilfe des GIANT-Webservers (bereitgestellt von HumanBase, https://hb.flatironinstitute.org/, abgerufen am 26.07.2019) durchgeführt. Als minimales Konfidenzintervall der Interaktion wurde 0,1 gewählt. Die maximale Anzahl der betrachteten Gene betrug sieben. Die Farbe der Verbindungslinien zwischen den Interaktionspartnern spiegelt die mögliche Interaktion wider, entsprechend einem Farbverlauf von grün (keine Interaktion; 0), über orange (mittlere Interaktionswahrscheinlichkeit von ca. 0,5) bis zu rot (hohe Interaktionswahrscheinlichkeit von 1). Graphik des Flatiron Institute als Ergebnis der Analyse zu "Tissue-specific interactions" von ARHGAP29 im Brustdrüsengewebe unter https://hb.flatironinstitute.org/gene/9411 und den oben aufgeführten Angaben; Lizenz CC BY 4.0 (https://creativecommons.org/licenses/by/4.0/). Legende in Teilen entsprechend der deutschen Übersetzung jener Legende zu Abbildung 4A „Probability of interaction of Rho GTPase activating protein 29 (ARHGAP29) with AKT1, SIRT1, PTPN13, CDC42, MAGEA11, and RHOD“ von Kolb et al. (2020), https://www.mdpi.com/20734409/9/12/2616/htm; Lizenz CC BY 4.0 (https://creativecommons.org/licenses/by/4.0/). 
3.4.2 Proteinexpression von ARHGAP29 und AKT1 in der Mammakarzinomzelllinie MDA-MB-231 nach dem knockdown von ARHGAP29

Bei der dreifach-negativen Zelllinie MDA-MB-231 (Neve et al. 2006; Prat et al. 2010) konnte auf RNA-Ebene eine signifikante Verminderung der ARHGAP29-Expression zum Zeitpunkt $\mathrm{t}_{120 \mathrm{~h}}$ nach erfolgter Transfektion nachgewiesen werden (siehe 3.1.2.2). Dies konnte auch auf Proteinebene bestätigt werden. So wurde 120 Stunden nach erfolgter transienter Transfektion eine signifikant verminderte $A R H-$ GAP29-Expression in der Population mit verminderter ARHGAP29-Expression erkennbar $(43,67 \pm 18,48$ SEM relative Expression ARHGAP29/GAPDH in \% vs. „Kontrolle“; $p=0,0381 ; n=3$; siehe Abbildung 18). Es fiel außerdem auf, dass MDA-MB-231-Mammakarzinomzellen mit verminderter ARHGAP29-Expression ebenfalls eine signifikant reduzierte AKT1-Expression aufwiesen (73 \pm 6,928 SEM relative Expression AKT1/GAPDH in \% vs. „Kontrolle“; $p=0,0176 ; n=3$; siehe Abbildung 18). 
A

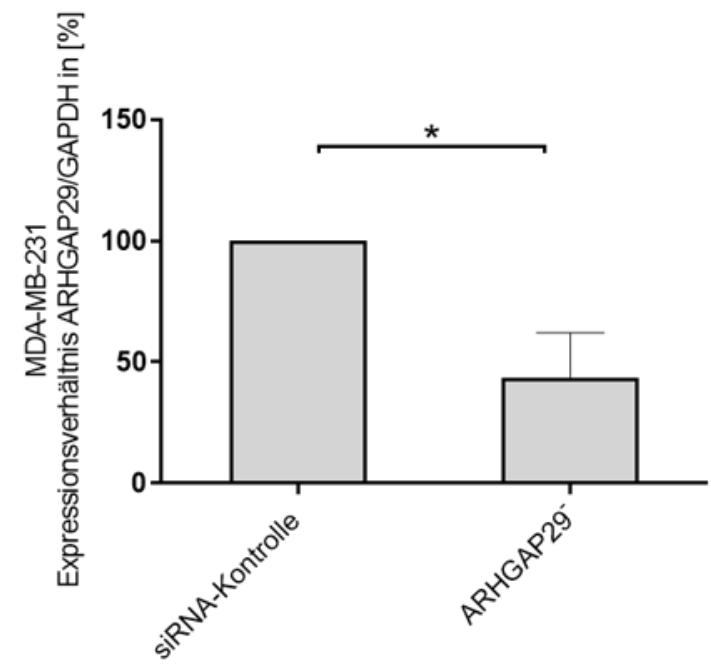

C

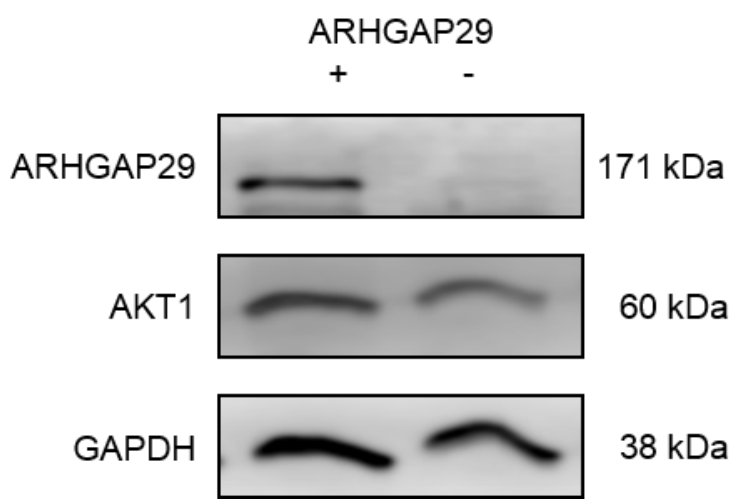

Abbildung 18: Nachweis der signifikant verminderten Expression von ARHGAP29 und AKT1 nach erfolgter transienter siRNA-Transfektion der Mammakarzinomzelllinie MDA-MD-231.

A: Proteinexpression von ARHGAP29 in der Mammakarzinomzellinie MDA-MD-231. Die Expression von ARHGAP29 auf Proteinebene wurde mithilfe des Western-Blot-Verfahren bestimmt und auf die GAPDH-Expression normiert. In der Behandlungsgruppe („ARHGAP29-“) erfolgte die transiente Transfektion der Mammakarzinomzelllinie MDA-MB-231 mit ARHGAP29-spezifischer siRNA und in der Kontrollgruppe („siRNA-Kontrolle“) mit unspezifischer siRNA.

B: Proteinexpression von AKT1 in der Mammakarzinomzelllinie MDA-MD-231. Die Expression von AKT1 auf Proteinebene wurde mithilfe des Western-Blot-Verfahren bestimmt und auf die GAPDHExpression normiert. In der Behandlungsgruppe („ARHGAP29-“) erfolgte die transiente Transfektion der Mammakarzinomzelllinie MDA-MB-231 mit ARHGAP29-spezifischer siRNA und in der Kontrollgruppe („siRNA-Kontrolle“) mit unspezifischer siRNA.

C: Repräsentative Western-Blot-Ausschnitte zu A und B. „ARHGAP29 +“ bezeichnet die mit unspezifischer siRNA behandelte Kontrollgruppe und „ARHGAP29 -" die mit ARHGAP29 spezifischer siRNA transfizierte Behandlungsgruppe. 
Es wurden mindestens biologische und technische Triplikate verwendet. Angegeben sind MW \pm SEM, Signifikanzen wurden mithilfe ungepaarter t-Tests ermittelt; $\left(^{*}\right) p<0,05$.

\subsubsection{Proteinexpression von ARHGAP29 und AKT1 in der Mammakarzinomzelllinie HCC1806 nach dem knockdown von ARHGAP29}

Auch die dreifach-negative Mammakarzinomzelllinie HCC1806 (Gazdar et al. 1998) wurde 120 Stunden nach transienter Transfektion hinsichtlich der ARHGAP29- und AKT1-Expression auf Proteinebene untersucht. Das Ergebnis bestätigte auf Proteinebene die signifikante Herunterregulierung von ARHGAP29 in den spezifisch gegen ARHGAP29 transfizierten Tumorzellen (40,80 \pm 10,19 SEM relative Expression ARHGAP29/GAPDH in \% vs. „Kontrolle“; $p=0,0004 ; n=5$; siehe Abbildung 19; Kolb et al. 2020), wie auch zuvor auf mRNA-Ebene (siehe 3.1.2.3; Kolb et al. 2020). Abbildung 19 zeigt die ebenfalls signifikant verminderte AKT1-Expression in der Gruppe mit reduzierter ARHGAP29-Expression, welche im Rahmen der Proteinexpressionsanalyse deutlich wurde $(45,25 \pm 6,613$ SEM relative Expression AKT1/GAPDH in \% vs. „Kontrolle“; $p=0,0002 ; n=4$; siehe Abbildung 19; Kolb et al. 2020). 
A

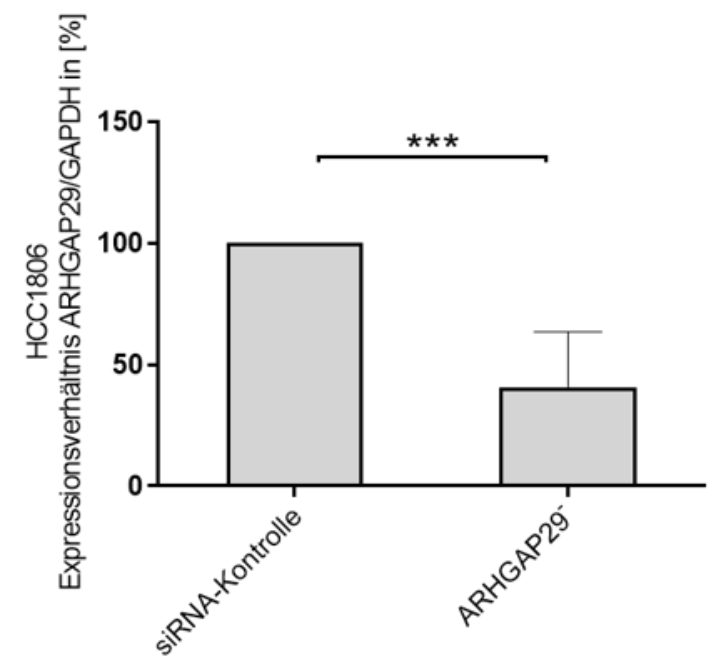

C

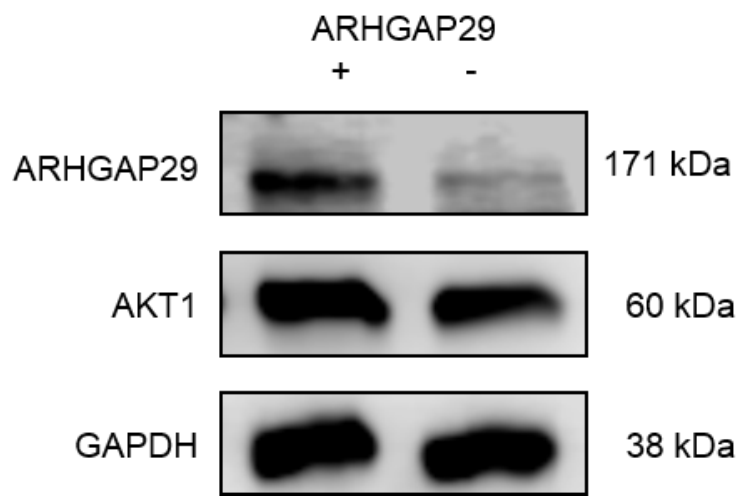

B

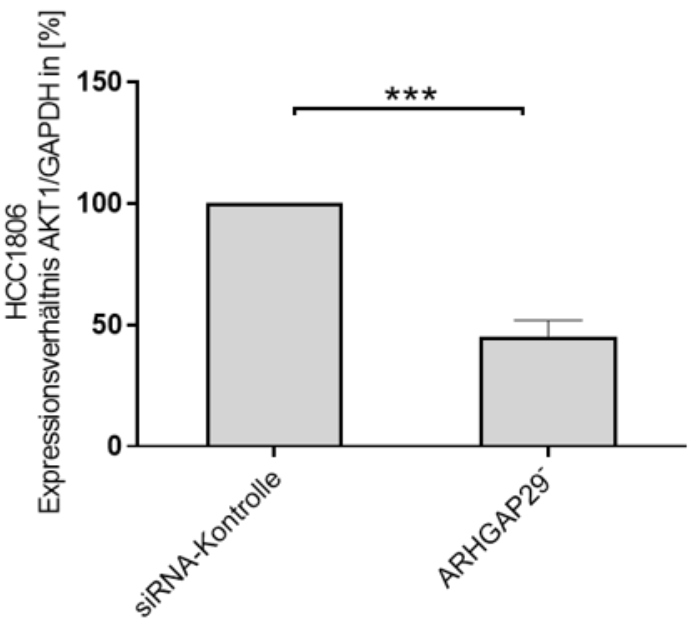

Abbildung 19: Nachweis der signifikant verminderten Expression von ARHGAP29 und AKT1 nach erfolgter transienter siRNA-Transfektion der Mammakarzinomzellinie HCC1806 (Kolb et al. 2020). A: Proteinexpression von ARHGAP29 in der Mammakarzinomzellinie HCC1806. Die Expression von ARHGAP29 auf Proteinebene wurde mithilfe des Western-Blot-Verfahren bestimmt und auf die GAPDH-Expression normiert. In der Behandlungsgruppe („ARHGAP29-“) erfolgte die transiente Transfektion der Mammakarzinomzelllinie HCC1806 mit ARHGAP29-spezifischer siRNA und in der Kontrollgruppe („siRNA-Kontrolle“) mit unspezifischer siRNA.

B: Proteinexpression von AKT1 in der Mammakarzinomzelllinie HCC1806 (Kolb et al. 2020). Die Expression von AKT1 auf Proteinebene wurde mithilfe des Western-Blot-Verfahren bestimmt und auf die GAPDH-Expression normiert. In der Behandlungsgruppe („ARHGAP29-“) erfolgte die transiente Transfektion der Mammakarzinomzelllinie HCC1806 mit ARHGAP29-spezifischer siRNA und in der Kontrollgruppe („siRNA-Kontrolle“) mit unspezifischer siRNA. Diese Abbildung wurde selbstständig erstellt, aber entspricht einem in Format und Beschriftung modifizierten Ausschnitt der Abbildung 4D von Kolb et al. (2020), https://www.mdpi.com/2073-4409/9/12/2616/htm; Lizenz CC BY 4.0 (https://creativecommons.org/licenses/by/4.0/). 
C: Repräsentative Western-Blot-Ausschnitte zu A und B (Kolb et al. 2020). „ARHGAP29 +" bezeichnet die mit unspezifischer siRNA behandelte Kontrollgruppe und „ARHGAP29 -“ die mit ARHGAP29 spezifischer siRNA transfizierte Behandlungsgruppe. Diese Abbildung wurde selbstständig erstellt, aber entspricht teilweise einem im Format modifizierten Ausschnitt der Abbildung 4D von Kolb et al. (2020), https://www.mdpi.com/2073-4409/9/12/2616/htm; Lizenz CC BY 4.0 (https://creativecommons.org/licenses/by/4.0/).

Es wurden mindestens biologische und technische Triplikate verwendet. Angegeben sind MW \pm SEM, Signifikanzen wurden mithilfe ungepaarter t-Tests ermittelt; $\left.{ }^{* \star *}\right) p<0,001$. Legende in Teilen entsprechend einer deutschen Übersetzung der Legende zu Abbildung 4D von Kolb et al. (2020), https://www.mdpi.com/2073-4409/9/12/2616/htm; Lizenz CC BY 4.0 (https://creativecommons.org/licenses/by/4.0/).

\subsubsection{Proteinexpression von ARHGAP29 und AKT1 in der Mammakarzinomzelllinie MCF-7-EMT nach dem knockdown von ARHGAP29}

Im Rahmen der Genexpressionsanalyse ließ sich, wie unter 3.1.2.4 beschrieben, bei der Mammakarzinomzelllinie MCF-7-EMT eine signifikante Reduzierung der ARHGAP29-mRNA-Expression 120 Stunden nach erfolgter Transfektion zeigen (Kolb et al. 2020). Auf Proteinebene wurde im Vergleich zur unspezifisch transfizierten Kontrollgruppe zwar kein signifikanter Effekt, aber ein Trend zu verringerter ARHGAP29-Expression in den knockdown-Zellen erkennbar $(63,67 \pm 16,23$ SEM relative Expression ARHGAP29/GAPDH in \% vs. „Kontrolle“; $p=0,0888 ; n=3$; siehe Abbildung 20; Kolb et al. 2020). Nach Behandlung der MCF-7-EMT mit gegen ARHGAP29 gerichteter siRNA war die AKT1-Expression zum Zeitpunkt t120h $_{\text {signifikant }}$ verringert gegenüber den mit unspezifischer Kontroll-siRNA behandelten Zellen (89,5 \pm 2,062 SEM relative Expression AKT1/GAPDH in \% vs. „Kontrolle“; $p=0,0022 ; n=4 ;$ siehe Abbildung 20; Kolb et al. 2020). 
A

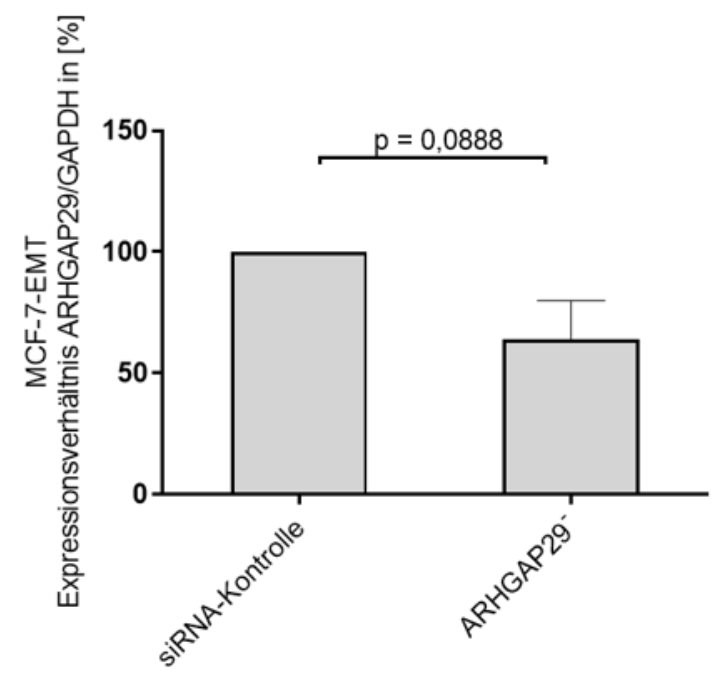

C
B

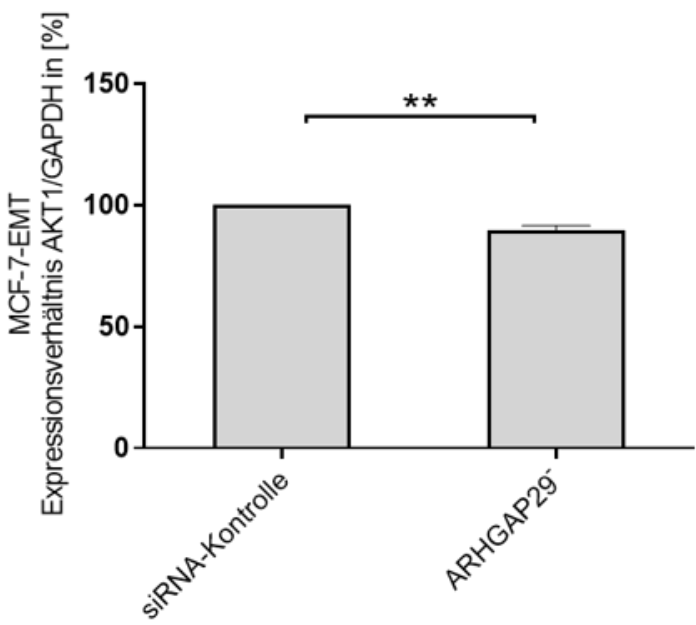

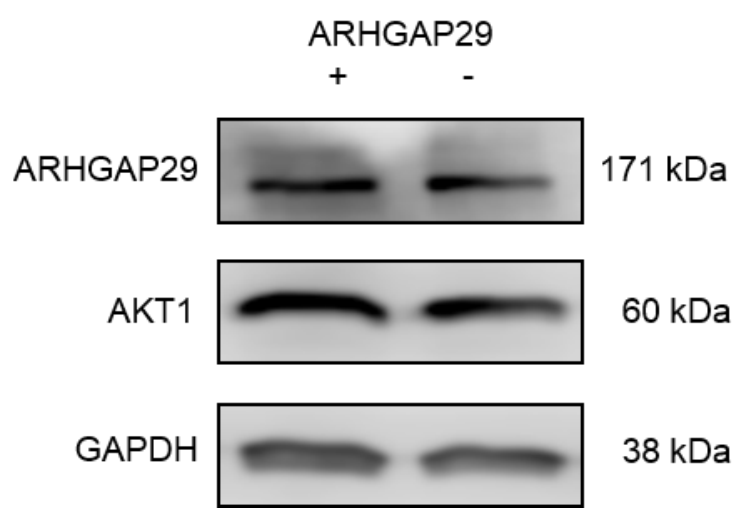

Abbildung 20: Nachweis der verminderten Expression von ARHGAP29 und AKT1 nach erfolgter transienter siRNA-Transfektion der Mammakarzinomzelllinie MCF-7-EMT (Kolb et al. 2020).

A: Proteinexpression von ARHGAP29 in der Mammakarzinomzelllinie MCF-7-EMT. Die Expression von ARHGAP29 auf Proteinebene wurde mithilfe des Western-Blot-Verfahren bestimmt und auf die GAPDH-Expression normiert. In der Behandlungsgruppe („ARHGAP29-“) erfolgte die transiente Transfektion der Mammakarzinomzelllinie MCF-7-EMT mit ARHGAP29-spezifischer siRNA und in der Kontrollgruppe („siRNA-Kontrolle“) mit unspezifischer siRNA.

B: Proteinexpression von AKT1 in der Mammakarzinomzellinie MCF-7-EMT (Kolb et al. 2020). Die Expression von AKT1 auf Proteinebene wurde mithilfe des Western-Blot-Verfahren bestimmt und auf die GAPDH-Expression normiert. In der Behandlungsgruppe („ARHGAP29-“) erfolgte die transiente Transfektion der Mammakarzinomzelllinie MCF-7-EMT mit ARHGAP29-spezifischer siRNA und in der Kontrollgruppe („siRNA-Kontrolle“) mit unspezifischer siRNA. Diese Abbildung wurde selbstständig erstellt, aber entspricht einem in Format und Beschriftung modifizierten Ausschnitt der Abbildung 4B von Kolb et al. (2020), https://www.mdpi.com/2073-4409/9/12/2616/htm; Lizenz CC BY 4.0 (https://creativecommons.org/licenses/by/4.0/). 
C: Repräsentative Western-Blot-Ausschnitte zu A und B (Kolb et al. 2020). „ARHGAP29 +“ bezeichnet die mit unspezifischer siRNA behandelte Kontrollgruppe und „ARHGAP29 -" die mit ARHGAP29 spezifischer siRNA transfizierte Behandlungsgruppe. Diese Abbildung wurde selbstständig erstellt, aber entspricht teilweise einem im Format modifizierten Ausschnitt der Abbildung 4B von Kolb et al. (2020), https://www.mdpi.com/2073-4409/9/12/2616/htm; Lizenz CC BY 4.0 (https://creativecommons.org/licenses/by/4.0/).

Es wurden mindestens biologische und technische Triplikate verwendet. Angegeben sind $M W \pm$ SEM, Signifikanzen wurden mithilfe ungepaarter t-Tests ermittelt; $\left({ }^{* *}\right) p<0,01$. Legende in Teilen entsprechend einer deutschen Übersetzung der Legende zu Abbildung 4B von Kolb et al. (2020), https://www.mdpi.com/2073-4409/9/12/2616/htm; Lizenz CC BY 4.0 (https://creativecommons.org/licenses/by/4.0/).

\subsubsection{Proteinexpression von ARHGAP29 und AKT1 in der Mammakarzinomzelllinie T-47D-EMT nach dem knockdown von ARHGAP29}

Wie in Abbildung 21 dargestellt, ließen sich auch in den nach Guttilla et al. (2012) und Ziegler et al. (2014) mesenchymal transformierten T-47D-EMT-Zellen zum Zeitpunkt $t_{120}$ nach erfolgter Transfektion eine signifikant verminderte ARHGAP29-Expression auf Proteinebene zeigen (58,5 \pm 9,403 SEM relative Expression ARHGAP29/GAPDH in \% vs. „Kontrolle“; $p=0,0045 ; n=4$; siehe Abbildung 21; Kolb et al. 2020), wie auch bereits auf RNA-Ebene (siehe 3.1.2.5; Kolb et al. 2020). Außerdem wurde eine signifikant reduzierte AKT1-Expression in der Zelllinie T-47D-EMT nach Verringerung der ARHGAP29-Expression mittels transienter Transfektion im Vergleich zur Kontrolle erkennbar (43,33 \pm 15,62 SEM relative Expression AKT1/GAPDH in \% vs. „Kontrolle“; $p=0,0222 ; n=3$; siehe Abbildung 21; Kolb et al. 2020). 
A

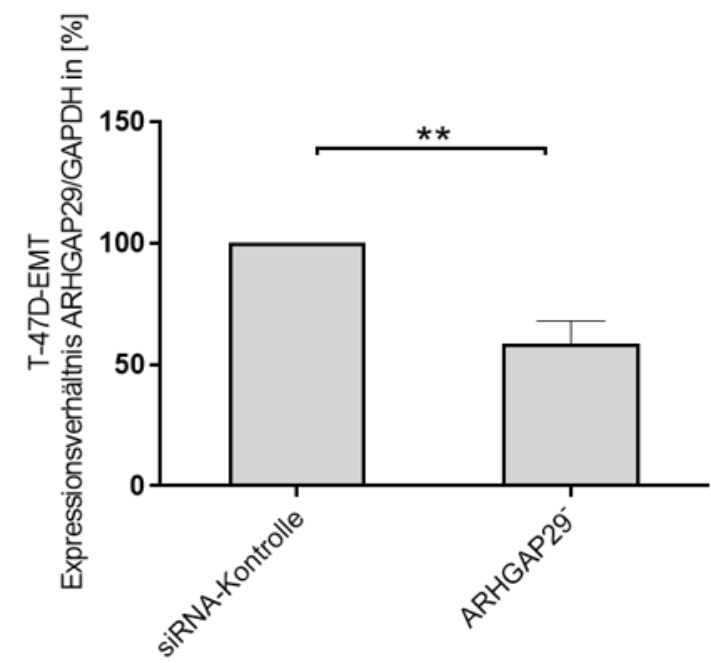

C

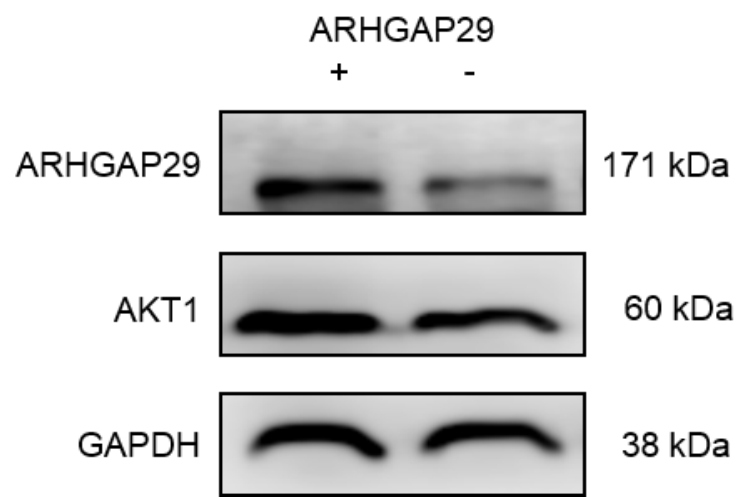

B

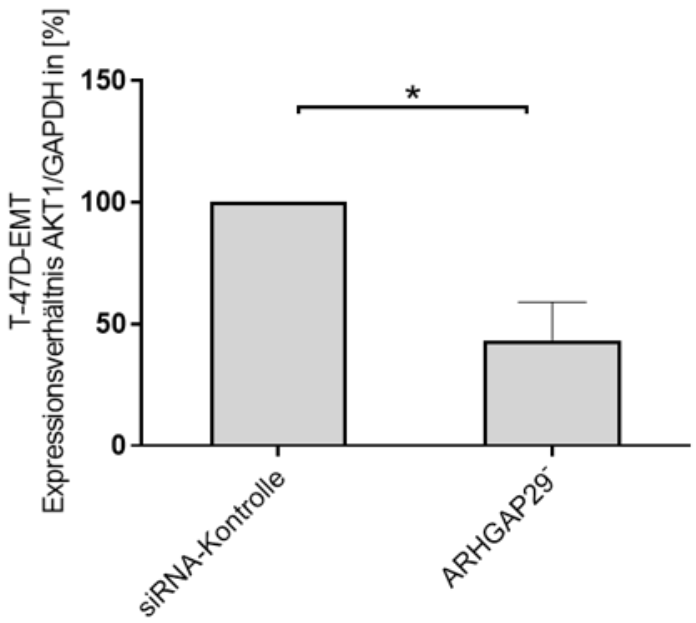

Abbildung 21: Nachweis der signifikant verminderten Expression von ARHGAP29 und AKT1 nach erfolgter transienter siRNA-Transfektion der Mammakarzinomzellinie T-47D-EMT (Kolb et al. 2020).

A: Proteinexpression von ARHGAP29 in der Mammakarzinomzellinie T-47D-EMT. Die Expression von ARHGAP29 auf Proteinebene wurde mithilfe des Western-Blot-Verfahren bestimmt und auf die GAPDH-Expression normiert. In der Behandlungsgruppe („ARHGAP29-“) erfolgte die transiente Transfektion der Mammakarzinomzelllinie T-47D-EMT mit ARHGAP29-spezifischer siRNA und in der Kontrollgruppe („siRNA-Kontrolle“) mit unspezifischer siRNA.

B: Proteinexpression von AKT1 in der Mammakarzinomzellinie T-47D-EMT (Kolb et al. 2020). Die Expression von AKT1 auf Proteinebene wurde mithilfe des Western-Blot-Verfahren bestimmt und auf die GAPDH-Expression normiert. In der Behandlungsgruppe („ARHGAP29-“) erfolgte die transiente Transfektion der Mammakarzinomzellinie T-47D-EMT mit ARHGAP29-spezifischer siRNA und in der Kontrollgruppe („siRNA-Kontrolle“) mit unspezifischer siRNA. Diese Abbildung wurde selbstständig erstellt, aber entspricht einem in Format und Beschriftung modifizierten Ausschnitt der Abbildung 4C von Kolb et al. (2020), https://www.mdpi.com/2073-4409/9/12/2616/htm; Lizenz 
CC BY 4.0 (https://creativecommons.org/licenses/by/4.0/).

C: Repräsentative Western-Blot-Ausschnitte zu A und B (Kolb et al. 2020). „ARHGAP29 + “ bezeichnet die mit unspezifischer siRNA behandelte Kontrollgruppe und „ARHGAP29 -" die mit ARHGAP29 spezifischer siRNA transfizierte Behandlungsgruppe. Diese Abbildung wurde selbstständig erstellt, aber entspricht teilweise einem im Format modifizierten Ausschnitt der Abbildung $4 \mathrm{C}$ von Kolb et al. (2020), https://www.mdpi.com/2073-4409/9/12/2616/htm; Lizenz CC BY 4.0 (https://creativecommons.org/licenses/by/4.0/).

Es wurden mindestens biologische und technische Triplikate verwendet. Angegeben sind $M W \pm$ SEM, Signifikanzen wurden mithilfe ungepaarter t-Tests ermittelt; $\left(^{*}\right) p<0,05,\left(^{* *}\right) p<0,01$. Legende in Teilen entsprechend einer deutschen Übersetzung der Legende zu Abbildung $4 \mathrm{C}$ von Kolb et al. (2020), https://www.mdpi.com/2073-4409/9/12/2616/htm; Lizenz CC BY 4.0 (https://creativecommons.org/licenses/by/4.0/). 


\section{Diskussion}

ARHGAP29 ist ein Rho GTPase aktivierendes Protein, das 1997 erstmals entdeckt wurde und eine supprimierende Wirkung mit einer Spezifität für RhoA gegenüber Rac und CDC42 besitzt (Saras et al. 1997; Xu et al. 2011; Qiao et al. 2017). ARHGAP29 nimmt über die Regulation von RhoA nicht nur Einfluss auf Zell-Matrix-Adhäsionen und die Polarität von endothelialen Zellen (Xu et al. 2011), sondern spielt auch eine Rolle in der Migration diverser benigner und maligner Zellen (Biggs et al. 2014; Miyazaki et al. 2017; Tagashira et al. 2018). ARHGAP29 erwies sich außerdem als einflussreich auf die Invasion und Metastasierung von Karzinomen (Miyazaki et al. 2017; Qiao et al. 2017). In diesem Zusammenhang ist YAP als transkriptioneller Koaktivator von ARHGAP29 bekannt (Qiao et al. 2017). YAP selbst ist als proinvasiver Faktor von aggressiven und mesenchymal transformierten Mammkarzinomzellen beschrieben (Hellinger et al. 2019). Zwar ist ARHGAP29 in diversen, invasiven Mammakarzinomzellinien (siehe Abbildung 4 unter 3.1.2; Kolb et al. 2020) und als einziges von 32 in Microarrays (Ziegler 2013; Ziegler et al. 2014) betrachteten Rho GTPase aktivierenden Enzymen nach epithelialer-mesenchymaler Transformation von MCF-7 erhöht exprimiert (siehe Abbildung 2 unter 3.1.1, Kolb et al. 2020), doch wurde die Rolle, die das Protein im Prozess der Invasion des Mammakarzinoms einnimmt, bisher nicht untersucht. Daher sollte im Rahmen dieser Arbeit der Einfluss von ARHGAP29 auf die Invasivität von vier Mammakarzinomzelllinien (MDA-MB-231, HCC1806, MCF-7-EMT, T-47D-EMT) untersucht werden. Die verwendeten MCF-7-EMT- und T-47D-EMT-Zellen wurde zwar nicht wie die den beschriebenen Microarrays zugrundeliegenden MCF-7-EMT-Zellen durch wiederholte Kokultivierung gewonnen, sondern durch Mammosphärenkultivierung nach Guttilla et al. (2012) und Ziegler et al. (2014), doch beschreiben Ziegler et al. (2014) selbst, dass Versuche mit den Zellen aus Mammosphärenkultivierung vergleichbare Ergebnisse hervorbrachten wie jene aus Kokultivierung. Daher sind beide Methoden zur mesenchymalen Transformation als gleichwertig und damit die daraus generierten Zellen als äquivalent einsetzbar anzusehen. Im Zuge der Experimente wurde die ARHGAP29-Expression in den genannten Mammakarzinomzelllinien mithilfe von siRNA-knockdowns für die Dauer der Experimente transient reduziert und die Effizienz dessen mithilfe von Gen- und Proteinexpressionsanalysen nachgewiesen. Mit den transient mit ARHGAP29-spezifischer siRNA oder Kontroll- 
siRNA transfizierten Mammakarzinomzellen erfolgten 2D-Invasionsassays in Kokultur mit Osteosarkomzellen sowie Proliferationsanalysen. Des Weiteren wurde die Signalkaskade um ARHGAP29 näher untersucht, indem die mögliche Interaktion mit AKT1 im Rahmen von Western Blots nach dem knockdown von ARHGAP29 analysiert wurde. Im Folgenden sollen die wie zuvor unter Punkt 3 vorgestellten Ergebnisse diskutiert werden.

\subsection{Einfluss des knockdowns auf die ARHGAP29-Expression von Mammakarzinomzellen}

Zur transienten Verminderung der ARHGAP29-Expression für die nachfolgenden Versuche wurden die Mammakarzinomzellen einem knockdown mit ARHGAP29spezifischer siRNA bzw. einer Kontroll-siRNA unterzogen (siehe 2.2.2.1). Die Bestätigung der Effizienz des knockdowns und der anhaltenden verminderten ARHGAP29-Expression zum experimentell relevanten Zeitpunkt (120 Stunden nach erfolgter Transfektion) erfolgte mithilfe quantitativer real-time-PCR (siehe 2.2.2.4) auf mRNA-Ebene und mittels Western Blots (siehe 2.2.3) auf Proteinebene. Sowohl die Analyse der Genexpression als auch die Proteinexpressionsanalyse zeigten signifikant verminderte ARHGAP29-Expressionen, verglichen mit der Kontrollgruppe (siehe 3.1.2 und 3.4, Kolb et al. 2020). Einzig in der Proteinexpressionsanalyse der ARHGAP29-Expression der Zelllinie MCF-7-EMT ließ sich nur ein Trend erkennen, doch auf mRNA-Ebene zeigte sich ebenfalls eine signifikante Reduktion der ARHGAP29-Expression für diese Zellinie (Kolb et al. 2020). Die nachgewiesene Verminderung der ARHGAP29-Expression durch den knockdown stellt die Grundlage zur Bewertung der weiteren Ergebnisse dar.

\subsection{Einfluss der verminderten ARHGAP29-Expression auf die Invasivität von Mammakarzinomzellen}

Vier Mammakarzinomzelllinien wurden unter transient reduzierter ARHGAP29-Expression hinsichtlich ihrer Invasionsfähigkeiten untersucht, darunter zwei Zelllinien, die aufgrund der fehlenden Expression von Progesteron- und Östrogenrezeptoren und der nicht vorhandenen HER2/neu-Überexpression als dreifach negativ bezeichnet werden - MDA-MB-231, HCC1806 - (Gazdar et al. 1998; Neve et al. 2006; Prat 
et al. 2010) und zwei nach Guttilla et al. (2012) und Ziegler et al. (2014) mesenchymal transformierte Zelllinien - MCF-7-EMT, T-47D-EMT. Da bereits eine erhöhte Expression von ARHGAP29 für jede der verwendeten vier Zelllinien demonstriert werden konnte (siehe 3.1.2.1; Kolb et al. 2020) und mehrere Publikationen vorliegen, die auch für die gleichen Zellinien eine verstärkte Invasivität in 2D-Invasionassays und Kokultur mit Osteosarkomzellen oder menschlichen Osteoblasten zeigen konnten (Ziegler et al. 2014; Gründker et al. 2016; Hellinger et al. 2019), galt als Hypothese in dieser Arbeit, dass eine verminderte ARHGAP29-Expression eine verminderte Invasivität der Mammakarzinomzellen mit sich bringen würde. Es zeigte sich ein signifikanter, doch zum Teil überraschender Einfluss von ARHGAP29 auf die Invasivität der Mammakarzinomzellen.

\subsubsection{Einfluss der verminderten ARHGAP29-Expression auf die Invasivität der Mammakarzinomzelllinien HCC1806, MCF-7-EMT und T-47D-EMT}

Wie bereits beschrieben, nimmt ARHGAP29 nachgewiesenermaßen Einfluss auf die Invasion und Metastasierung maligner Tumorzellen (Miyazaki et al. 2017; Qiao et al. 2017). Außerdem ist ARHGAP29 erhöht exprimiert in invasiven Mammakarzinomzellen (siehe 3.1.2.1; Kolb et al. 2020) und sein transkriptioneller Koaktivator YAP (Qiao et al. 2017) fördert die Invasion von Mammakarzinomzellen (Hellinger et al. 2019). Die Rolle von ARHGAP29 im Invasionsprozess von Mammakarzinomzellen wurde bisher jedoch nicht untersucht. In 2D-Invasionsassys von Mammakarzinomzellen ging die Herunterregulierung der ARHGAP29-Expression in drei der vier Mammakarzinomzelllinien (HCC1806, MCF-7-EMT, T-47D-EMT) mit einer signifikant eingeschränkten Invasivität einher (siehe 3.2.2, 3.2.3 und 3.2.4; Kolb et al. 2020). Eine Beeinträchtigung der Proliferationsfähigkeit konnte als Ursache hierbei jedoch ausgeschlossen werden (Kolb et al. 2020). Zum Teil führte der ARHGAP29knockdown sogar zu gesteigerter Proliferation (siehe 3.3) bei verminderter Invasivität, was diesen vorgefundenen Effekt sogar weiter bestärkt (Kolb et al. 2020).

Die bisher beschriebenen Effekte von ARHGAP29 auf die Invasion von Tumorzellen wurden stets auf die Suppression des Signalweges um RhoA zurückgeführt (Miyazaki et al. 2017; Qiao et al. 2017). Generell ist die Rolle von RhoA in der „InvasionsMetastasierungskaskade“ (Hanahan und Weinberg 2011) beim Mammakarzinom jedoch umstritten (Kalpana et al. 2019) - neben einer antiinvasiven und tumorsuppressiven Funktion (Simpson et al. 2004; Lawson et al. 2016; Humphries et al. 2017; 
Kalpana et al. 2019) wird RhoA auch eine proinvasive Rolle (Pillé et al. 2005; Chan et al. 2010; Daubriac et al. 2018) bei Brustkrebs zugeschrieben. Neue Erkenntnisse zeigen, dass RhoA die Expression von Chemokinrezeptoren und so die Metastasierung von Brustkrebs negativ beeinflussen kann (Kalpana et al. 2019). Im Allgemeinen steuert Rho(A) die Bildung von Stressfasern und ist in regulatorische Prozesse rund um Zell-Zell- und Zell-Matrix-Kontakte involviert (Ridley und Hall 1992; Hall 2005; Yilmaz und Christofori 2009). ARHGAP29 wiederum kann den RhoA-ROCKSignalweg inhibieren und folglich die Stressfaserbildung negativ beeinflussen (Xu et al. 2011; Post et al. 2013; Miyazaki et al. 2017; Qiao et al. 2017; Tagashira et al. 2018). Die Rasterkraftmikroskopie zeigt, dass metastasierte Tumorzellen ein flexibleres Zytoskelett besitzen als benigne Zellen (Cross et al. 2007), wodurch diese die Lücken in der extrazelluläre Matrix im Rahmen der Metastasierung passieren können (Wolf et al. 2003; Qiao et al. 2017). Zugleich weisen MCF-7-Mammakarzinomzellen nach RhoA-Verminderung, die mit der suppressiven Wirkung von ARHGAP29 vergleichbar ist, reduzierte Zell-Zell-Kontakte und verstärkte Migrationseigenschaften auf (Simpson et al. 2004). Auch in renalen Karzinomzellen können die Migrations- und Invasionsfähigkeiten durch ARHGAP29-Überexpression signifikant gesteigert werden (Miyazaki et al. 2017). In Verbindung mit den verringerten Invasionsraten der Zelllinien HCC1806, MCF-7-EMT und T-47D-EMT nach ARHGAP29Verminderung (siehe 3.2.2, 3.2.3 und 3.2.4; Kolb et al. 2020) weist dies auf eine relevante Rolle von ARHGAP29 hinsichtlich der Invasion von mesenchymal transformierten und invasiven Mammakarzinomzellen hin, die sich durch die Begünstigung eines flexiblen Zytoskeletts durch RhoA-Suppression, aber auch über geringer adhäsive, motilere Zellen (Simpson et al. 2004; Humphries et al. 2017; Miyazaki et al. 2017) erklären lässt. Dennoch bleibt ARHGAP29 ein weitgehend unerforschter Faktor im Rahmen der Invasion von Brustkrebs- bzw. generell von (malignen) Tumorzellen. Dementsprechend ist dringend weitere Forschung rund um ARHGAP29, seine Rolle in den Prozessen der Invasion und Metastasierung und ARHGAP29 als mögliches therapeutisches Ziel nötig.

\subsubsection{Einfluss der verminderten ARHGAP29-Expression auf die Invasivität der Mammakarzinomzelllinie MDA-MB-231}

Unerwarteterweise ließ sich eine signifikant gesteigerte In-vitro-Invasionsfähigkeit der Mammakarzinomzelllinie MDA-MB-231 nach ARHGAP29-knockdown erkennen 
(siehe 3.2.1). Dies stellte sich insofern als unerwarteter Effekt dar, dass neben der MDA-MB-231 eine andere sogenannten dreifach negative Mammakarzinomzelllinie, hier HCC1806, verwendet wurde (Gazdar et al. 1998; Neve et al. 2006; Prat et al. 2010). Da bei beiden dreifach negativen Zelllinien gegensätzliche Ergebnisse vorgefunden wurden, ist so einerseits nicht anzunehmen, dass die fehlende Expression der Hormon- und Wachstumsfaktorrezeptoren ausschlaggebend war für jene Effekte. Die Möglichkeit zelllinienspezifischer Effekte kann andererseits aber nicht ausgeräumt werden.

Wie bereits erwähnt, wird RhoA in einigen Publikationen als invasions- und tumorsupprimierenden Faktor bei Mammakarzinomzellen bezeichnet, unter anderem auch bei MDA-MB-231 (Simpson et al. 2004; Lawson et al. 2016; Humphries et al. 2017; Kalpana et al. 2019). Dennoch besagen andere Quellen das Gegenteil und belegen einen proinvasiven Einfluss von RhoA auf Brustkrebszellen der Linie MDA-MB-231, die auch im Rahmen dieser Arbeit verwendet wurde und nach ARHGAP29-Verminderung signifikant verstärkt invasiv war, siehe auch 3.2.1, (Pillé et al. 2005; Chan et al. 2010; Daubriac et al. 2018). Konsistent damit ist RhoA überexprimiert in Tumoren der Brust, wobei die Expression mit der Tumorprogression zunimmt (Fritz et al. 1999). Darüber hinaus ist RhoA in unterschiedlichem Maße beteiligt an verschiedenen Formen der Zellbewegung (Parri und Chiarugi 2010). So kann bei gesteigerter Aktivität von RhoA eine erhöhte zelluläre Motilität vorliegen (Sahai und Marshall 2002). Die verstärkte Invasivität der ARHGAP29-knockdownZellen könnte somit auf eine Motilitätssteigerung der Zellen durch Aufhebung der RhoA-Hemmung zurückzuführen sein. Der zugrunde liegende Mechanismus, mit dem ARHGAP29 die Motilität der MDA-MB-231-Zellen beeinflussen könnte, sollte daher in weiteren Experimenten näher beleuchtet werden.

Vergleicht man die Zelllinie MDA-MB-231 mit den anderen im Rahmen dieser Arbeit eingesetzten Zelllinien, sticht jene durch ihr vielfältiges Mutationsspektrum inklusive der Mutation im KRAS-Gen hervor (Kozma et al. 1987; Ikediobi et al. 2006). In MDA-MB-231 ist die KRAS-Aktivität und -Expression deutlich höher als diese in MCF-7 und T-47D (Kim et al. 2015). Ein KRAS-knockdown in MDA-MB-231 beeinträchtigt die Invasion in vitro und die Metastasierung in vivo, wohingegen eine KRAS-Überexpression die invasiven Eigenschaften in MCF-7 fördert (Kim et al. 
2015). Dies verdeutlicht den großen Einfluss von KRAS in der „Invasions-Metastasierungskaskade“" (Hanahan und Weinberg 2011). Tumore aus MDA-MB-231-Zellen mit einer inhärenten KRAS-Mutation weisen eine geringe YAP-Expression auf (Lefort et al. 2020). Eine Transduktion von onkogenem KRAS in primären humanen Mammazellen führt zu verstärkter Phosphorylierung und damit auch zur Inaktivierung von YAP (Lefort et al. 2020). Durch Einführung eines konstitutiv aktiven YAPs kann die Metastasierungsfähigkeit der MDA-MB-231 noch gesteigert werden (Lefort et al. 2020) und auch für die Invasivität von MDA-MB-231 ist der positive Einfluss von YAP belegt (Hellinger et al. 2019). Auch im Rahmen dieser Arbeit ließ sich die Invasionsfähigkeit der KRAS mutierten Mammakarzinomzellen noch verstärken durch Verminderung der Expression von ARHGAP29 (siehe 3.2.1). Mammakarzinomzellen ohne KRAS-Mutation waren jedoch nach ARHGAP29-Verminderung schwächer invasiv als die Kontrolle (siehe 3.2.2, 3.2.3 und 3.2.4; Kolb et al. 2020). Auch Qiao et al. (2017) bringen ARHGAP29 in Verbindung mit dem YAP-Signalweg - YAP kann die Transkription von ARHGAP29 verstärken und so dessen Expression erhöhen. Zwar wurde dies in gastralen Karzinomzellen (MKN-28) untersucht (Qiao et al. 2017), doch interessanterweise ist für diese Zellen in der Literatur keine KRAS-Mutation dokumentiert. Dies führt zu der Annahme, dass ARHGAP29 nicht nur eine Regulation durch YAP bei Vorliegen eines KRAS-Wildtyps erfahren kann, sondern wiederum in Anwesenheit von mutiertem KRAS auch Einfluss auf die Aktivität von YAP und damit auf die Invasion und Metastasierung von Tumorzellen nehmen könnte. Darüber hinaus demonstrierten Meng et al. (2018), dass eine Überexpression von ARHGAP29 die Phosphorylierung und damit die Inaktivierung von YAP induziert. Im Kontext dessen, dass MDA-MB-231 im Vergleich zu MCF-7 eine deutlich höhere ARHGAP29-Expression aufweisen als die anderen betrachteten Mammakarzinomzelllinien (siehe Abbildung 4; Kolb et al. 2020) erhärtet sich die Annahme, dass das stark exprimierte ARHGAP29 - womöglich in Zusammenspiel mit onkogenem KRAS - die YAP-Aktivität und damit die Invasionsfähigkeit von aggressiven Mammakarzinomzellen in Schach halten könnte, wohingegen bei verminderter ARHGAP29-Expression und gleichzeitig mutiertem KRAS die Inhibition von YAP aufgehoben werden und dies eine verstärkte Invasion und Metastasierung möglich machen könnte.

Abgesehen vom besonderen Mutationsprofil der MDA-MB-231 hebt sich diese Zelllinie durch ihren nicht einheitlich definierten molekularen Subtypen ab. Während 
Neve et al. (2006) diese als Zelllinie vom sogenannten Basal-ähnlichen (basal like) Subtypen einordnet, wird sie gleichzeitig auch als sogenannte Claudin-low-zugehörige Linie bezeichnet (Prat et al. 2010); Claudin-low beschreibt hierbei einen Subtypen des Mammakarzinoms, welcher sich durch eine geringe oder fehlende Expression von E-Cadherin und Claudinen als Bestandteile von Verschluss- und Adhäsionskontakten sowie durch hohe Expression von EMT- und Stammzell-assoziierten Kennzeichen und solchen die Immunantwort betreffend auszeichnet (Herschkowitz et al. 2007; Prat et al. 2010). Im Gegensatz zu den zuvor genannten Publikationen liegen auch Hinweise dafür vor, dass sich die Zelllinie MDA-MB-231 keinem (bisher bekannten) Subtypen zuordnen lässt und kaum Übereinstimmungen im Transkriptom von Proben aus metastasiertem Brustkrebs des Basal-like-Typus aufweist (Liu et al. 2019). Demzufolge muss der Subtyp des Mammakarzinoms, dem die betrachtete Zelllinie entsprungen sein mag, noch (weiter) erschlossen werden, um so auch die Mechanismen, die zu der starken Invasivität dieser Zelllinie beitragen, noch genauer beurteilen zu können.

Ein anderer generell zu bedenkender Faktor ist das (2D-)Zelllinienmodell als experimentelle Grundlage. Zwar werden einer Auswahl an Zelllinien große Übereinstimmungen hinsichtlich genomischer Aberrationen und Deregulationen mit den zugehörigen Primärtumoren und überdauernde Expressionsmuster nachgesagt (Neve et al. 2006), jedoch existieren ebenfalls aktuelle Belege dafür, dass deutliche Unterschiede im somatischen Mutationsmuster zwischen Brustkrebszelllinien und Brustkrebsproben bestehen könnten (Liu et al. 2019). Organoide als 3D-Modelle sind dahingehend vorteilhaft, dass sie zum einen in Bezug auf ihr Transkriptom besser mit Brustkrebsproben korrelieren (Liu et al. 2019), zum anderen aber auch dahingehend, dass sie „die histologischen Architektur, Genexpression und genomische Kennzeichen des Ursprungstumors“ (Broutier et al. 2017) bewahren würden. In 2DKultur hingegen lassen sich Zell-Zell- und Zell-Matrix-Interaktionen nicht zufriedenstellend darstellen und molekulare Interaktionen aus 2D- und 3D-Modellen stimmen nicht immer überein (Shamir und Ewald 2014). Da die Erkenntnisse dieser Arbeit zum Einfluss von ARHGAP29 auf die Invasion von Mammakarzinomzellen in vitro in 2D-Invasionsassays gewonnen wurden, sollten diese in geeigneten In-vivo-Modellen oder 3D-Invasionsassays bestätigt werden. 
Zusammenfassend demonstrieren die Ergebnisse dieser Arbeit, dass ARHGAP29 Einfluss auf die Invasivität von Mammakarzinomzellen nimmt. Außerdem wird deutlich, dass, trotz der außerordentlichen Errungenschaften der Brustkrebsforschung, die Möglichkeit bisher unbekannter Interaktionen und Forschungen zu bedenken sind und es gilt diese zu untersuchen. Folglich sind sowohl weitere Experimente nötig, in denen der Mechanismus, welcher der Interaktion von ARHGAP29 und RhoA sowie zwischen ARHGAP29, YAP und KRAS und dem jeweiligen Einfluss auf die Invasionseigenschaften des Mammakarzinoms zugrunde liegt, weiter untersucht wird. Hierbei sollte sowohl die Wahl der Zelllinie als auch die Dimensionalität des gewählten experimentellen Aufbaus beachtet werden.

\subsection{Einfluss von ARHGAP29 auf die Proliferation von Mammakarzinomzellen}

Um einen möglichen Einfluss der reduzierten ARHGAP29-Expression auf die Proliferationsfähigkeiten der vier Mammakarzinomzelllinien und damit einen möglichen kausalen Faktor der veränderten Invasionseigenschaften zu eruieren, wurden Proliferationsanalysen vorgenommen (siehe 2.2.1.5). Während in den Zelllinien MDA-MB-231 und T-47D-EMT kein signifikanter Einfluss des ARHGAP29-knockdowns auf die Proliferation der Zellen erkannt werden konnte (siehe 3.3.1 und 3.3.4; Kolb et al. 2020), fand sich eine signifikant verstärkte Proliferation in den Zelllinien MCF-7-EMT und HCC1806 der knockdown-Population, verglichen mit der Kontrolle (siehe 3.3.2 und 3.3.3; Kolb et al. 2020).

Mariani et al. (2001) entdeckten zwar, dass migrierende Gliomzellen nicht nur über eine erhöhte Genexpression von ARHGAP29 verfügen, sondern auch über eine Herunterregulierung proliferationsrelevanter Gene, jedoch ist bisher generell und auch hinsichtlich des Mammakarzinoms im Speziellen wenig darüber bekannt, wie sich ARHGAP29 bzw. eine veränderte Expression oder Regulierung auf die Proliferationsfertigkeiten von Zellen auswirkt. In mehreren Studien wurde jedoch die Regulation der Proliferation durch RhoA, das durch ARHGAP29 negativ beeinflusst wird (Saras et al. 1997; Xu et al. 2011; Qiao et al. 2017), betrachtet. Zhang C et al. (2016) konnten einen Zusammenhang zwischen der Reexpression von RhoA und verstärkt proliferierenden Mammakarzinomzellen demonstrieren. In dieser Studie waren unter anderem MCF-7-Zellen in Gebrauch (Zhang C et al. 2016), sodass sich 
der aufgezeigte Effekt bei RhoA-Reexpression als konsistent mit der signifikant gesteigerten Proliferationsrate der MCF-7-EMT nach ARHGAP29-knockdown (Kolb et al. 2020) und aufgehobener Suppression von RhoA annehmen lässt. Auch konnte bereits gezeigt werden, dass mesenchymal transformierte MCF-7-Zellen eine abweichende Regulation proliferationsrelevanter Gene (Ziegler et al. 2014) und erhöhte Proliferationsraten verglichen mit ihren untransformierten Gegenstücken aufweisen (Guttilla et al. 2012). Dies lässt vermuten, dass eine von Grund auf erhöhte Proliferationsneigung mesenchymal transformierter MCF-7-Zellen durch eine verminderte ARHGAP29-Expression und folglich verminderte RhoA-Suppression weiter gesteigert werden kann. Bei Zhang C et al. (2016) kamen jedoch auch MDA-MB-231 zum Einsatz. So steht die Aussage von Zhang C et al. (2016) bezüglich der MDA-MB-231 im Kontrast zum Ergebnis der Proliferationsanalyse in ARHGAP29-defizienten Zellen. Chan et al. (2010) wiederum konnte keinen signifikanten Einfluss eines RhoA-knockdowns auf die Proliferation der gleichen Mammakarzinomzelllinien nachweisen, wohingegen eine andere Publikation beschreibt, dass eine RhoA-Inhibition in MDA-MB-231 eine verringerte Proliferation dieser Zellen mit sich brachte (Pillé et al. 2005). Die Regulation der Aktivität von RhoA ist jedoch komplex, sodass die in den Publikationen beschriebenen Effekte nicht zwangsläufig durch einen möglichen Einfluss von ARHGAP29 zu erklären sind, sondern auch andere der zahlreichen Regulatorproteine von Rho involviert sein könnten. Dennoch liefern eben diese Publikationen erste Hinweise für eine mögliche Erklärung der vorgefundenen Auswirkungen auf die Proliferation der Mammakarzinomzellen.

Zusammenfassend kann also gesagt werden, dass mithilfe der Proliferationsassays ausgeschlossen werden konnte, dass weder die verminderte (HCC1806, MCF-7-EMT, T-47D-EMT; Kolb et al. 2020) noch die verstärkte Invasionsfähigkeit (MDA-MB-231) durch die gleichsinnig veränderte Proliferation der Zellen verursacht wurde. Trotz des signifikanten Zugewinns an Proliferationsfertigkeit bzw. des Trends zur erhöhten Proliferationsfähigkeit offenbarte sich bei drei Zelllinien eine geringere Invasivität (HCC1806, MCF-7-EMT, T-47D-EMT; Kolb et al. 2020), wohingegen bei nicht signifikant veränderter Proliferation bei MDA-MB-231 ein signifikant positiver Effekt auf die Invasionsfähigkeit vorlag. Dennoch bleibt der zugrundliegende Mechanismus, der der signifikant verstärkten Proliferation zweier Mammakarzinomzelllinien nach ARHGAP29-knockdown zugrunde liegt, unklar und 
benötigt weitere Erforschung. Ob und welchen Einfluss ARHGAP29 auf die Proliferation weiterer Mammakarzinomzelllinien in vitro und in vivo nimmt und in welchem Kontext dies zu den Invasions- und Metastasierungseigenschaften der Zellen steht, sollte in weiteren Experimenten näher beleuchtet werden.

\subsection{Einfluss des ARHGAP29-knockdowns auf die Proteinexpression von AKT1 und eine mögliche Signalkaskade}

Wie bereits erwähnt, ließen In-silico-Analysen eine Interaktion zwischen ARHGAP29 und AKT1 vermuten (Kolb et al. 2020). Aus diesem Grund wurde die Proteinexpression von AKT1 in ARHGAP29-knockdown-Zellen und mit Kontroll-siRNA behandelten Mammakarzinomzellen mittels Western Blots verglichen (siehe 2.2.3). AKT1 zeigte sich signifikant reduziert exprimiert bei vermindert exprimiertem ARHGAP29 nach ARHGAP29-knockdown (siehe 3.4; Kolb et al. 2020).

AKT1 ist eine Serin-Threonin-Kinase (Jones et al. 1991a) und als eine von drei Isoformen von Proteinkinase B (AKT/PKB) Teil des PI3K/AKT-Signalweges (Franke et al. 1995), der bei über $70 \%$ von Brustkrebspatienten Abweichungen aufweist (López-Knowles et al. 2010). Obwohl zahlreiche Publikationen existieren, die die Signalkaskade um und die Rolle von PI3K und der verschiedenen AKT-Isoformen beim Mammakarzinom diskutieren, wurde bisher noch nicht von der Interaktion von ARHGAP29 und AKT1 berichtet. Western Blots konnten jedoch zeigen, dass eine verminderte ARHGAP29-Expression in Mammakarzinomzellen mit einer signifikant reduzierten AKT1-Expression einhergeht (siehe 3.4; Kolb et al. 2020). Es ließ sich zwar - anders als bei den anderen drei Zelllinien - bei den MCF-7-EMT-Mammakarzinomzellen neben einer signifikant reduzierten ARHGAP29-mRNA-Expression und einer signifikant reduzierten AKT1-Proteinexpression nach ARHGAP29-knockdown nur ein Trend zur verminderten ARHGAP29-Proteinexpression zeigen (Kolb et al. 2020) und die verminderte AKT1-Expression ist auch nicht gleichzusetzen mit einer aufgehobenen Aktivität, da die Aktivierung von AKT1 abhängig von Phosphorylierungen an Ser473 und Th3208 ist (Alessi et al. 1996), doch lassen die Ergebnisse der Proteinexpressionsanalysen in der Gesamtheit einen Zusammenhang mit der Signalkaskade um ARHGAP29 vermuten. AKT(1) wird positiv reguliert durch PAR1 (proteinase activated receptor 1; Yang et al. 2009), TIS21 (tetradecanoyl phorbol 
acetate-inducable sequence 21; Choi et al. 2016) und Caveolin-1 (Joglekar et al. 2015) und negativ reguliert durch PIPP (Inositol-Polyphosphat-5-Phosphatase; Ooms et al. 2015), miR409-3p (microRNA409-3p; Zhang $G$ et al. 2016), PTEN (phosphatase and tensin homolog; Stambolic et al. 1998; Hohensee et al. 2017), SHIP (signaling inositol polyphosphate phosphatase; Huber et al. 1999), PHLPP (pleckstrin homology domain and leucine rich repeat protein phosphatase; Gao et al. 2005) und PP2A (protein phosphatase 2A; Ugi et al. 2004), (Hinz und Jücker 2019). Für keinen der genannten Faktoren sind Hinweise für eine Interaktion mit ARHGAP29 zu finden. Aufgrund der vor allem pro-invasiven Rolle von ARHGAP29 (siehe 3.2.2, 3.2.3 und 3.2.4) und einer gleichsinnig verminderten Expression der beiden Proteine (Kolb et al. 2020), lässt sich aber eine ähnliche Bedeutung von AKT1 auf den Prozess der Invasion und Metastasierung von Brustkrebszellen und eine mögliche Überschneidung der umgebenden Signalkaskaden vermuten. Umso erstaunlicher ist es, dass der Großteil der Studien um AKT1 einen inhibitorischen Effekt auf die Invasion und Metastasierung vom Mammakarzinom belegen (Hinz und Jücker 2019). Konsistent damit zeigt sich allein der aufgezeigte Effekt der signifikant gesteigerten Invasivität der Mammakarzinomzelllinie MDA-MB-231 nach ARHGAP29-knockdown im Zusammenhang mit der verminderten AKT1-Expression. Dazu im Gegensatz steht wiederum die signifikant verminderte Invasionsfähigkeit der übrigen Zelllinien (HCC1806, MCF-7-EMT, T-47D-EMT) bei ARHGAP29-knockdown und neben der verminderten AKT1-Expression (Kolb et al. 2020).

Neben der Fülle an Publikationen, die die anti-migratorische, anti-invasive Rolle von AKT1 beschreiben, existieren jedoch auch Hinweise dafür, dass AKT1 Im Rahmen der Invasion und Metastasierung von Brustkrebs fördernd wirkt (Hinz und Jücker 2019). In murinen Mammaepithelzellen korreliert die AKT1-Überexpression mit einer erhöhten Invasivität durch erhöhte Matrixmetalloproteinase(MMP)-2-Expression (Park et al. 2001). Die Ergebnisse von Yang et al. (2009) lassen darauf schließen, dass über den PAR1-AKT-Signalweg die Migrations-, Invasions- und Metastasierungsfähigkeiten von diversen Mammakarzinomzelllinien verbessert werden können (Hinz und Jücker 2019). Zwar wurden in diesem Fall auch MDA-MB-231 verwendet, doch wurde die ARHGAP29-Expression und der Einfluss auf PAR1 und AKT1 nicht erhoben (Yang et al. 2009). So müssen diese Ergebnisse getrennt von jenen dieser Arbeit, die die Zelllinie MDA-MB-231 betreffen, betrachtet werden. In 
vitro bei MDA-MB-231-Zellen mit Metastasierung ins Gehirn (MDA-MB-231 BR) führt eine PTEN-Überexpression zu verminderter AKT1-Aktivität und folglich zu verminderter Migration sowie in einem Ex-vivo-Modell zu reduzierter Invasivität (Hohensee et al. 2017). Durch AKT1-knockdown lässt sich außerdem die Invasivität beim inflammatorischen Mammakarzinom reduzieren (Lehman et al. 2012). Eine weitere Publikation führt an, dass verbesserte Invasionseigenschaften in malignen Zellen durch eine Rap2a induzierte Hochregulation von phosphoryliertem AKT vermittelt wird (Wu et al. 2015). ARHGAP29 wiederum ist als Effektor von Rap2 beschrieben (Myagmar et al. 2005). Im Rahmen dieser Arbeit wurde jedoch nur die Proteinexpression, nicht aber der Aktivitätszustand von AKT1 nach ARHGAP29knockdown untersucht. Dennoch könnten die Ergebnisse der Proteinexpression im Kontext der genannten Publikationen erste Hinweise auf eine mögliche Signalkaskade um Rap2, ARHGAP29 und AKT1 darstellen.

Des Weiteren ist eine Publikation zu erwähnen, die bei AKT1-Gendeletion sowohl im murinen In-vivo-Modell eine verringerte Metastasierung von HER2/neu induzierten Mamma-Tumoren und eine verminderte Phosphorylierung von TSC2 vorfand, als auch in vitro eine reduzierte zelluläre Migration bei HER2/neu-Expression und fehlender AKT1-Expression zeigen konnte (Ju et al. 2007). Neben dieser Publikation deutet eine weitere daraufhin, dass AKT1 über die Phosphorylierung von TSC2 unterschiedliche Wirkung auf dessen Expression und damit auch auf RhoA nimmt (Liu et al. 2006; Ju et al. 2007). So fanden sich bei AKT1- und HER2/neu-Expression Zeichen einer Aktivierung von RhoA und eine verstärkte Phosphorylierung von TSC2 (Ser-939) gegenüber der Phosphorylierung bei AKT1-Deletion, wobei die Expression vom Gesamt-TSC2 unverändert war (Ju et al. 2007). Liu et al. (2006) dagegen beschreiben, dass konstitutives AKT1 in humanen Mammakarzinomzellen die Phosphorylierung (Thr-1462) und damit die Degradation von TSC2 fördert und so die Aktivierung von Rho ausbleibt, was zu verminderter Bildung von Stressfasern und fokalen Adhäsionen, aber auch zu reduzierter Motilität und Migration und verringerten Invasionsraten führt. Dies ist kongruent mit der supprimierenden Wirkung von ARHGAP29 auf RhoA (Saras et al. 1997; Xu et al. 2011; Post et al. 2013; Qiao et al. 2017) und deutet an, dass die Möglichkeit einer Signalkaskade um ARHGAP29, AKT1 und TSC2 mit Wirkung auf RhoA besteht, auch wenn der genaue Mechanismus und Effekt von AKT1 auf TSC2 und damit auf RhoA noch unvollständig geklärt bleibt. 
Dennoch steht der von Liu et al. (2006) beschriebene negative Effekt von konstitutiv aktivem AKT1 auf die Migration und Invasion von Mammakarzinomzellen im klaren Gegensatz zu den Daten dieser Arbeit bezüglich drei der vier Mammakarzinomzelllinien. Eine Ausnahme stellt, wie schon erwähnt, die Zelllinie MDA-MB-231 dar, deren Invasivität durch Verminderung der ARHGAP29 mit gleichsinnig veränderter AKT1-Expression gesteigert werden konnte (siehe 3.2.1). In Konsistenz damit sind sowohl MDA-MB-231-Zellen mit unbeeinträchtigter AKT1-Expression als auch mit AKT1-Überexpression schwächer invasiv als Zellen, die AKT1 nicht exprimieren (Yoeli-Lerner et al. 2005). Hinsichtlich der Invasion und Metastasierung vom nichtkleinzelligen Bronchialkarzinom scheint der genetische Hintergrund, das heißt eine KRAS-Mutation, Einfluss auf die Funktion von AKT1 zu nehmen - so korreliert die AKT1-Expression invers mit den Invasionseigenschaften der mutationstragenden Zellen (Rao et al. 2017). Dies ist konsistent mit der verstärkten Invasivität der KRASmutierten Mammakarzinomzellinie nach ARHGAP29-knockdown und mit verminderter AKT1-Expression. Die übrigen Zelllinien weisen keine KRAS-Mutation auf, doch die Ursprungszelllinien der mesenchymal transformierten Zelllinien - MCF-7 und T-47D - verfügen über eine Mutation des Gens für die katalytische Untereinheit von Phosphoinositid-3-Kinase (PIK3CA, Phosphatidylinositol-4,5-Bisphosphate 3Kinase Catalytic Subunit Alpha; Ikediobi et al. 2006). Die PIK3CA-Mutation vermittelt nachweislich eine erhöhte Sensitivität von MCF-7-Zellen für den PI3K-Inhibitor GDC-0941 und den AKT-Inhibitor MK-2206 (Beaver et al. 2013). Schlussfolglich zeigen diese Publikationen, wie entscheidend genetische Mutationen das Verhalten von malignen Zellen sowohl in pathophysiologischen Prozessen, wie der Invasion und Metastasierung, als auch in Hinblick auf die Therapie der entsprechenden onkologischen Krankheitsbilder beeinflussen können. Hinsichtlich der widersprüchlichen Datenlage zur Rolle von AKT1 bei der Invasion von Tumorzellen und der spärlichen Erkenntnisse zur Signalkaskade um ARHGAP29 und AKT1, geben die Ergebnisse dieser Arbeit erste Belege für eine Interaktion von ARHGAP29 und AKT1 und erste Hinweise für Signalkaskaden um Rap2, ARHGAP29 und AKT1 sowie um ARHGAP29, AKT1 und TSC2. So könnte ARHGAP29 nicht nur direkt auf RhoA regulierend wirken, sondern darüber hinaus auch über AKT1 und TSC2.

In der Gesamtheit kann also gesagt werden, dass das Wissen über den zugrundeliegenden Mechanismus und Signalweg einer Interaktion zwischen ARHGAP29 und AKT1 unvollständig bleibt und weiterführende Experimente diesbezüglich sowie 
zum Einfluss der erkannten Interaktion auf die „Invasions-Metastasierungskaskade“ (Hanahan und Weinberg 2011) von Mammakarzinomzellen nötig sind. Hierbei sollte außerdem dem genetischen Hintergrund des Mammakarzinoms und verfügbarerer Zelllinien sowie seinem Einfluss auf die Rolle von AKT1 im Invasionsprozess und in der Interaktion von ARHGAP29 mit bekannten Regulatoren von AKT1 und möglichen Überschneidungen mit dem PI3K-Signalweg Beachtung geschenkt werden.

\subsection{Fazit und Ausblick}

Im Rahmen dieser Arbeit konnte erstmal gezeigt werden, dass ARHGAP29 Einfluss auf die Invasionsfähigkeiten von vier verschiedenen Mammakarzinomzelllinien nimmt (Kolb et al. 2020). So waren die Invasionsraten dreier Zelllinien signifikant vermindert nach ARHGAP29-knockdown (Kolb et al. 2020), wohingegen jene der Zelllinie MDA-MB-231 signifikant erhöht wurde. Durch die RhoA supprimierende Wirkung scheint ARHGAP29 Einfluss auf das Zytoskelett zu nehmen und fördert die Invasion von Mammakarzinomzellen (Kolb et al. 2020). Zugleich hat ARHGAP29 in Gegenwart einer KRAS-Mutation hemmenden Einfluss auf die Invasivität von Mammakarzinomzellen. Es lässt sich eine inhibierende Wirkung von ARHGAP29 bei gleichzeitigem Vorliegen von onkogenem KRAS vermuten. Die zugrundliegenden Mechanismen, wie ARHGAP29 die Invasivität der Mammakarzinomzellen beeinflusst, bleiben dennoch nicht vollständig geklärt und erfordern weitere Experimente.

Des Weiteren hat ARHGAP29 keinen signifikanten Einfluss auf die Proliferation der Zellinien MDA-MB-231 und T-47D-EMT, spielt aber wohl eine hemmende Rolle in der Proliferation der Zelllinie HCC1806 und MCF-7-EMT, deren Proliferationsfähigkeit sich durch ARHGAP29-knockdown signifikant erhöhen lässt (Kolb et al. 2020). Auch wenn unklar bleibt, auf welchem Mechanismus dies basiert, kann ausgeschlossen werden, dass der aufgefundene Effekt auf die Invasivität der Tumorzellen proliferationsbedingt zustande kam.

Außerdem macht diese Arbeit zum ersten Mal sichtbar, dass ARHGAP29 mit AKT1 interagieren und so dessen Expression regulieren kann (Kolb et al. 2020). Darüber hinaus lassen sich Berührungen der Signalwege mit RAP2 und TSC2 vermuten, was im Kontext weiterer Forschung bestätigt werden sollte. Zusammenfassend 
kann gesagt werden, dass sich ARHGAP29 als einflussreicher Regulator der Invasivität vom Mammakarzinom in vitro darstellt. Die Forschungsergebnisse dieser Arbeit verdeutlichen aber auch, dass Brustkrebs eine sehr heterogene Erkrankung ist, die individuelle, auf die patientinnenspezifische molekulare Pathologie des Mammakarzinoms ausgerichtete Therapie benötigt. Daher sind In-vivo-Studien erforderlich, um die vorgefundenen Effekte zu bestätigen und in den Kontext der molekularen Heterogenität des Mammakarzinoms einzuordnen. So besteht mit ARHGAP29 die Chance auf einen neuen therapeutischen Angriffspunkt zur Therapie des invasiven Mammakarzinoms. 


\section{$5 \quad$ Zusammenfassung}

Trotz jahrzehntelanger Forschung und des dementsprechenden Fortschritts stellt das Mammakarzinom immer noch das häufigste Karzinom der Frau dar. Mit der Fernmetastasierung verschlechtert sich die Prognose betroffener Patientinnen deutlich. Therapiekonzepte, die die Metastasierung von Grund auf verhindern, sind daher erforderlich. In der lokalen Invasion als initial erforderlichen Schritt zur Metastasierung findet sich ein Angriffspunkt für derartige Therapiekonzepte des Mammakarzinoms wieder. ARHGAP29 als RhoA supprimierendes Protein ist erhöht exprimiert in aggressiven und mesenchymal transformierten Mammakarzinomzellen. Als einziges von 32 GTPase aktivierenden Enzymen ist dessen Expression nach induzierter EMT signifikant erhöht in mesenchymal transformierten Mammakarzinomzellen. Daher sollte ein möglicher Einfluss von ARHGAP29 auf die Invasivität von aggressiven und mesenchymal transformierten Mammakarzinomzellen untersucht werden. Dafür wurde die ARHGAP29-Expression zunächst mithilfe von ARHGAP29 spezifischer siRNA-knockdowns für die Dauer der Versuche vermindert und die Effizienz dessen im Rahmen von Gen- und Proteinexpressionsanalysen bestätigt. Die Analyse der Invasionsfähigkeit nach ARHGAP29-knockdown erfolgte mit einem in der Arbeitsgruppe etablierten In-vitro-Invasionsassay in Kokultur mit Osteosarkomzellen. Die verminderte Expression von ARHGAP29 führte zu signifikant erniedrigten Invasionsraten der Mammakarzinomzelllinien HCC1806, MCF-7-EMT und T-47D-EMT, die sich durch verringerte Hemmung von RhoA und folglich erhöhte Stressfaserbildung erklären ließe. Die KRAS mutierte Zelllinie MDA-MB-231 war nach ARHGAP29-knockdown signifikant invasiver. Die molekulare Grundlage wird in einer Interaktion von onkogenem KRAS und ARHGAP29 als Inhibitor von YAP vermutet. Proliferationsanalysen wurden durchgeführt und damit bestätigt, dass der vorgefundene Effekt auf die Invasivität unabhängig von den Proliferationsfähigkeiten ist. So war die Proliferationsfähigkeit der Mammakarzinomzelllinien MDA-MB-231 und T-47D-EMT nicht signifikant beeinflusst von der Expressionsreduktion von ARHGAP29, wohingegen jene von HCC1806 und MCF-7-EMT signifikant gesteigert wurde. Interaktionsanalysen führten AKT1 als möglichen Interaktionspartner von ARHGAP29 an. Daher wurde in Western Blots die Expression von AKT1 nach dem knockdown von ARHGAP29 untersucht. Die signifikant ver- 
minderte ARHGAP29-Expression bzw. der Trend zur reduzierten ARHGAP29-Expression ging mit einer signifikant reduzierten AKT1-Expression einher. ARHGAP29 konnte daher als Regulator der Expression von AKT1 identifiziert werden.

Die Ergebnisse dieser Arbeit stellen damit erstmals ARHGAP29 als einflussreichen Faktor im Rahmen der Invasion von aggressiven und mesenchymal transformierten Mammakarzinomzellen dar und liefern neue Hinweise auf die Signalkaskade, die ARHGAP29 umgibt. Um zugrundliegende Mechanismen restlos aufzudecken und den aufgezeigten Zusammenhang therapeutisch nutzbar machen zu können, bedarf es weiterer Forschung. 


\section{$6 \quad$ Literaturverzeichnis}

Ahmed SM, Thériault BL, Uppalapati M, Chiu CWN, Gallie BL, Sidhu SS, Angers S (2012): KIF14 negatively regulates Rap1a-Radil signaling during breast cancer progression. J Cell Biol 199, 951-967

Alessi DR, Andjelkovic M, Caudwell B, Cron P, Morrice N, Cohen P, Hemmings BA (1996): Mechanism of activation of protein kinase B by insulin and IGF-1. EMBO J 15 , $6541-6551$

American Type Culture Collection (2016a): HCC1806 (ATCC ® CRL-2335 ${ }^{\mathrm{TM}}$ ). https://www.lgcstandards-atcc.org/products/all/CRL-2335.aspx?geo_country=de\#characteristics; aufgerufen am 20.05.2020

American Type Culture Collection (2016b): MCF7 (ATCC® HTB-22 ${ }^{\text {TM }}$ ). https://www.lgcstandards-atcc.org/Products/All/HTB-22.aspx?geo_country=de\#characteristics; abgerufen am 20.05.2020

American Type Culture Collection (2016c): MDA-MB-231 (ATCC ${ }^{\circ}$ HTB-26 ${ }^{\mathrm{TM}}$ ). https://www.lgcstandards-atcc.org/products/all/HTB-26.aspx?geo_country=de\#characteristics; abgerufen 20.05.2020

American Type Culture Collection (2016d): MG-63 (ATCC $®$ CRL-1427 ${ }^{\mathrm{TM}}$ ). https://www.lgcstandards-atcc.org/Products/All/CRL-1427.aspx?geo_country=de\#characteristics; abgerufen am 20.05.2020

American Type Culture Collection (2016e): T-47D (ATCC ${ }^{\circledR}$ HTB $133^{\mathrm{TM}}$ ). https://www.lgcstandards-atcc.org/Products/All/HTB-133.aspx?geo_country=de\#characteristics; abgerufen am 20.05.2020

Armbrecht M, Eppendorf AG (Hrsg.) (2013): Application note Nr. 279: Detektion von Kontaminationen in DNA und Protein-Proben durch photometrische Messungen. Eppendorf AG. https://www.eppendorf.com/product-media/doc/de/59828/Eppendorf_Detection_Application-Note_279_BioPhotometer-D30_Detection-contamination-DNA-protein-samplesphotometric-measurements.pdf; abgerufen am 02.09.19

Association of Breast Surgery at Baso 2009 (2009): Surgical guidelines for the management of breast cancer. Eur J Surg Oncol 35 Suppl 1, 1-22

Astrinidis A, Cash TP, Hunter DS, Walker CL, Chernoff J, Henske EP (2002): Tuberin, the tuberous sclerosis complex 2 tumor suppressor gene product, regulates Rho activation, cell adhesion and migration. Oncogene 21, 8470-8476

Baltimore D (1970): RNA-dependent DNA polymerase in virions of RNA tumour viruses. Nature 226, 1209-1211

Barnes B, Buttmann-Schweiger N, Dahm S, Fiebig J, Franke M, Gurung-Schönfeld I, Haberland J, Kraywinkel K, Wienecke A (2019a): Übersichten zu den Krebsneuerkrankungs- und Krebssterbefällen. In: Robert Koch-Institut und Gesellschaft der epidemiologischen Krebsregister in Deutschland e.V. (Hrsg.): Krebs in Deutschland für 2015/2016, 12. Ausgabe, Berlin 2019, 16-17

Barnes B, Buttmann-Schweiger J, Christ M, Dahm S, Fiebig J, Folkerts J, Franke M, Gurung-Schönfeld I, Haberland J, Hansmann J et al. (2019b): Brustdrüse. In: Robert 
Koch-Institut und Gesellschaft der epidemiologischen Krebsregister in Deutschland e.V. (Hrsg.): Krebs in Deutschland für 2015/2016, 12. Ausgabe, Berlin 2019, 78-81

Beaver JA, Gustin JP, Yi KH, Rajpurohit A, Thomas M, Gilbert SF, Rosen DM, Ho Park B, Lauring J (2013): PIK3CA and AKT1 mutations have distinct effects on sensitivity to targeted pathway inhibitors in an isogenic luminal breast cancer model system. Clin Cancer Res $\underline{19}, 5413-5422$

Bellacosa A, Testa JR, Staal SP, Tsichlis PN (1991): A retroviral oncogene, akt, encoding a serine-threonine kinase containing an SH2-like region. Science 254, 274-277

Biggs LC, Naridze RL, DeMali KA, Lusche DF, Kuhl S, Soll DR, Schutte BC, Dunnwald M (2014): Interferon regulatory factor 6 regulates keratinocyte migration. J Cell Sci 127 , 2840-2848

Billiau A, Edy VG, Heremans H, van Damme J, Desmyter J, Georgiades JA, de Somer P (1977): Human interferon: mass production in a newly established cell line, MG-63. Antimicrob Agents Chemother 12, 11-15

Bloom HJG, Richardson WW (1957): Histological grading and prognosis in breast cancer: A study of 1409 cases of which 359 have been followed for 15 years. Br J Cancer 11, 359-377

Boyden S (1962): The chemotactic effect of mixtures of antibody and antigen on polymorphonuclear leucocytes. J Exp Med 115, 453-466

Brabletz T, Kalluri R, Nieto MA, Weinberg RA (2018): EMT in cancer. Nat Rev Cancer $\underline{18}$, 128-134

Bradford MM (1976): A rapid and sensitive method for the quantitation of microgram quantities of protein utilizing the principle of protein-dye binding. Anal Biochem $\underline{72}, 248-254$

Bray F, Ferlay J, Soerjomataram I, Siegel RL, Torre LA, Jemal A (2018): Global cancer statistics 2018: GLOBOCAN estimates of incidence and mortality worldwide for 36 cancers in 185 countries. CA Cancer J Clin $\underline{68}, 394-424$

Broders AC (1932): Carcinoma in situ contrasted with benign penetrating epithelium. JAMA $\underline{99}, 1670-1674$

Broutier L, Mastrogiovanni G, Verstegen MMA, Francies HE, Gavarró LM, Bradshaw CR, Allen GE, Arnes-Benito R, Sidorova O, Gaspersz MP et al. (2017): Human primary liver cancer-derived organoid cultures for disease modeling and drug screening. Nat Med $\underline{23}$, $1424-1435$

Burnette WN (1981): „Western blotting“: electrophoretic transfer of proteins from sodium dodecyl sulfate-polyacrylamide gels to unmodified nitrocellulose and radiographic detection with antibody and radioiodinated protein A. Anal Biochem 112, 195-203

Cailleau R, Young R, Olivé M, Reeves Jr. WJ (1974): Breast tumor cell lines from pleural effusions. J Natl Cancer Inst $\underline{53}, 661-674$

Cardoso F, Senkus E, Costa A, Papadopoulos E, Aapro M, André F, Harbeck N, Aguilar Lopez B, Barrios CH, Bergh J et al. (2018): 4th ESO-ESMO international consensus guidelines for advanced breast cancer (ABC 4). Ann Oncol 29, 1634-1657 
Cardoso F, Kyriakides S, Ohno S, Penault-Llorca F, Poortmans P, Rubio IT, Zackrisson S, Senkus E, ESMO Guidelines Committee (2019): Early breast cancer: ESMO clinical practice guidelines for diagnosis, treatment and follow-up. Ann Oncol $\underline{30}, 1194-1220$

Chambers AF, Groom AC, MacDonald IC (2002): Dissemination and growth of cancer cells in metastatic sites. Nat Rev Cancer 2 , 563-572

Chan CH, Lee SW, Li CF, Wang J, Yang WL, Wu CY, Wu J, Nakayama KI, Kang HY, Huang HY et al. (2010): Deciphering the transcriptional complex critical for RhoA gene expression and cancer metastasis. Nat Cell Biol 12, 457-467

Chandrasekharan D, Ramanathan A (2014): Identification of a novel heterozygous truncation mutation in exon 1 of ARHGAP29 in an indian subject with nonsyndromic cleft lip with cleft palate. Eur J Dent $\underline{8}, 528-532$

Chatr-aryamontri A, Breitkreutz BJ, Heinicke S, Boucher L, Winter A, Stark C, Nixon J, Ramage L, Kolas N, O'Donnell L et al. (2013): The BioGRID interaction database: 2013 update. Nucleic Acids Res 41, D816-D823

Choi JA, Jung YS, Kim JY, Kim HM, Lim IK (2016): Inhibition of breast cancer invasion by TIS21/BTG2/Pc3-Akt1-Sp1-Nox4 pathway targeting actin nucleators, mDia genes. Oncogene $\underline{35}, 83-93$

Coffer PJ, Woodgett JR (1991): Molecular cloning and characterisation of a novel putative protein-serine kinase related to the CAMP-dependent and protein kinase $\mathrm{C}$ families. Eur $\mathrm{J}$ Biochem 201, 475-481

Compton SJ, Jones CG (1985): Mechanism of dye response and interference in the Bradford protein assay. Anal Biochem 151, 369-374

Cross SE, Jin YS, Rao J, Gimzewski JK (2007): Nanomechanical analysis of cells from cancer patients. Nat Nanotechnol $\underline{2}, 780-783$

Crowell JA, Steele VE, Fay JR (2007): Targeting the AKT protein kinase for cancer chemoprevention. Mol Cancer Ther $\underline{6}, 2139-2148$

Daubriac J, Han S, Grahovac J, Smith E, Hosein A, Buchanan M, Basik M, Boucher Y (2018): The crosstalk between breast carcinoma-associated fibroblasts and cancer cells promotes RhoA-dependent invasion via IGF-1 and PAI-1. Oncotarget $\underline{9}, 10375-10387$

D'Ortho MP, Stanton H, Butler M, Atkinson SJ, Murphy G, Hembry RM (1998): MT1-MMP on the cell surface causes focal degradation of gelatin films. FEBS Lett $\underline{421}, 159-164$

Elbashir SM, Harborth J, Lendeckel W, Yalcin A, Weber K, Tuschl T (2001): Duplexes of 21-nucleotide RNAs mediate RNA interference in cultured mammalian cells. Nature $\underline{411}$, 494-498

Elston CW, Ellis IO (1991): Pathological prognostic factors in breast cancer. I. The value of histological grade in breast cancer: experience from a large study with long-term followup. Histopathology $\underline{19}$, 403-410

Etienne-Manneville S, Hall A (2002): Rho GTPases in cell biology. Nature $\underline{420}$, 629-635

Ferlay J, Colombet M, Soerjomataram I, Mathers C, Parkin DM, Piñeros M, Znaor A, Bray $F$ (2019): Estimating the global cancer incidence and mortality in 2018: GLOBOCAN sources and methods. Int J Cancer $\underline{144}, 1941-1953$ 
Ferlay J, Ervik M, Lam F, Colombet M, Mery L, Piñeros M, Znaor A, Soerjomataram I, Bray F (2020): Global cancer observatory: cancer today. Breast cancer fact sheet. International Agency for Research on Cancer. https://gco.iarc.fr/today/data/factsheets/cancers/20-Breast-fact-sheet.pdf; abgerufen am 18.02.2020.

Fidler IJ (2003): The pathogenesis of cancer metastasis: the „seed and soil“ hypothesis revisited. Nat Rev Cancer $\underline{3}$, 453-458

Fire A, Xu S, Montgomery MK, Kostas SA, Driver SE, Mello CC (1998): Potent and specific genetic interference by double-stranded RNA in Caenorhabditis elegans. Nature $\underline{391}$, 806-811

Folkman J (1986): How is blood vessel growth regulated in normal and neoplastia tissue? G. H. A. clowes memorial award lecture. Cancer Res $\underline{46}$, 467-473

Franke TF, Yang SI, Chan TO, Datta K, Kazlauskas A, Morrison DK, Kaplan DR, Tsichlis PN (1995): The protein kinase encoded by the Akt proto-oncogene is a target of the PDGF-activated phosphatidylinositol 3-kinase. Cell 81, 727-736

Friedl P, Wolf K (2003): Tumour-cell invasion and migration: diversity and escape mechanisms. Nat Rev Cancer $\underline{3}, 362-374$

Friedl P, Zänker KS, Bröcker EB (1998): Cell migration strategies in 3-D extracellular matrix: differences in morphology, cell matrix interactions, and integrin function. Microsc Res Tech $\underline{43}, 369-378$

Fritz G, Just I, Kaina B (1999): Rho GTPases are over-expressed in human tumors. Int J Cancer $\underline{81}, 682-687$

Gao T, Furnari F, Newton AC (2005): PHLPP: a phosphatase that directly dephosphorylates Akt, promotes apoptosis, and suppresses tumor growth. Mol Cell $\underline{18}, 13-24$

Gazdar AF, Kurvari V, Virmani A, Gollahon L, Sakaguchi M, Westerfield M, Kodagoda D, Stasny V, Cunningham HT, Wistuba II et al. (1998): Characterization of paired tumor and non-tumor cell lines established from patients with breast cancer. Int J Cancer $\underline{78}, 766-$ 774

Girgert R, Emons G, Gründker C (2012): Inactivation of GPR30 reduces growth of triplenegative breast cancer cells: possible application in targeted therapy. Breast Cancer Res Treat 134, 199-205

Giuliano AE, Connolly JL, Edge SB, Mittendorf EA, Rugo HS, Solin LJ, Weaver DL, Winchester DJ, Hortobagyi GN (2017): Breast cancer - major changes in the American Joint Committee on Cancer eighth edition cancer staging manual. CA Cancer J Clin 67, 290303

Gomez GA, Veldman MB, Zhao Y, Burgess S, Lin S (2009): Discovery and characterization of novel vascular and hematopoietic genes downstream of Etsrp in zebrafish. PLoS One $\underline{4}$, e4994

Goncharova E, Goncharov D, Noonan D, Krymskaya VP (2004): TSC2 modulates actin cytoskeleton and focal adhesion through TSC1-binding domain and the Rac1 GTPase. J Cell Biol 167, 1171-1182 
Greene CS, Krishnan A, Wong AK, Ricciotti E, Zelaya RA, Himmelstein DS, Zhang R, Hartmann BM, Zaslavsky E, Sealfon SC et al. (2015): Understanding multicellular function and disease with human tissue-specific networks. Nat Genet $\underline{47}, 569-576$

Gründker C, Bauerschmitz G, Schubert A, Emons G (2016): Invasion and increased expression of S100A4 and CYR61 in mesenchymal transformed breast cancer cells is downregulated by $\mathrm{GnRH}$. Int J Oncol $\underline{48}, 2713-2721$

Gupta GP, Massagué J (2006): Cancer metastasis: building a framework. Cell 127, 679_ 695

Guttilla IK, Phoenix KN, Hong X, Tirnauer JS, Claffey KP, White BA (2012): Prolonged mammosphere culture of MCF-7 cells induces an EMT and repression of the estrogen receptor by microRNAs. Breast Cancer Res Treat 132, 75-85

Hall A (2005): Rho GTPases and the control of cell behaviour. Biochem Soc Trans $\underline{33}$, 891-895

Hanahan D, Weinberg RA (2011): Hallmarks of cancer: the next generation. Cell $\underline{144}$, 646-674

Hellinger JW, Hüchel S, Goetz L, Bauerschmitz G, Emons G, Gründker C (2019): Inhibition of CYR61-S100A4 axis limits breast cancer invasion. Front Oncol $\underline{9}, 1074$

Herschkowitz JI, Simin K, Weigman VJ, Mikaelian I, Usary J, Hu Z, Rasmussen KE, Jones LP, Assefnia S, Chandrasekharan S et al. (2007): Identification of conserved gene expression features between murine mammary carcinoma models and human breast tumors. Genome Biol $\underline{8}$, R76

Hinz N, Jücker M (2019): Distinct functions of AKT isoforms in breast cancer: a comprehensive review. Cell Commun Signal $\underline{17}, 154$

Hohensee I, Chuang HN, Grottke A, Werner S, Schulte A, Horn S, Lamszus K, Bartkowiak K, Witzel I, Westphal M et al. (2017): PTEN mediates the cross talk between breast and glial cells in brain metastases leading to rapid disease progression. Oncotarget $\underline{8}, 6155-$ 6168

Holliday DL, Speirs V (2011): Choosing the right cell line for breast cancer research. Breast Cancer Res $\underline{13}, 215$

Huber M, Helgason CD, Damen JE, Scheid M, Duronio V, Liu L, Ware MD, Humphries RK, Krystal G (1999): The role of SHIP in growth factor induced signalling. Prog Biophys Mol Biol 71, 423-434

Humphries B, Wang Z, Li Y, Jhan JR, Jiang Y, Yang C (2017): ARHGAP18 downregulation by miR-200b suppresses metastasis of triple-negative breast cancer by enhancing activation of RhoA. Cancer Res $\underline{77}$, 4051-4064

Huttenhower C, Haley EM, Hibbs MA, Dumeaux V, Barrett DR, Coller HA, Troyanskaya OG (2009): Exploring the human genome with functional maps. Genome Res $\underline{19}$, 10931106

lacovides DC, Johnson AB, Wang N, Boddapati S, Korkola J, Gray JW (2013): Identification and quantification of AKT isoforms and phosphoforms in breast cancer using a novel nanofluidic immunoassay. Mol Cell Proteomics 12, 3210-3220 
Ikediobi ON, Davies H, Bignell G, Edkins S, Stevens C, O'Meara S, Santarius T, Avis T, Barthorpe S, Brackenbury L et al. (2006): Mutation analysis of 24 known cancer genes in the $\mathrm{NCl}-60$ cell line set. Mol Cancer Ther $\underline{5}, 2606-2612$

Joglekar M, Elbezanti WO, Weitzman MD, Lehman HL, van Golen KL (2015): Caveolin-1 mediates inflammatory breast cancer cell invasion via the Akt1 pathway and RhoC GTPase. J Cell Biochem 116, 923-933

Jones PF, Jakubowicz T, Pitossi FJ, Maurer F, Hemmings BA (1991a): Molecular cloning and identification of a serine/threonine protein kinase of the second-messenger subfamily. Proc Natl Acad Sci U S A $\underline{88}, 4171-4175$

Jones PF, Jakubowicz T, Hemmings BA (1991b): Molecular cloning of a second form of rac protein kinase. Cell Regul 2, 1001-1009

Ju X, Katiyar S, Wang C, Liu M, Jiao X, Li S, Zhou J, Turner J, Lisanti MP, Russell RG et al. (2007): Akt1 governs breast cancer progression in vivo. Proc Natl Acad Sci U S A 104, 7438-7443

Kalluri R, Weinberg RA (2009): The basics of epithelial-mesenchymal transition. J Clin Invest $\underline{119}, 1420-1428$

Kalpana G, Figy C, Yeung M, Yeung KC (2019): Reduced RhoA expression enhances breast cancer metastasis with a concomitant increase in CCR5 and CXCR4 chemokines signaling. Sci Rep $\underline{9}, 16351$

Kerrien S, Aranda B, Breuza L, Bridge A, Broackes-Carter F, Chen C, Duesbury M, Dumousseau M, Feuermann M, Hinz U et al. (2012): The IntAct molecular interaction database in 2012. Nucleic Acids Res $\underline{40}$, D841-D846

Keydar I, Chen L, Karby S, Weiss FR, Delarea J, Radu M, Chaitcik S, Brenner HJ (1979): Establishment and characterization of a cell line of human breast carcinoma origin. Eur $\mathrm{J}$ Cancer $\underline{15}$, 659-670

Kiernan JA (2018): Does progressive nuclear staining with hemalum (alum hematoxylin) involve DNA, and what is the nature of the dye-chromatin complex? Biotech Histochem $\underline{93}, 133-148$

Kim RK, Suh Y, Yoo KC, Cui YH, Kim H, Kim MJ, Gyu Kim I, Lee SJ (2015): Activation of KRAS promotes the mesenchymal features of basal-type breast cancer. Exp Mol Med 47, e137

Kolb K, Hellinger J, Kansy M, Wegwitz F, Bauerschmitz G, Emons G, Gründker C (2020): Influence of ARHGAP29 on the invasion of mesenchymal-transformed breast cancer cells. Cells $\underline{9}, 2616$

Konishi H, Kuroda S, Tanaka M, Matsuzaki H, Ono Y, Kameyama K, Haga T, Kikkawa U (1995): Molecular cloning and characterization of a new member of the RAC protein kinase family: association of the pleckstrin homology domain of 3 types of RAC protein kinase with protein kinase $C$ subspecies and $\beta y$ subunits of $G$ proteins. Biochem Biophys Res Commun 216, 526-534

Kozma SC, Bogaard ME, Buser K, Saurer SM, Bos JL, Groner B, Hynes NE (1987): The human c-Kirsten ras gene is activated by a novel mutation in codon 13 in the breast carcinoma cell line MDA-MB231. Nucleic Acids Res $\underline{15}$, 5963-5971 
Laemmli UK (1970): Cleavage of structural proteins during the assembly of the head of bacteriophage T4. Nature 227, 680-685

Lakhani S, Ellis I, Schnitt S, Tan P, van de Vijver M: WHO classification of tumours of the breast (WHO classification of tumours, 4th edition). IARC Publications, Lyon 2012

Lauffenburger DA, Horwitz AF (1996): Cell migration: a physically integrated molecular process. Cell $\underline{84}, 359-369$

Lawson CD, Fan C, Mitin N, Baker NM, George SD, Graham DM, Perou CM, Burridge K, Der CJ, Rossman KL (2016): Rho GTPase transcriptome analysis reveals oncogenic roles for Rho GTPase-activating proteins in basal-like breast cancers. Cancer Res $\underline{76}$, 38263837

Leavesley DI, Ferguson GD, Wayner EA, Cheresh DA (1992): Requirement of the integrin beta 3 subunit for carcinoma cell spreading or migration on vitronectin and fibrinogen. $J$ Cell Biol 117, 1101-1107

Lefort S, Tan S, Balani S, Rafn B, Pellacani D, Hirst M, Sorensen PH, Eaves CJ (2020): Initiation of human mammary cell tumorigenesis by mutant KRAS requires YAP inactivation. Oncogene $\underline{39}, 1957-1968$

Lehman HL, Van Laere SJ, van Golen CM, Vermeulen PB, Dirix LY, van Golen KL (2012): Regulation of inflammatory breast cancer cell invasion through Akt1/PKBa phosphorylation of RhoC GTPase. Mol Cancer Res $\underline{10}$, 1306-1318

Leinhos L: Myofibroblast differentiation in hypoxia: a novel role for ArhGAP29. Mol. med. Diss. Göttingen 2019

Leinhos L, Peters J, Krull S, Helbig L, Vogler M, Levay M, van Belle GJ, Ridley AJ, Lutz S, Katschinski DM, Zieseniss A (2019): Hypoxia suppresses myofibroblast differentiation by changing RhoA activity. J Cell Sci 132, jcs223230

Leitlinienprogramm Onkologie (Deutsche Krebsgesellschaft, Deutsche Krebshilfe, AWMF (Arbeitsgemeinschaft der Wissenschaftlichen Medizinischen Fachgesellschaften e.V.); Hrsg.) (2020): Interdisziplinäre S3-Leitlinie für die Früherkennung, Diagnostik, Therapie und Nachsorge des Mammakarzinoms, Version 4.3. http://www.leitlinienprogrammonkologie.de/leitlinien/mammakarzinom/; abgerufen am 19.02.2020

Leslie EJ, Mansilla MA, Biggs LC, Schuette K, Bullard S, Cooper M, Dunnwald M, Lidral AC, Marazita ML, Beaty TH, Murray JC (2012): Expression and mutation analyses implicate ARHGAP29 as the etiologic gene for the cleft lip with or without cleft palate locus identified by genome-wide association on chromosome 1p22. Birth Defects Res A Clin Mol Teratol $\underline{94}, 934-942$

Letra A, Maili L, Mulliken JB, Buchanan E, Blanton SH, Hecht JT (2014): Further evidence suggesting a role for variation in ARHGAP29 in nonsyndromic cleft lip/palate. Birth Defects Res A Clin Mol Teratol 100, 679-685

Li CW, Xia W, Lim SO, Hsu JL, Huo L, Wu Y, Li LY, Lai CC, Chang SS, Hsu YH et al. (2016): AKT1 inhibits epithelial-to-mesenchymal transition in breast cancer through phosphorylation-dependent Twist1 degradation. Cancer Res $\underline{76}$, 1451-1462

Licata L, Briganti L, Peluso D, Perfetto L, lannuccelli M, Galeota E, Sacco F, Palma A, Nardozza AP, Santonico E et al. (2012): MINT, the molecular interaction database: 2012 update. Nucleic Acids Res $\underline{40}$, D857-861 
Liotta LA (1986): Tumor invasion and metastases - role of the extracellular matrix: rhoads memorial award lecture. Cancer Res $\underline{46}, 1-7$

Liu H, Radisky DC, Nelson CM, Zhang H, Fata JE, Roth RA, Bissell MJ (2006): Mechanism of Akt 1 inhibition of breast cancer cell invasion reveals a protumorigenic role for TSC2. Proc Natl Acad Sci U S A 103, 4134-4139

Liu H, Busch T, Eliason S, Anand D, Bullard S, Gowans LJJ, Nidey N, Petrin A, Augustine-Akpan EA, Saadi I et al. (2017): Exome sequencing provides additional evidence for the involvement of ARHGAP29 in mendelian orofacial clefting and extends the phenotypic spectrum to osolated cleft palate. Birth Defects Res $\underline{109}$, 27-37

Liu K, Newbury PA, Glicksberg BS, Zeng WZD, Paithankar S, Andrechek ER, Chen B (2019): Evaluating cell lines as models for metastatic breast cancer through integrative analysis of genomic data. Nat Commun $\underline{10}, 2138$

López-Knowles E, O'Toole SA, McNeil CM, Millar EKA, Qiu MR, Crea P, Daly RJ, Musgrove EA, Sutherland RL (2010): PI3K pathway activation in breast cancer is associated with the basal-like phenotype and cancer-specific mortality. Int J Cancer $\underline{126}, 1121-$ 1131

Maaser K, Wolf K, Klein CE, Niggemann B, Zänker KS, Bröcker EB, Friedl P (1999): Functional hierarchy of simultaneously expressed adhesion receptors: integrin $\alpha 2 \beta 1$ but not CD44 mediates MV3 melanoma cell migration and matrix reorganization within threedimensional hyaluronan-containing collagen matrices. Mol Biol Cell 10, 3067-3079

Mariani L, Beaudry C, McDonough WS, Hoelzinger DB, Demuth T, Ross KR, Berens T, Coons SW, Watts G, Trent JM et al. (2001): Glioma cell motility is associated with reduced transcription of proapoptotic and proliferation genes: a cDNA microarray analysis. $\mathrm{J}$ Neurooncol $\underline{53}, 161-176$

Matlock B, Thermo Fisher Scientific Incorporated (Hrsg.) (2015): Technical note 52646: Assessment of nucleic acid purity. https://assets.thermofisher.com/TFS-Assets/CAD/Product-Bulletins/TN52646-E-0215M-NucleicAcid.pdf; abgerufen am 13.01.2019

Matsumoto Y, Tanaka K, Harimaya K, Nakatani F, Matsuda S, Iwamoto Y (2001): Small GTP-binding protein, Rho, both increased and decreased cellular motility, activation of matrix metalloproteinase 2 and invasion of human osteosarcoma cells. Jpn J Cancer Res $\underline{92}, 429-438$

McManus MT, Sharp PA (2002): Gene silencing in mammals by small interfering RNAs. Nat Rev Genet $\underline{3}, 737-747$

Meng Z, Qu Y, Lin KC, Kumar A, Placone JK, Fang C, Wang KC, Lu S, Pan M, Hong AW et al. (2018): RAP2 mediates mechanoresponses of the Hippo pathway. Nature $\underline{560}, 655$ 660

Mewes HW, Heumann K, Kaps A, Mayer K, Pfeiffer F, Stocker S, Frishman D (1999): MIPS: a database for genomes and protein sequences. Nucleic Acids Res 27, 44-48

Miller RA, Christoforou N, Pevsner J, McCallion AS, Gearhart JD (2008): Efficient arraybased identification of novel cardiac genes through differentiation of mouse ESCs. PLoS One $\underline{3}$, e2176 
Miyazaki J, Ito K, Fujita T, Matsuzaki Y, Asano Takako, Hayakawa M, Asano Tomohiko, Kawakami Y (2017): Progression of human renal cell carcinoma via inhibition of RhoAROCK Axis by PARG1. Transl Oncol $\underline{10}, 142-152$

Mullis K, Faloona F, Scharf S, Saiki R, Horn G, Erlich H (1986): Specific enzymatic amplification of DNA in vitro: the polymerase chain reaction. Cold Spring Harb Symp Quant Biol $\underline{51}, 263-273$

Myagmar BE, Umikawa M, Asato T, Taira K, Oshiro M, Hino A, Takei K, Uezato H, Kariya $\mathrm{KI}$ (2005): PARG1, a protein-tyrosine phosphatase-associated RhoGAP, as a putative Rap2 effector. Biochem Biophys Res Commun $\underline{329}$, 1046-1052

Nabeshima K, Inoue T, Shimao Y, Sameshima T (2002): Matrix metalloproteinases in tumor invasion: Role for cell migration. Pathol Int $\underline{52}, 255-264$

Neve RM, Chin K, Fridlyand J, Yeh J, Baehner FL, Fevr T, Clark L, Bayani N, Coppe JP, Tong $F$ et al. (2006): A collection of breast cancer cell lines for the study of functionally distinct cancer subtypes. Cancer Cell $\underline{10}, 515-527$

Nieto MA (2017): Context-specific roles of EMT programmes in cancer cell dissemination. Nat Cell Biol 19, 416-418

Ooms LM, Binge LC, Davies EM, Rahman P, Conway JRW, Gurung R, Ferguson DT, Papa A, Fedele CG, Vieusseux JL et al. (2015): The inositol polyphosphate 5-phosphatase PIPP regulates AKT1-dependent breast cancer growth and metastasis. Cancer Cell $\underline{28}, 155-169$

Park BK, Zeng X, Glazer RI (2001): Akt1 induces extracellular matrix invasion and matrix metalloproteinase-2 activity in mouse mammary epithelial cells. Cancer Res $\underline{61}$, 76477653

Parri M, Chiarugi P (2010): Rac and Rho GTPases in cancer cell motility control. Cell Commun Signal $\underline{8}, 23$

Paul BJ, Palmer K, Sharp JC, Pratt CH, Murray SA, Dunnwald M (2017): ARHGAP29 mutation is associated with abnormal oral epithelial adhesions. J Dent Res $\underline{96}, 1298-1305$

Perou CM, Jeffrey SS, van de Rijn M, Rees CA, Eisen MB, Ross DT, Pergamenschikov A, Williams CF, Zhu SX, Lee JCF et al. (1999): Distinctive gene expression patterns in human mammary epithelial cells and breast cancers. Proc Natl Acad Sci U S A $\underline{96}, 9212$ 9217

Perou CM, Sørlie T, Eisen MB, van de Rijn M, Jeffrey SS, Rees CA, Pollack JR, Ross DT, Johnsen H, Akslen LA et al. (2000): Molecular portraits of human breast tumours. Nature $\underline{406}, 747-752$

Pillé JY, Denoyelle C, Varet J, Bertrand JR, Soria J, Opolon P, Lu H, Pritchard LL, Vannier JP, Malvy C et al. (2005): Anti-RhoA and anti-RhoC siRNAs inhibit the proliferation and invasiveness of MDA-MB-231 breast cancer cells in vitro and in vivo. Mol Ther 11 , 267-274

Post A, Pannekoek WJ, Ross SH, Verlaan I, Brouwer PM, Bos JL (2013): Rasip1 mediates Rap1 regulation of Rho in endothelial barrier function through ArhGAP29. Proc Natl Acad Sci U S A $\underline{110}, 11427-11432$ 
Post A, Pannekoek WJ, Ponsioen B, Vliem MJ, Bos JL (2015): Rap1 spatially controls ArhGAP29 to inhibit Rho signaling during endothelial barrier regulation. Mol Cell Biol $\underline{35}$, 2495-2502

Prat A, Parker JS, Karginova O, Fan C, Livasy C, Herschkowitz JI, He X, Perou CM (2010): Phenotypic and molecular characterization of the claudin-low intrinsic subtype of breast cancer. Breast Cancer Res 12, R68

Prat A, Pineda E, Adamo B, Galván P, Fernández A, Gaba L, Díez M, Viladot M, Arance A, Muñoz M (2015): Clinical implications of the intrinsic molecular subtypes of breast cancer. Breast 24, S26-S35

Qiao Y, Chen J, Lim YB, Finch-Edmondson ML, Seshachalam VP, Qin L, Jiang T, Low BC, Singh H, Lim CT, Sudol M (2017): YAP regulates actin dynamics through ARHGAP29 and promotes metastasis. Cell Reports $\underline{19}$, 1495-1502

Rabinovitz I, Mercurio AM (1997): The integrin a6ß4 functions in carcinoma cell migration on Laminin-1 by mediating the formation and stabilization of actin-containing motility structures. J Cell Biol 139, 1873-1884

Rao G, Pierobon M, Kim IK, Hsu WH, Deng J, Moon YW, Petricoin EF, Zhang YW, Wang Y, Giaccone G (2017): Inhibition of AKT1 signaling promotes invasion and metastasis of non-small cell lung cancer cells with K-RAS or EGFR mutations. Sci Rep ㄱ, 7066

Reisner AH, Nemes P, Bucholtz C (1975): The use of Coomassie Brilliant Blue G250 perchloric acid solution for staining in electrophoresis and isoelectric focusing on polyacrylamide gels. Anal Biochem $\underline{64}, 509-516$

Renart J, Reiser J, Stark GR (1979): Transfer of proteins from gels to diazobenzyloxymethyl-paper and detection with antisera: a method for studying antibody specificity and antigen structure. Proc Natl Acad Sci U S A $\underline{76}$, 3116-3120

Ridley AJ, Hall A (1992): The small GTP-binding protein rho regulates the assembly of focal adhesions and actin stress fibers in response to growth factors. Cell $\underline{70}, 389-399$

Ridley AJ, Schwartz MA, Burridge K, Firtel RA, Ginsberg MH, Borisy G, Parsons JT, Horwitz AR (2003): Cell migration: integrating signals from front to back. Science $\underline{302}, 1704$ 1709

Ripperger T, von Neuhoff N, Kamphues K, Emura M, Lehmann U, Tauscher M, Schraders M, Groenen P, Skawran B, Rudolph C et al. (2007): Promoter methylation of PARG1, a novel candidate tumor suppressor gene in mantle-cell lymphomas. Haematologica $\underline{92}$, 460-468

Sahai E, Marshall CJ (2002): RHO-GTPases and cancer. Nat Rev Cancer 2 , 133-142

Sahai E, Marshall CJ (2003): Differing modes of tumour cell invasion have distinct requirements for Rho/ROCK signalling and extracellular proteolysis. Nat Cell Biol $\underline{5}, 711-719$

Sameni M, Moin K, Sloane BF (2000): Imaging proteolysis by living human breast cancer cells. Neoplasia $\underline{2}, 496-504$

Saras J, Franzén P, Aspenström P, Hellman U, Gonez LJ, Heldin CH (1997): A novel GTPase-activating protein for Rho interacts with a PDZ domain of the protein-tyrosine phosphatase PTPL1. J Biol Chem 272, 24333-24338 
Shamir ER, Ewald AJ (2014): Three-dimensional organotypic culture: experimental models of mammalian biology and disease. Nat Rev Mol Cell Biol 15, 647-664

Sigma-Aldrich, Merck KGaA (Hrsg.): Quantitative PCR - PCR technologies guide. https://www.sigmaaldrich.com/technical-documents/articles/biology/quantitative-pcr.html; abgerufen am 23.08.2019

Simpson KJ, Dugan AS, Mercurio AM (2004): Functional analysis of the contribution of RhoA and RhoC GTPases to invasive breast carcinoma. Cancer Res $\underline{64}, 8694-8701$

Sinn HP, Kreipe H (2013): A brief overview of the WHO classification of breast tumors, 4th edition, focusing on issues and updates from the 3rd edition. Breast Care (Basel) $\underline{8}, 149$ 154

Sørlie T, Perou CM, Tibshirani R, Aas T, Geisler S, Johnsen H, Hastie T, Eisen MB, van de Rijn M, Jeffrey SS et al. (2001): Gene expression patterns of breast carcinomas distinguish tumor subclasses with clinical implications. Proc Natl Acad Sci U S A 98, 10869 10874

Soule HD, Vazguez J, Long A, Albert S, Brennan M (1973): A human cell line from a pleural effusion derived from a breast carcinoma. J Natl Cancer Inst $\underline{51}, 1409-1416$

Spears M, Cunningham CA, Taylor KJ, Mallon EA, Thomas JSJ, Kerr GR, Jack WJL, Kunkler IH, Cameron DA, Chetty U, Bartlett JMS (2012): Proximity ligation assays for isoform-specific Akt activation in breast cancer identify activated Akt1 as a driver of progression. J Pathol 227, 481-489

Stambolic V, Suzuki A, de la Pompa JL, Brothers GM, Mirtsos C, Sasaki T, Ruland J, Penninger JM, Siderovski DP, Mak TW (1998): Negative regulation of PKB/Akt-dependent cell survival by the tumor suppressor PTEN. Cell $\underline{95}, 29-39$

Subramanian A, Tamayo P, Mootha VK, Mukherjee S, Ebert BL, Gillette MA, Paulovich A, Pomeroy SL, Golub TR, Lander ES et al. (2005): Gene set enrichment analysis: a knowledge-based approach for interpreting genome-wide expression profiles. Proc Natl Acad Sci U S A 102, 15545-15550

Tagashira T, Fukuda T, Miyata M, Nakamura K, Fujita H, Takai Y, Hirata KI, Rikitake Y (2018): Afadin facilitates vascular endothelial growth factor-induced network formation and migration of vascular endothelial cells by inactivating Rho-associated kinase through ArhGAP29. Arterioscler Thromb Vasc Biol 38, 1159-1169

Temin HM, Mizutani S (1970): RNA-dependent DNA polymerase in virions of rous sarcoma virus. Nature 226, $1211-1213$

Towbin H, Staehelin T, Gordon J (1979): Electrophoretic transfer of proteins from polyacrylamide gels to nitrocellulose sheets: procedure and some applications. Proc Natl Acad Sci U S A $\underline{76}, 4350-4354$

Ugi S, Imamura T, Maegawa H, Egawa K, Yoshizaki T, Shi K, Obata T, Ebina Y, Kashiwagi A, Olefsky JM (2004): Protein phosphatase 2A negatively regulates insulin's metabolic signaling pathway by inhibiting Akt (protein kinase B) activity in 3T3-L1 adipocytes. Mol Cell Biol 24, 8778-8789

Vega FM, Ridley AJ (2008): Rho GTPases in cancer cell biology. FEBS Lett $\underline{582,2093-}$ 2101 
Von Alten J, Fister S, Schulz H, Viereck V, Frosch KH, Emons G, Gründker C (2006): $\mathrm{GnRH}$ analogs reduce invasiveness of human breast cancer cells. Breast Cancer Res Treat $\underline{100}, 13-21$

Wheelock MJ, Shintani Y, Maeda M, Fukumoto Y, Johnson KR (2008): Cadherin switching. J Cell Sci 121, 727-735

Wolf K, Mazo I, Leung H, Engelke K, von Andrian UH, Deryugina El, Strongin AY, Bröcker E-B, Friedl P (2003): Compensation mechanism in tumor cell migration: mesenchymalamoeboid transition after blocking of pericellular proteolysis. J Cell Biol 160, 267-277

Wolf K, Wu YI, Liu Y, Geiger J, Tam E, Overall C, Stack MS, Friedl P (2007): Multi-step pericellular proteolysis controls the transition from individual to collective cancer cell invasion. Nat Cell Biol $\underline{9}$, 893-904

Wong AK, Krishnan A, Troyanskaya OG (2018): GIANT 2.0: genome-scale integrated analysis of gene networks in tissues. Nucleic Acids Res $\underline{46}$, W65-W70

Wu JX, Zhang DG, Zheng JN, Pei DS (2015): Rap2a is a novel target gene of p53 and regulates cancer cell migration and invasion. Cell Signal 27, 1198-1207

Xu K, Sacharidou A, Fu S, Chong DC, Skaug B, Chen ZJ, Davis GE, Cleaver O (2011): Blood vessel tubulogenesis requires Rasip1 regulation of GTPase signaling. Dev Cell $\underline{20}$, $526-539$

Xu Q, Duan H, Gan L, Liu X, Chen F, Shen X, Tang YQ, Wang S (2017): MicroRNA-1291 promotes endometrial fibrosis by regulating the ArhGAP29-RhoA/ROCK1 signaling pathway in a murine model. Mol Med Rep $\underline{16}, 4501-4510$

Yang E, Boire A, Agarwal A, Nguyen N, O'Callaghan K, Tu P, Kuliopulos A, Covic L (2009): Blockade of PAR1 signaling with cell-penetrating pepducins inhibits Akt survival pathways in breast cancer cells and suppresses tumor survival and metastasis. Cancer Res $\underline{69}, 6223-6231$

Yilmaz M, Christofori G (2009): EMT, the cytoskeleton, and cancer cell invasion. Cancer Metastasis Rev 28, 15-33

Yoeli-Lerner M, Yiu GK, Rabinovitz I, Erhardt P, Jauliac S, Toker A (2005): Akt blocks breast cancer cell motility and invasion through the transcription factor NFAT. Mol Cell $\underline{20}$, $539-550$

Zeisberg M, Neilson EG (2009): Biomarkers for epithelial-mesenchymal transitions. J Clin Invest $\underline{119}, 1429-1437$

Zhang C, Wang HJ, Bao QC, Wang L, Guo TK, Chen WL, Xu LL, Zhou HS, Bian JL, Yang YR et al. (2016): NRF2 promotes breast cancer cell proliferation and metastasis by increasing RhoA/ROCK pathway signal transduction. Oncotarget $\underline{7}, 73593-73606$

Zhang G, Liu Z, Xu H, Yang Q (2016): miR-409-3p suppresses breast cancer cell growth and invasion by targeting Akt1. Biochem Biophys Res Commun $\underline{469}$, 189-195

Ziegler E: Characterization of human breast cancer cells affected by coculture conditions and kisspeptin-10. Mol. med. Diss. Göttingen 2013 
Ziegler E, Hansen MT, Haase M, Emons G, Gründker C (2014): Generation of MCF-7 cells with aggressive metastatic potential in vitro and in vivo. Breast Cancer Res Treat $\underline{148}, 269-277$ 


\section{Danksagung}

Hiermit möchte ich mich sowohl bei Frau Prof. Dr. med. J. Gallwas, aktuelle chefärztliche Leitung, als auch bei Herrn Prof. Dr. med. G. Emons, ehemaliger Chefarzt der Frauenklinik der Universitätsmedizin Göttingen, bedanken, als medizinische Doktorandin in der Abteilung der Gynäkologie experimentell tätig gewesen sein zu dürfen.

Außerdem danke ich meinem Doktorvater Herrn Prof. Dr. rer. nat. C. Gründker sowie meiner Betreuerin Frau Dr. rer. nat. J. W. Hellinger für ihrer beider Unterstützung, ihre wertvollen Ratschläge und Anregungen sowie ihre Zuverlässigkeit und stetige Erreichbarkeit.

Außerdem möchte ich mich auch bei Frau S. Blume für ihre fachkundige Unterstützung und die sehr gute Zusammenarbeit im Labor bedanken. Diesen Dank möchte ich auch meinen Mitdoktorandinnen in der Abteilung der molekularen Gynäkologie der Universitätsmedizin Göttingen aussprechen. 